\begin{tabular}{l} 
2. To: (Receiving Organization) \\
Distribution \\
\hline 5. Proj./Prog./Dept./Div.: \\
TWRS \\
\hline
\end{tabular}

8. Originator Remarks: Approval/Release

11. Receiver Remarks:
3. From: (Originating Organization)
Process Analys is

6. Design Authority/ Design Agent/Cog. Engr.:

4. Related EDT No.:

NA

7. Purchase Order No.:

NA

9. Equip./Component No.:

NA

10. System/Bldg./Facility:

NA

12. Major Assm. DWg. No.:

NA

13. Permit/Permit Application No.: NA

14. Required Response Date:

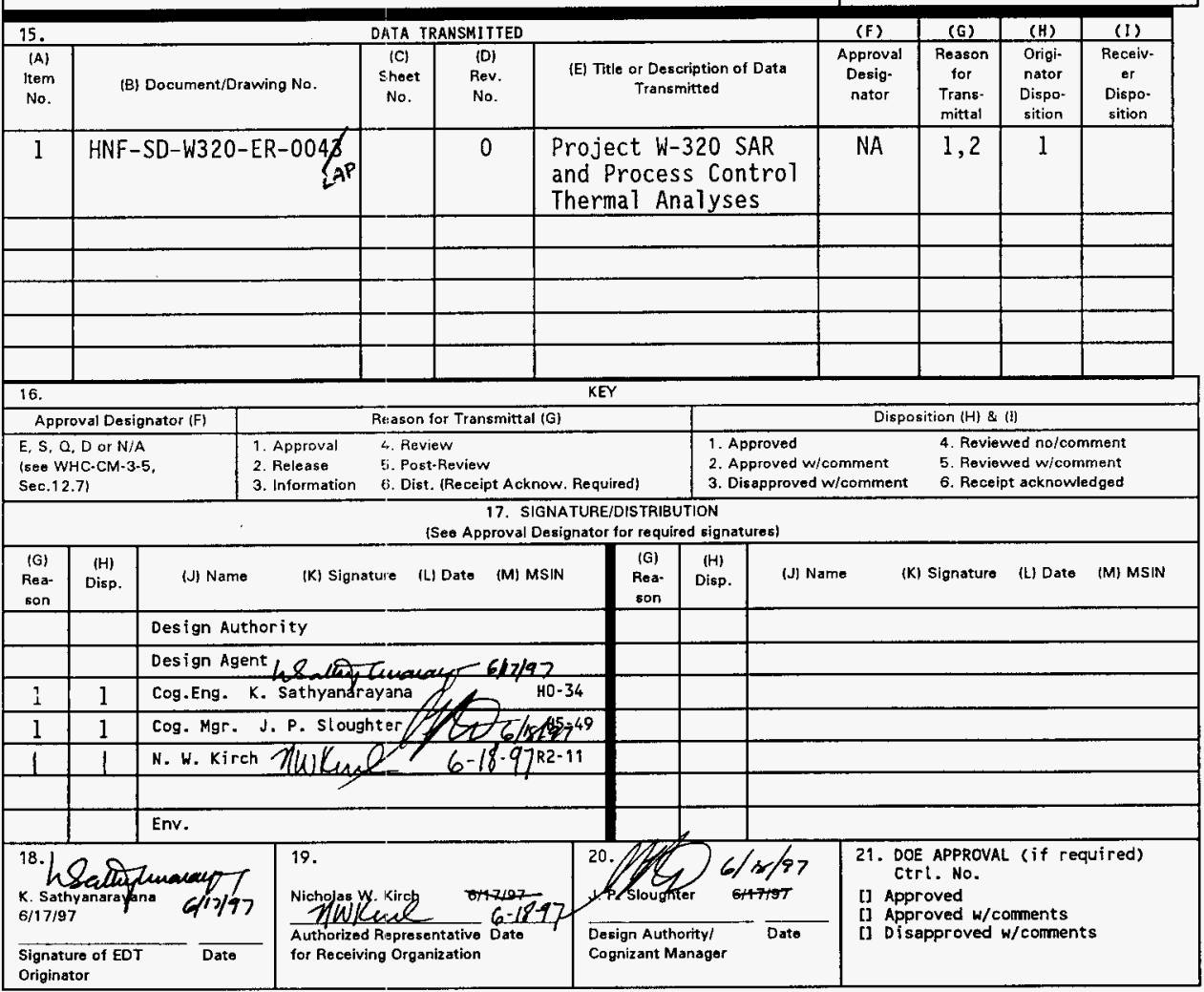


THIS PAGE INTENTIONALLY LEFT BLANK 


\title{
Project W-320 SAR and Process Control Thermal Analyses
}

\author{
K. Sathyanarayana \\ Numatec Hanford Inc, Richland, WA 99352 \\ U.S. Department of Energy Contract DE-AC06-96RL13200 \\ $\begin{array}{lll}\text { EDT/ECN: } & 607750 & \text { UC: } 2000 \\ \text { Org Code: } & 8 C 453 & \text { Charge Code: } \text { D2M78 } \\ \text { B\&R Code: } & \text { EW3130010 } & \text { Total Pages: } \log _{\beta 3} 112\end{array}$
}

Key Words: Project $W-320$, Tank 241-C-106, Tank 241-AY-102, HUB, GOTH, GOTHIC, Process control, thermal hydraulic

Abstract: This report summarizes the results of thermal hydraulic computer modeling supporting Project W-320 for procsss control and SAR documentation. Parametric analyses were performed for the maximum steady/ state waste temperature. The parameters included heat load distribution, tank heat load, fluffing factor and thermal conductivity. Uncertainties in the fluffing factor and heat load distribution had the largest effect on maximum waste temperature. Safety analyses were performed for off normal events including loss of ventilation, loss of evaporation and loss of secondary chiller. The loss of both the primary and secondary ventilation was found to be the most limiting event with saturation temperature in the bottom waste reaching in just over 30 days. An evaluation was perfiormed for the potential lowering of the supernatant level in tank 241-AY102. The evaluation included a loss of ventilation and steam bump analyses. The reduced supernatant level decreased the time to reach saturation temperature in the waste for the loss of ventilation by about ont: week. However, the consequence of a steam bump were dramatically reduced.

IRADEMARK DISCLAIMER. Feference herein to any specific commercial product, process, or service by trade name, trademark, naanufacturer, or otherwise, does not necessarily constitute or imply its endorsement, recommendation, or favoring by the United States Government or any agency thereof or its contractors or subcontractors.

Printed in the United States of America. To obtain copies of this document, contact: Document Control Services, P.O. Fiox 950, Mailstop H6-08, Richland HA 99352, Phone (509) 372-2420; Fax (509) 376-4989.
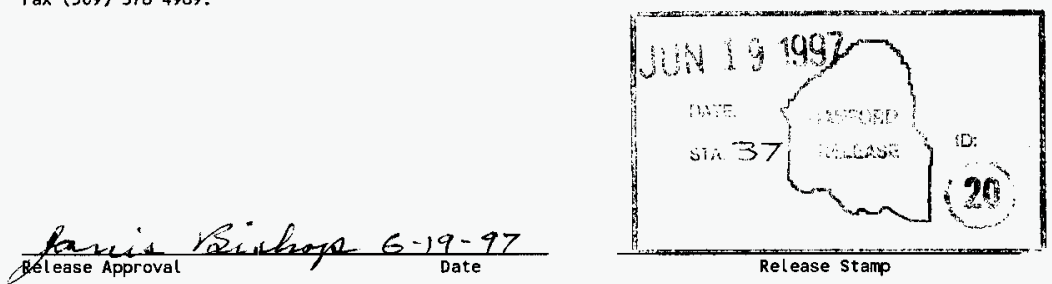

\section{Approved for Public Release}


THIS PACE INTENTIONALLY LEFT BLANK 


\author{
D.M. Ogden \\ B.C. Fryer \\ John Marvin, Inc. \\ Richland, Washington \\ K. Sathyanaryana \\ Numatec Hanford Corporation \\ Richland, Washington
}

\author{
Issued by \\ NUMATEC HANFORD CORPORATION \\ for the \\ U.S. DEPARTMENT OF ENERGY \\ RICHLAND OPERATIONS OFFICE \\ RICHLAND, WASHINGTON
}




\section{HNF-SD-W320-ER-004 REV 0}

\section{CONTENTS}

1.0 INTRODUCTION $\ldots \ldots \ldots \ldots \ldots \ldots \ldots \ldots \ldots \ldots \ldots \ldots \ldots \ldots \ldots \ldots \ldots$

2.0 COMPUTER MODEL DESCRIPTION $\ldots \ldots \ldots \ldots \ldots \ldots \ldots \ldots \ldots$

2.1 HUB STEADY STATE MODEL $\ldots \ldots \ldots \ldots \ldots \ldots \ldots$

2.2 GOTH $2-D$ SECTOR MODEL $\ldots \ldots \ldots \ldots \ldots \ldots \ldots \ldots \ldots \ldots$

2.3 GOTHIC $1-D$ TANK MODEL $\ldots \ldots \ldots \ldots \ldots \ldots \ldots \ldots$

2.4 GOTH 2 -D STEAM BUMP MODEL $\ldots \ldots \ldots \ldots \ldots \ldots \ldots$

2.5 GOTH 1 -D SLUICING MODEL . . . . . . . . . . . . . . . . 5

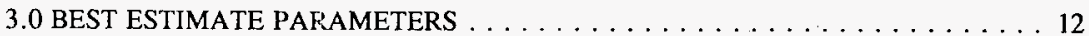

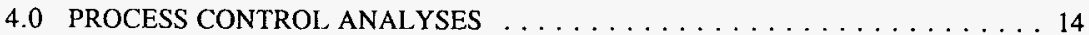

4.1 STEADY STATE BEST ESTIMATE ANALYSES . . . . . . . . . . . 14

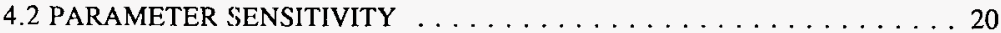

4.2 .1 Heat Load Distribution . . . . . . . . . . . . . . . . . . . 20

4.2 .2 Fluffing Factor $\ldots \ldots \ldots \ldots \ldots \ldots \ldots \ldots \ldots$

4.2 .3 Thermal Conductivity . . . . . . . . . . . . . . . 34

4.2 .4 Tank Heat Load . . . . . . . . . . . . . . . . . . 40

4.2.5 Summary of Parametric Analyses . . . . . . . . . . . . . 40

4.3 TANK 241-C-106 SLUICING EVALUATION . . . . . . . . . . . . . . 44

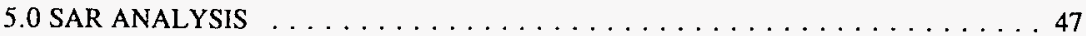

5.1 LOSS OF VENTILATION $\ldots \ldots \ldots \ldots \ldots \ldots \ldots \ldots \ldots \ldots$

5.1.1 Loss of Primary and Secondary Ventilation . . . . . . . . . . . 47

5.1 .2 Loss of Secondary Ventilation . . . . . . . . . . . . . . . . 48

5.1 .3 Loss of Primary Ventilation . . . . . . . . . . . . . . . 48

5.1.4 Loss of Primary Ventilation - 2 Foot Transfer . . . . . . . . . . 48

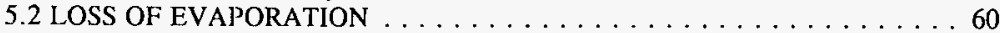

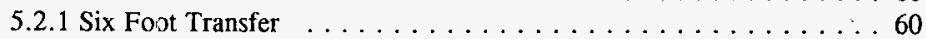

5.2 .2 Two Foot Transfer . . . . . . . . . . . . . . . 60

5.3 LOSS OF CHILLER $\ldots \ldots \ldots \ldots \ldots \ldots \ldots \ldots \ldots \ldots \ldots \ldots \ldots \ldots \ldots$

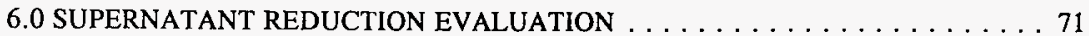

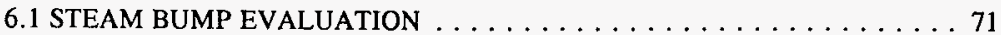

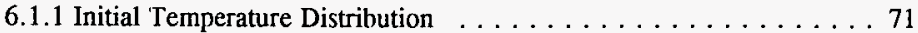

6.1 .2 Steam Vent Paths . . . . . . . . . . . . . . . 73

6.1.3 Pool Condensation . . . . . . . . . . . . . . 73

6.1.4 Full Supernatant Pool . . . . . . . . . . . . . . . . . 73

6.1.5 Maximum Supernatant Removal . . . . . . . . . . . . 82

6.1.6 Minimum Supernatant Removal . . . . . . . . . . . . 88

6.2 OTHER OFF NORMAL EVENTS $\ldots \ldots \ldots \ldots \ldots \ldots \ldots \ldots$ 


\section{HNF-SD-W320-ER-004 REV 0}

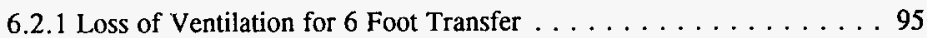

6.2 .2 Loss of Ventilation for 2 Foot Transfer . . . . . . . . . 95

7.0 CONCLUSIONS $\ldots \ldots \ldots \ldots \ldots \ldots \ldots \ldots \ldots \ldots \ldots \ldots \ldots \ldots \ldots \ldots$

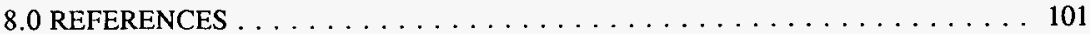

\section{TABLES}

Table 1.1 Summary of Computer Analyses. . . . . . . . . . . . . . 2

Table 3.1 Best Estimate Parameters ... . . . . . . . . . . . . . . . 13

Table 4.1 Heat Load Distribution for 241-C-106 Based Hanford Waste Model. . . . . . . 21

Table 4.2. Summary of Parametric Analyses. . . . . . . . . . . . . . . 41

\section{FIGURES}

Figure 2.1 Plan View of Region Modeled by GOTH 3 Region model. . . . . . . . . 7 Figure 2.2 Side View of GOTH 3 Region 2-D Tank 241-AY-102 Model - Inner Region. . 8

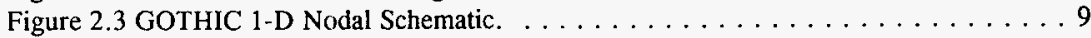

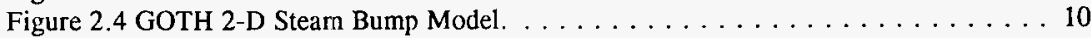

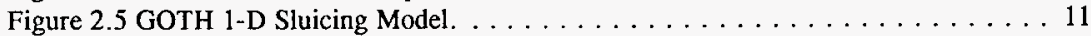

Figure 4.1 Best Estimate Steady State Analyses for 2 Foot Transfer. . . . . . . . . 16

Figure 4.2 Best Estimate Steady State Analyses for 6 Foot Transfer. . . . . . . . . . 17

Figure 4.3 Best Estimate Steady State Analyses for 6 foot Transfer without Chilling. . . . 18

Figure 4.4 Steady State Temperature for 6 Foot Transfer with Optimistic Fluffing Factor. . 19

Figure 4.5 Heat Load Distribution Analyses, 6 Foot Transfer. . . . . . . . . . . 23

Figure 4.6 Heat Load Distribution Analyses, 6 Foot Transfer with Increased Annulus Flow. 24

Figure 4.7 Heat Load Distribution Analyses, 2 Foot Transfer. . . . . . . . . . . . ' 25

Figure 4.8 Heat Load Distribution Analyses, 2 Foot Transfer With Annulus Flow. . . . . 26

Figure 4.9 Fluffing Factor Sensitivity, 6 Foot Transfer, Increased Fluffing Factor. . . . . 28

Figure 4.10 Fluffing Factor Sensitivity, 6 Foot Transfer, Increased Annulus Flow. . . . . 29

Figure 4.11 Fluffing Factor Sensitivity, 6 Foot Transfer, Decreased Fluffing Factor. . . . 30

Figure 4.12 Fluffing Factor Sensitivity, 2 Foot Transfer, Increase Fluffing Factor. . . . . 31

Figure 4.13 Fluffing Factor Sensitivity, 2 Foot Transfer, With Annulus flow . . . . . . 32

Figure 4.14 Fluffing Factor Sensitivity, 2 Foot Transfer, Decreased Fluffing Factor.

Figure 4.15 Thermal Conductivity Sensitivity, 6 Foot Transfer, Decreased K. . . . . . 36

Figure 4.16 Thermal Conductivity Sensitivity, 6 Foot Transfer, Increased Annulus Flow. . 37

Figure 4.17 Thermal Conductivity Sensitivity, 6 Foot Transfer, Increased K. . . . . . . 38

Figure 4.18 Thermal Conductivity Sensitivity, 2 Foot Transfer, Decreased K. . . . . . . 39

Figure 4.19 Waste Temperature Distribution for $10 \%$ Increase in Heat Load. . . . . . . . 42

Figure 4.20 Waste Temperature Distribution for 10\% Decrease in Heat Load. . . . . . . . 43

Figure 4.21 Waste Temperature During Sluicing for $241-C-106 \ldots \ldots \ldots \ldots \ldots$ 


\section{HNF-SD-W320-ER-004 REV 0}

Figure 4.22 Waste Temperature for 241-C-106 for Sluicing Ventilation System. . . . . 46 Figure 5.1 Loss of Ventilation, Pool Temperature. . . . . . . . . . . . . . 50

Figure 5.2 Loss of Ventilation, Transient Temperature Distribution. . . . . . . . . . 51

Figure 5.3 Loss of Ventilation with Recovery, Pool Temperature. . . . . . . . . . . . 52

Figure 5.4 Loss of Ventilation with Recovery, Transient Temperature Distribution. . . . . 53 Figure 5.5 Loss of Secondary Ventilation, Transient Temperature Distribution. . . . . . . 54

Figure 5.6 Loss of Secondary Vertilation, Transient Pool Temperature. . . . . . . . . . 55

Figure 5.7 Loss of Primary Ventilation, Transient Temperature Distribution. . . . . . . . 56

Figure 5.8 Loss of Primary Ventilation, Pool Temperature. . . . . . . . . . . . . . 57

Figure 5.9 Loss of Primary Ventilation, 2 Foot Transfer, Pool Temperature. . . . . . . . 58

Figure 5.10 Loss of Primary Ventilation, 2 Foot Transfer, Waste Temperature Distribution.

. . . . . . . . . . 62

Figure 5.11 Loss of Evaporation, 6 Foot Transfer, Waste Temperature. . . . . . . . . . 62

Figure 5.12 Loss of Evaporation, 6 Foot Transfer, Pool Temperature. . . . . . . . . . . 63

Figure 5.13 Loss of Evaporation, 6 Foot Transfer, With Increased Annulus Flow, Waste

Temperature. . . . . . . . . . . . . . . . . . . 64

Figure 5.14 Loss of Evaporation, 2 Foot Transfer, Waste Temperature. . . . . . . . . 65

Figure 5.15 Loss of Evaporation, 2 Foot Transfer, With Annulus Flow, Waste Temperature.66

Figure 5.16 Loss of Chiller, 6 Foot Transfer, Waste Temperature. . . . . . . . . . . . 68

Figure 5.17 Loss of Chiller, 6 Foot Transfer, Pool Temperature. . . . . . . . . . . . . . 69

Figure 5.18 Loss of Chiller, 6 Foot Transfer, Increased Annulus Flow, Waste Temperature. 70

Figure 6.1 Waste Temperature Distribution Following a Loss of Ventilation. . . . . . . . 72

Figure 6.2 Saturation and Dome Pressure, 20 Foot Pool. . . . . . . . . . . . . . 75

Figure 6.3 Integrated Vapor flow Through Vent Paths, 20 Foot Pool. . . . . . . . . . 76

Figure 6.4 Vapor Fraction Contour at 35 Seconds, 20 Foot Pool. . . . . . . . . . . . 77

Figure 6.5 Vapor Velocity Contours at 35 Seconds, 20 Foot Pool. . . . . . . . . . . 78

Figure 6.6 Vapor Volume Firaction Contours at 72 Seconds, 20 Foot Pool . . . . . . . . . 79

Figure 6.7 Integrated Liquid Flow Through Vent Paths, 20 Foot Pool. . . . . . . . . . 80

Figure 6.8 Integrated Particle Mass Through Vent Paths, 20 Foot Pool. . . . . . . . . 81

Figure 6.9 Saturation and Dome Pressure, 1 Foot Pool. . . . . . . . . . . . 83

Figure 6.10 Vapor Fraction Contour, 1 Foot Pool. . . . . . . . . . . . . . . . . . . 84

Figure 6.11 Vapor Velocity Contour, 1 Foot Pool. . . . . . . . . . . . . . . . 85

Figure 6.12 Integrated Vapor Flow Through Vent Paths, 1 Foot Pool. . . . . . . . . . . 86

Figure 6.13 Integrated Liquid Flow Through vent Paths, 1 Foot Pool. . . . . . . . . . . 87

Figure 6.14 Bottom Saturation and Dome Pressures, 7 Foot Pool. . . . . . . . . . . . . . 89

Figure 6.15 Vapor Fraction Contour, 7 Foot Pool. . . . . . . . . . . . . . . . . . . 90

Figure 6.16 Vapor Velocity Contour, 7 Foot Pool. . . . . . . . . . . . . . . . 91

Figure 6.17 Integrated Vapor Flow Out the Vent Paths, 7 Foot Pool. . . . . . . . . . . 92

Figure 6.18 Integrated Liquid Flow Out the Vent Paths, 7 Foot Pool. . . . . . . . . . . . 93

Figure 6.19 Integrated Particle Flow Out the Vent Paths, 7 Foot Pool. . . . . . . . . . 94

Figure 6.20 Loss of Ventilation, 8 Foot Pool, 6 Foot Transfer, Waste Temperature. . . . 96

Figure 6.21 Loss of Ventilation, 2 Foot Pool, 6 Foot Transfer, Waste Temperature. . . . 97

Figure 6.22 Loss of Ventilation, 2 Foot Pool, 2 Foot Transfer, Waste Temperature. . . . 98 


\section{HNF-SD-W320-ER-004 REV 0}

Figure A.1 Waste Temperature Distribution for GOTHIC Model. . . . . . . . . . . . A-3 Figure A.2 Waste Temperature Distibution for HUB Model. . . . . . . . . . . . . . A-4

Figure A.3 Waste Temperature Distribution for Closed Form Solution. . . . . . . . . A A-5 APPENDIXES

APPENDIX A GOTHIC Model Benchmark With HUB Model . . . . . . . . . . . . A-1 


\section{HNF-SD-W320-ER-004 REV 0}

\subsection{INTRODUCTION}

A thermal evaluation of Project W-320 was performed by Sathyanaryana et.al. 1997. This study included an evaluation of tank 241-AY-102 annulus cooling system, transfer of tank 241-C-106 waste into tank 241-AY-102, the sluicing process for tank 241-C-106 and process control strategies. This evaluation used conservative values for important physical properties including waste fluffing factor and tank 241-C-106 total heat load. A review of these and other thermal parameters was conclucted and a set of best estimate values were established (Reynolds 1997). A thermal evaluation of tank 241-AY-102, which supports the process control for 241AY-102, has been performed using this set of best estimate parameters. This evaluation includes parametric analyses for the important thermal parameters, safety analyses of off normal events and a study of the consequence of supernatant removal. The computer models for the evaluation of 241-C-106 process control have been further enhanced and a more complete evaluation of 241-C106 process control has also been performed.

The focus of the previous thermal evaluation for Project W-320 was design support and process control. Thermal analyses have subsequently been performed to support the project Safety Analyses Report (SAR) (HNF-SD-WM-TSR-006). These thermal analyses included loss of ventilation, loss of evaporation and loss of annulus system chiller.

The Project W-320 flammable gas control strategy for tank 241-AY-102 includes the possible reduction of the supiernatant depth from nearly 20 feet to between one and 8 feet (Pasamehmetoglu 1997). The purpose of the reduction is to limit the magnitude of a possible spontaneous Gas Release Event (GRE) in 241-AY-102. This supernatant reduction influences the thermal response of tank 241-AY-102 for some off normal events. A thermal evaluation was performed for a loss of ventilation and steam bump events.

A summary description of the computer models used for the analyses presented in this report are provided in Section 2.0. A discussion of the best estimate thermal parameters is provided in Section 3.0 A more complete discussion is provided in the previous report (Sathyanaryana 1997). The updated process control analyses using best estimate parameters are provided in Section 4.0. The SAR analysis support is presented in Section 5.0. The supernatant reduction evaluation is provide in Section 6.0. A summary of the analyses presented in the following sections is provided in Table 1.1. 
HNF-SD-W320-ER-004 REV 0

Table 1.1 Summary of Computer Analyses.

\begin{tabular}{|c|c|c|c|c|c|c|c|c|c|c|}
\hline $\begin{array}{r} \\
\text { Figure } \\
\end{array}$ & $\begin{array}{l}\text { Description } \\
\text { Den } \\
\end{array}$ & $\begin{array}{l}\text { Waste } \\
\text { Transfer } \\
\text { Wt }\end{array}$ & $\begin{array}{l}\text { Slot } \\
\text { Flow } \\
\text { cfm }\end{array}$ & $\begin{array}{l} \\
\text { Annulus } \\
\text { Chiller }\end{array}$ & $\begin{array}{c}\text { Heat } \\
\text { Load } \\
\text { Btu/hr }\end{array}$ & $\begin{array}{l}\text { Heat } \\
\text { Load } \\
\text { Dist }\end{array}$ & $\begin{array}{l}3 \\
\text { Fluff } \\
\text { Factor }\end{array}$ & $\begin{array}{l}\text { Thermal } \\
\text { Cond- } \\
\text { uctivity } \\
\text { Btw/hr- } \\
\text { ft- }^{\circ}\end{array}$ & $\begin{array}{l}\text { Annulus } \\
\text { Emi- } \\
\text { feny } \\
\text { Factor }\end{array}$ & $\begin{array}{l}\text { File } \\
\text { Name }\end{array}$ \\
\hline 4.1 & Base Case, $2 \mathrm{ft}$ transfer & 2 & 0 & no & 50,670 & $\mathrm{BE}$ & 1.4 & 0.37 & & $a y-2 b 3$ \\
\hline 4.2 & Base Case, $6 \mathrm{ft}$ transfer & 6 & 2000 & yes & 156,000 & BE & 1.4 & 0.41 & 0.37 & ay_6b2 \\
\hline 4.3 & $\begin{array}{l}\text { Best Estimate W/O } \\
\text { chilling }\end{array}$ & 6 & 3000 & no & 156,000 & $\mathrm{BE}$ & 1.4 & 0.41 & 0.32 & ay_6bl \\
\hline 4.4 & Optimistic parameters & 6 & 1200 & no & 156,000 & $\mathrm{BE}$ & 1.0 & 0.44 & 057 & $a y \_6 b 4$ \\
\hline 4.5 & Agnew heat distribution & 6 & 2000 & yes & 156,000 & $\begin{array}{l}\text { Ag- } \\
\text { new }\end{array}$ & 1.4 & 0.41 & 0.37 & ay_6ftp \\
\hline 4.6 & Above with > slat flow & 6 & 3000 & yes & 156,000 & $\mathrm{BE}$ & 1.4 & 0.41 & 0.32 & ay_6ftp2 \\
\hline 4.7 & Agnew Heat Distribution & 2 & 0 & no & 50,670 & $\begin{array}{l}\text { Ag- } \\
\text { new }\end{array}$ & 1.4 & 0.37 & & ay_2ftp \\
\hline 4.8 & Above with annulus flow & 2 & 150 & no & 50,670 & $\begin{array}{l}\text { Ag- } \\
\text { new }\end{array}$ & 1.4 & 0.37 & 0.7 & ay_2ftp2 \\
\hline 4.9 & Increased fluff factor & 6 & 2000 & yes & 156,000 & $\mathrm{BE}$ & 1.7 & 0.38 & 0.37 & ay_6ftf \\
\hline 4.10 & Above with > slot flow & 6 & 3300 & yes & 156,000 & $\mathrm{BE}$ & 1.7 & 0.38 & 0.32 & ay_6ftf3 \\
\hline 4.11 & Decreased fluff fuctor & 6 & 2000 & yes & 156,000 & $\mathrm{BE}$ & 1 & 0.44 & 0.37 & ay_6fu2 \\
\hline 4.12 & Increased fluff factor & 2 & 0 & no & 50,670 & $\mathrm{BE}$ & 1.7 & 0.35 & & ay_2ftf \\
\hline 4.13 & Above with annulus flow & 2 & 150 & no & 50,670 & $\mathrm{BE}$ & 1.7 & 0.35 & 0.7 & ay_2ftr2 \\
\hline 4.14 & Decreased fluff factor & 2 & 0 & no & 50,670 & $\mathrm{BE}$ & 1 & 0.37 & & ay_ $2 \mathrm{ftr} 3$ \\
\hline 4.15 & Decreased $\mathrm{K}$ & 6 & 2000 & yes & 156,000 & $\mathrm{BE}$ & 1.4 & 0.33 & 0.37 & ay_6ki \\
\hline 4.16 & Above with > slot flow & 6 & 3000 & yes & 156,000 & $\mathrm{BE}$ & 1.4 & 0.33 & 0.32 & ay_6k3 \\
\hline 4.17 & Increased K & 6 & 2000 & yes & 156,000 & $\mathrm{BE}$ & 1.4 & 0.5 & 0.37 & ay_6k2 \\
\hline 4.18 & Decreased K & 2 & 0 & yes & 50,670 & $\mathrm{BE}$ & 1.4 & 0.3 & & ay_2kl \\
\hline 4.19 & Increase heat load & 6 & 2000 & yes & 168,300 & $\mathrm{BE}$ & 1.4 & 0.41 & 0.37 & ay_6ftp3 \\
\hline 4.20 & Decreased heat load & 6 & 2000 & yes & 143,700 & $\mathrm{BE}$ & 1.4 & 0.41 & 0.37 & ay_6ftp4 \\
\hline $4.21-22$ & C106 sluicing evaluation & & & & & & & & & \\
\hline $5.1-2$ & Loss of all ventilation & 6 & none & nо & 156,000 & $\mathrm{BE}$ & 1.4 & 0.41 & & ay_ $6 \mathrm{p} 20 \mathrm{v}$ \\
\hline
\end{tabular}


HNF-SD-W320-ER-004 REV 0

\begin{tabular}{|c|c|c|c|c|c|c|c|c|c|c|}
\hline $\begin{array}{l}\text { Figure } \\
\text { Fom }\end{array}$ & Description & $\begin{array}{l}\text { Waite } \\
\text { Transfer } \\
\mathbf{f t}\end{array}$ & $\begin{array}{l}\text { Slot } \\
\mathrm{clow}\end{array}$ & $\begin{array}{l}\text { Annulus } \\
\text { Chiller }\end{array}$ & $\begin{array}{l}\text { Heat } \\
\text { Load } \\
\text { Btw/hr }\end{array}$ & $\begin{array}{l}\text { Heat } \\
\text { Load } \\
\text { Dist }\end{array}$ & Finf & $\begin{array}{l}\text { Thermal } \\
\text { Cond- } \\
\text { uctivity } \\
\text { Btuhlor } \\
\text { ft-o }\end{array}$ & $\begin{array}{l}\text { Annulus } \\
\text { Efrit- } \\
\text { Ieny } \\
\text { Factor }\end{array}$ & $\begin{array}{l}\text { File } \\
\text { Name }\end{array}$ \\
\hline $5.3-4$ & above with recovery & 6 & 2000 & yes & 156,000 & BE & 1.4 & 0.41 & 0.37 & ay_6p $20 \mathrm{v} 2$ \\
\hline $5.5-6$ & Loss of annulus ventilation & 6 & 2000 & yes & 156,000 & $\mathrm{BE}$ & 1.4 & 0.41 & 0.37 & ay_6ftvs \\
\hline $5.7-8$ & Loss of primary vent & 6 & 2000 & yes & 156,000 & $\mathrm{BE}$ & 1.4 & 0.41 & 0.37 & ay_6ftvp \\
\hline $5.9-10$ & Loss of primary vent & 2 & 0 & no & 50,670 & $\mathrm{BE}$ & 1.4 & 0.41 & & ay_2ftv \\
\hline $5.11-12$ & Loss of evaporation & 6 & 2000 & yes & 156,000 & $\mathrm{BE}$ & 1.4 & 0.41 & & ay_6fte \\
\hline 5.13 & Above with > slot flow & 6 & 3000 & yes & 156,000 & $\mathrm{BE}$ & 1.4 & 0.41 & 0.37 & ay_6fte? \\
\hline 5.14 & Loss of evaporation & 2 & 0 & no & 50,670 & $\mathrm{BE}$ & 1.4 & 0.37 & & ay_2fte \\
\hline 5.15 & Above with slot flow & 2 & 150 & no & 50,670 & $\mathrm{BE}$ & 1.4 & 0.37 & 0.7 & ay_2fte? \\
\hline $5.16-17$ & Loss of chiller & 6 & 2000 & no & 156,000 & $\mathrm{BE}$ & 1.4 & 0.41 & 0.37 & ay_6fic \\
\hline 5.18 & Above with > slot flow & 6 & 3000 & no & 156,000 & $\mathrm{BE}$ & 1.4 & 0.41 & 0.32 & ay_6ftc2 \\
\hline $6.2-8$ & Stean bump/20 ft pool & 6 & & & & & & & & \\
\hline $6.9-13$ & Steam bump/1 ft pool & 6 & & & & & & & & \\
\hline $6.14-19$ & Steam bump $/ 7 \mathrm{ft}$ pool & 6 & & & & & & & & \\
\hline 6.20 & Loss of vent, $8 \mathrm{ft}$ pool & 6 & 0 & no & 156,000 & $\mathrm{BE}$ & 1.4 & 0.41 & & ay_6p $8 v$ \\
\hline 6.21 & Loss of vent, $2 \mathrm{ft}$ pool & 6 & 0 & no & 156,000 & $\mathrm{BE}$ & 1.4 & 0.41 & & ay_6ftv \\
\hline 6.22 & Loss of vent, $2 \mathrm{ft}$ pool & 2 & 0 & no & 50,670 & $\mathrm{BE}$ & 1.4 & 0.37 & & ay_2fiv 3 \\
\hline
\end{tabular}




\section{HNF-SD-W320-ER-004 REV 0}

\subsection{COMPUTER MODEL DESCRIPTION}

A overview of the computer models used to perform the thermal evaluations are provided in the following sections. A more complete discussion of these models is provided in Sathyanaryana 1997.

\subsection{HUB STEADY STATE MODEL}

The HUB thermal analysis is based on a model that considers one-dimensional, steady state heat conduction for the settled sludge and accounts for the effects of heat loss due to primary ventilation flow and tank bottom slot cooling flow. The model assumes a uniformly distributed heat source in the heat conducting medium. The heat conducting medium consists of two layers of nonconvective, settled sludge and a layer of supernate on top. The bottom layer represents 32,000 gallons (Hanlon 1996) of current sludge in tank 241-AY-102, and the second layer represents the transferred tank 241-C-106 waste that has settled to a nonconvective state. Each of these two layers has its own thickness, thermal conductivity, heat source, and density. The heat loss due to the primary ventilation flow and secondary (annulus) ventilation flow, particularly that due to the air flow through the air slots at the bottom, are simultaneously included in the model. The evaporation of supernate at the pooldome air interface is modeled through the correlation of Bositer, et al. 1946, developed for the calculation of water evaporation rates in a quiet atmosphere by natural convection. The heat loss to the annulus flow in the tank bottom air slots is included in the calculations through an effectiveness parameter determined by the 2-D GOTH'model discussed in the following section. The cooling channel effectiveness was defined as the ratio of the increase in cooling air temperature to the maximum possible air temperature rise if the air reaches the sludge bottom temperature. The zero effectiveness corresponds to an adiabatic boundary condition at the bottom, and $100 \%$ effectiveness represents the case where the air flow in the slots will reach the sludge bottom temperature.

\subsection{GOTH 2-D SECTOR MIODEL}

The GOTH (Thurgood 1993) 2-D model (Sathyanaryana et.al. 1996) was developed to evaluate the cooling effectiveness of the floor cooling channels in the azimuthal and axial directions. The model consists of

a. three 2-dimensional (azimuthal and axial) sludge regions corresponding to the inner, middle and outer floor coolant channel regions

b. three 2-dimensional (azimuthal and axial) floor regions located directly below the sludge regions; and,

c. 1 inner, 1 middle and 1 outer tank floor air channel.

\footnotetext{
GOTH is a trademark of JMI, which is derived from GOTHIC - a registered trademark of the EPRI Corporation. 


\section{HNF-SD-W320-ER-004 REV 0}

Each sludge and floor regions's radial dimensions is equal to the corresponding coolant channel regions radial length. The model also includes the supernatant, dome gas and soil above the tank. A top view of the sludge regions and corresponding floor ventilation channels is shown in Figures 2.1 and 2.2.

\subsection{GOTHIC 1-D TANK MODEL}

A one dimensional GOTHIC (George 1995) model was developed for 241-AY-102. This model is intended to be fast running, providing an alternative model for both steady state and transient analyses. Unlike the GOTH models which modeled the waste as a fluid, the GOTHIC model treats the waste as a "conductor" component. This simplifies the model which increase the computational speed and reduces the problem setup time. A schematic of the GOTHIC model is shown in Figure 2.3. The supernatant and dome space are modeled as a single lumped parameter volume (volume 7). Convective, evaporative and radiation heat transfer from the liquid pool are included. The waste conductor includes separate regions for the existing 241-AY-102 waste and the transferred $241-\mathrm{C}-106$ waste. The region representing the $\mathrm{C}-106$ waste is further divided as needed to model axial variation in waste properties. The floor annulus ventilation is modeled as three distributed volumes. The heat transfer coefficient for the distributed volumes is adjusted to provide the efficiency factor determined from the GOTH model described in Section 2.2.

\subsection{GOTH 2-D STEAM BUMP MODEL}

The GOTH computer: used for the steam bump analyses has a two fluid phases in addition to a particle field formulation. It solves for the velocities of the solid particle, liquid and gas fields using interfacial shear and momentum transfer between each of the phases and the momenum conservation equation for each phase. It also calculates the volume fractions, temperature and density of each phase by solving the mass and energy conservation equations for all three phases (solid particles, liquid and gas). The code also treats the non-Newtonian behavior of liquid-particle mixtures insluding the effects of mixture yield strength. For a more complete discussion of the GOTH code the reader is referred to Sathyanaryana et.al. 1996, Appendix A.

The GOTH model used for the steam bump analyses is a two dimensional, axi-symmetric model shown in Figure 2.4. The node cell lengths within the waste are 0.5 feet and 2 feet in the supernatant. Vent paths corresponding to the ventilation inlet and outlet and the pump pit drain lines are included in the model. These are connected to atmospheric pressure boundary conditions. The primary and annulus ventilation systems are not modeled. Instead, the initial waste temperature profile is input into the model based on analyses of the loss of ventilation using the model described in the previous section.

\subsection{GOTH 1-D SLUICING MODEL}

The sluicing of 241-C-106 was modeled with a 1-D GOTH model shown in Figure 2.5. 


\section{HNF-SD-W320-ER-004 REV 0}

The model consists of six axial nodes (initial waste level) and a dome/supernatant node. A later model used for the analyses presented in this report included 12 axial nodes for the waste.

Boundary conditions for the inlet and outlet ventilation and infiltration are included for summer average conditions. The inlet chiller (pre-sluicing) and recycle ventilation (used during sluicing) configurations were also modeled. The incoming sluicing flow and outgoing slurry flow were modeled as boundary conditions. The surrounding tank soil was modeled to help establish the proper initial conditions at the start of sluicing. For a more complete discussion of the model and typical analyses results the reader is referred to previous Project W-320 thermal evaluation (Sathyanaryana et.al. 1997). 
Figure 2.1 Plan View of Region Modeled by GOTH 3 Region model.

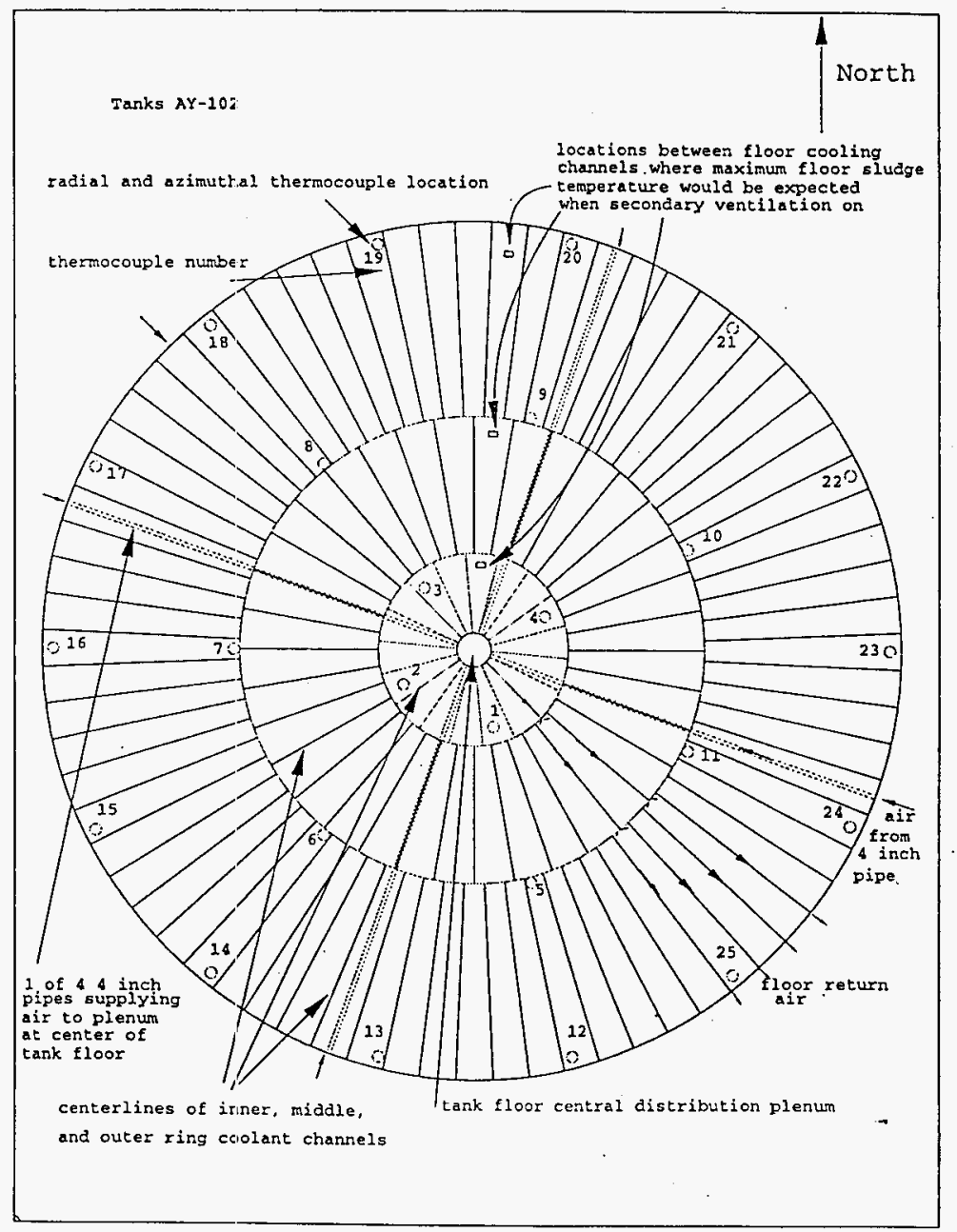




\section{HNF-SD-W320-ER-004 REV 0}

Figure 2.2 Side View of GOTH 3 Region 2-D Tank 241-AY-102 Model - Inner Region.

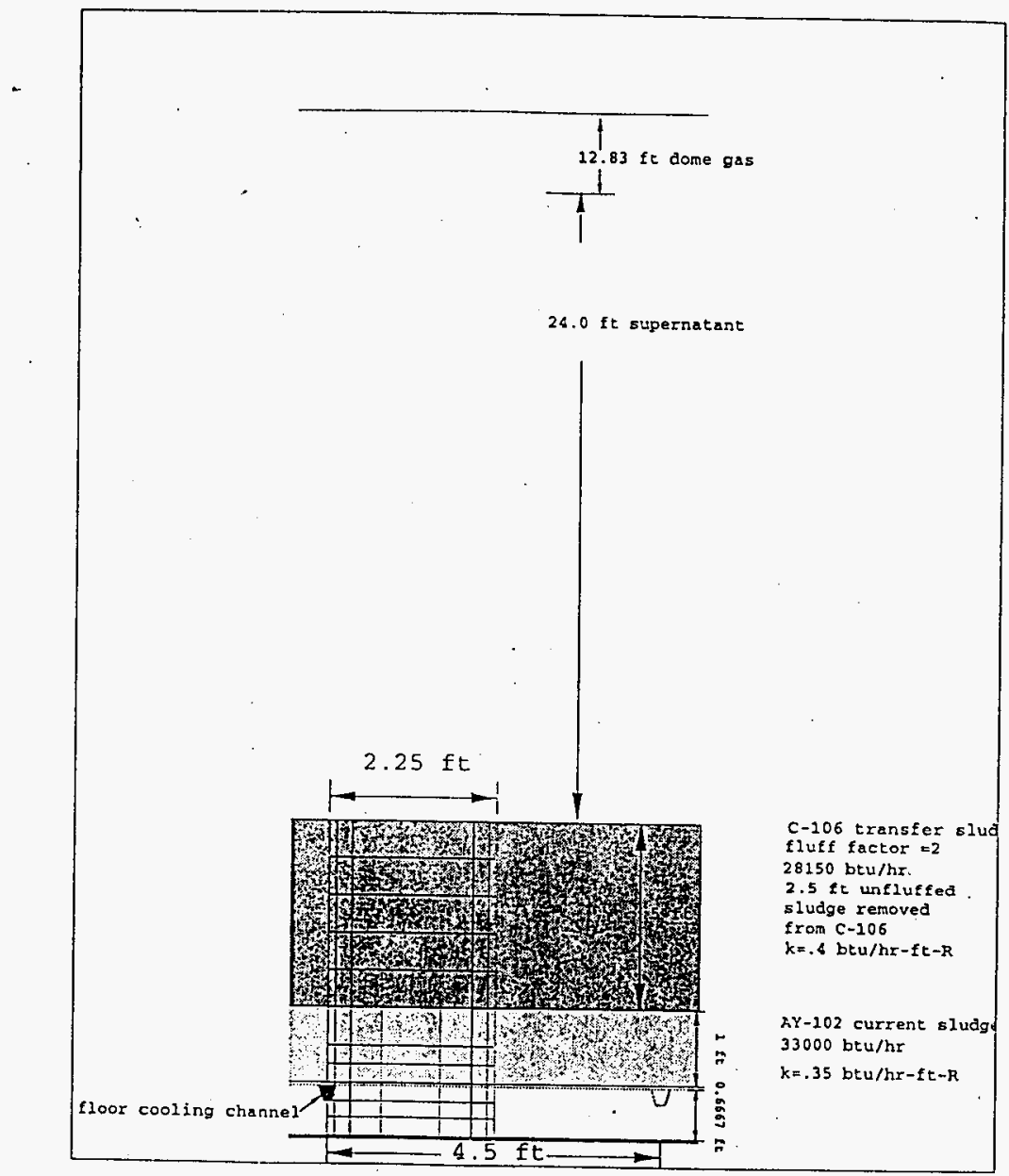


Figure 2.3 GOTHIC 1-D Nodal Schematic.

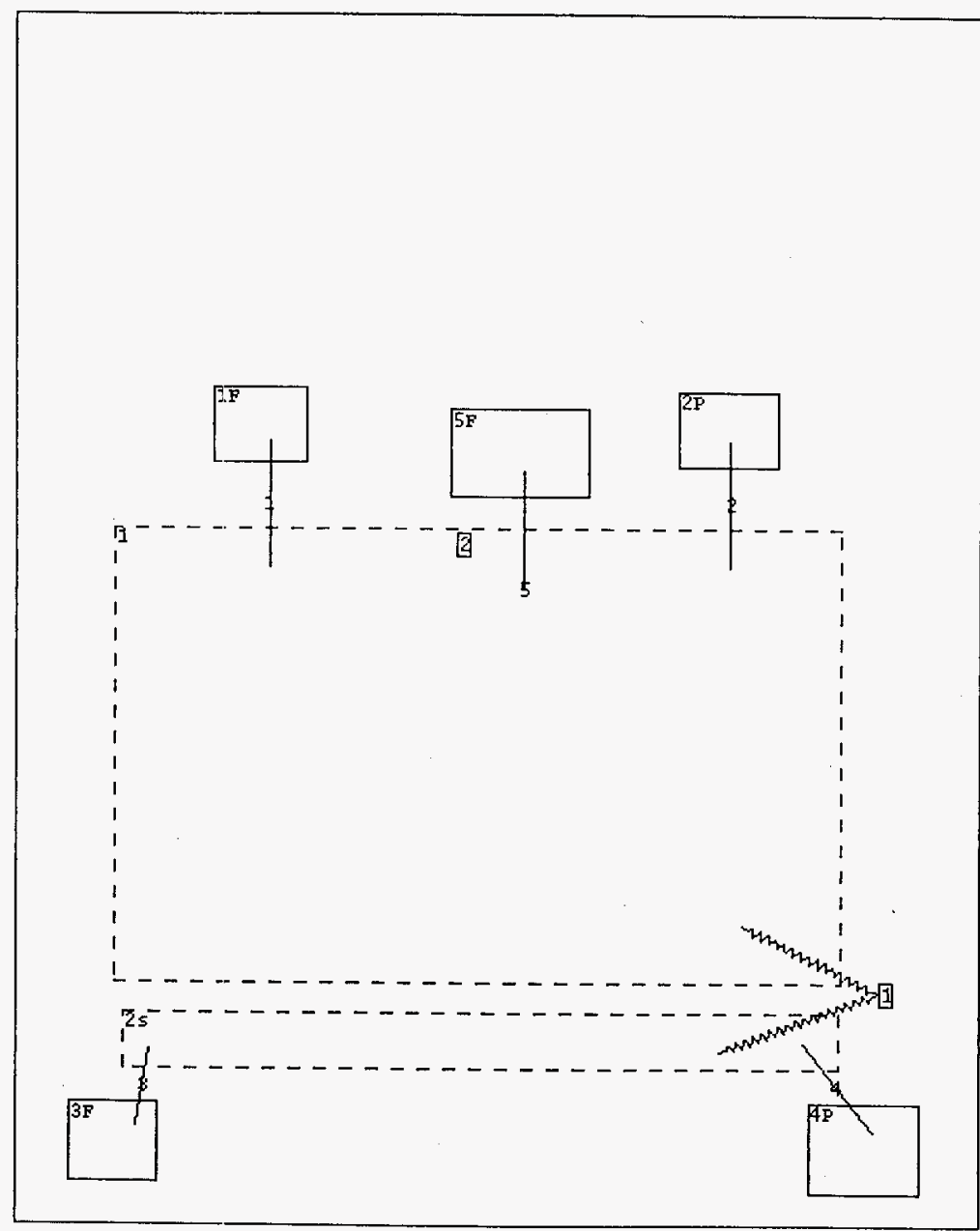


HNF-SD-W320-ER-004 REV 0

Figure 2.4 GOTH 2-D Steam Bump Model.

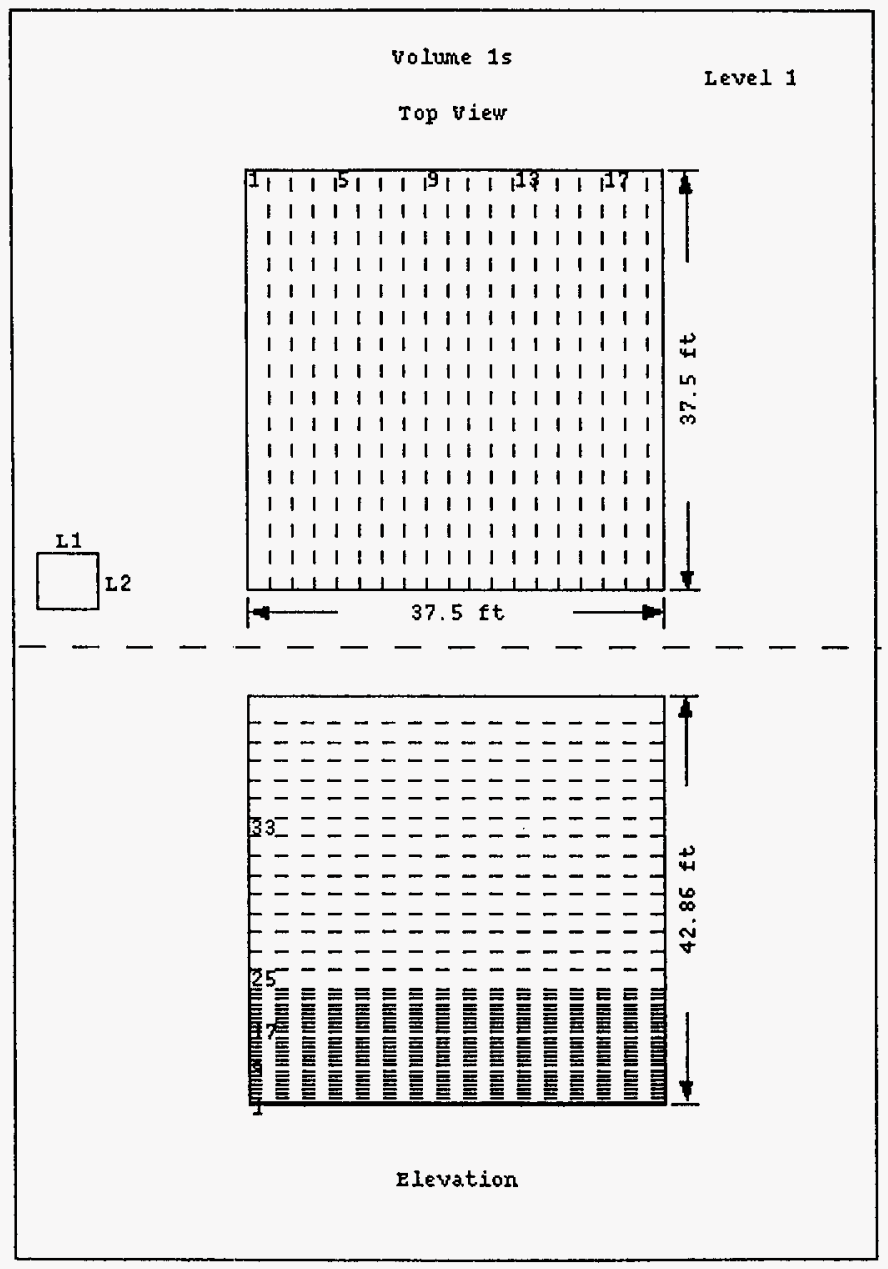


HNF-SD-W320-ER-004 REV O

ligure 2.5 GOTH 1-D Sluicing Model.

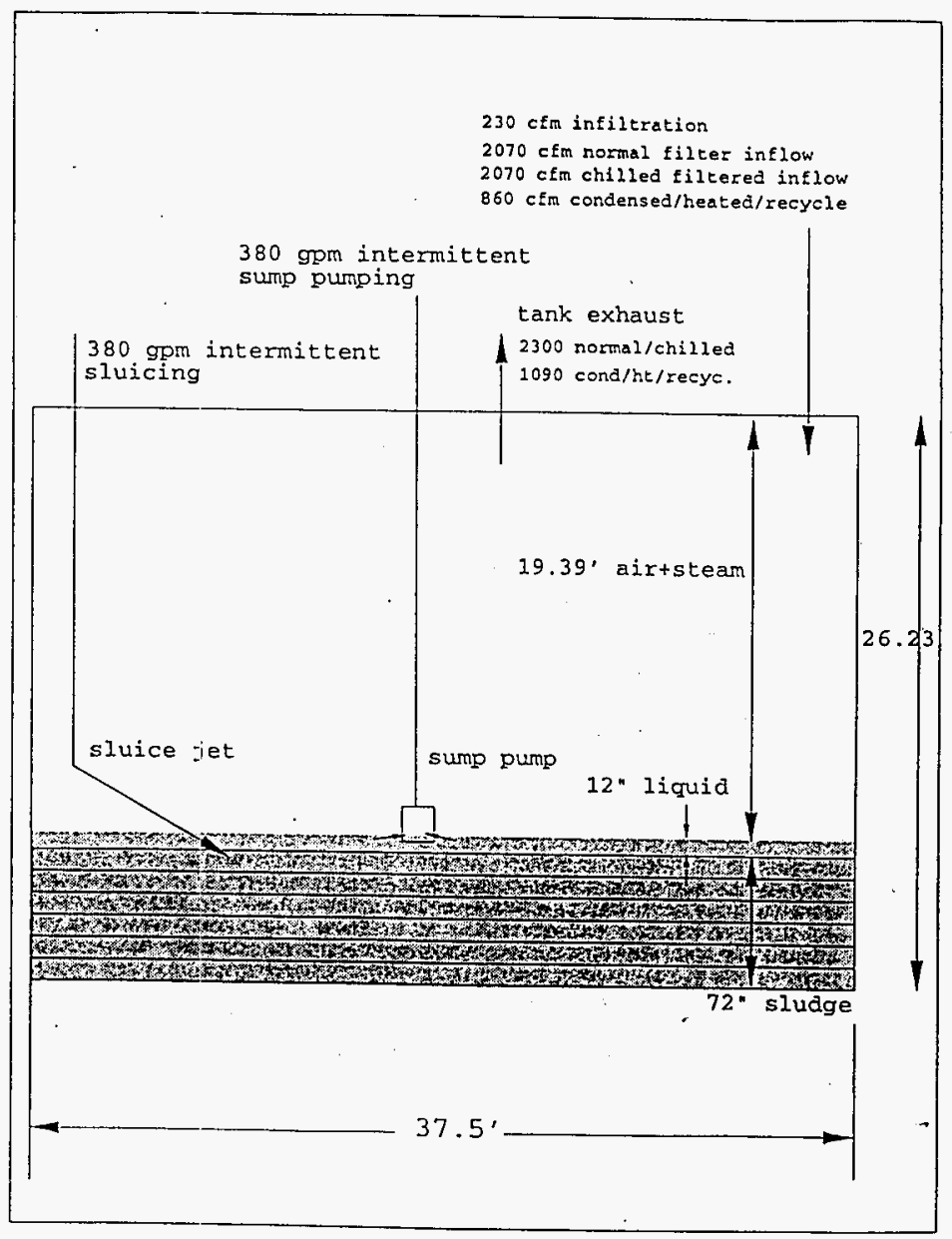




\section{HNF-SD-W320-ER-004 REV 0}

\section{3,0 BEST ESTIMATE PARAMETERS}

The previous Projects W-320 thermal analyses (Sathyanaryana et.al. 1997) used conservative and bonding assumptions for the purpose of scoping design analyses and process control evaluations. A set of best estimate parameters were developed for the updated process control analyses and the SAR analyses documented in this report. These parameters are presented in the following section.

Parameters which have a significant effect on the thermal analyses are given in Table 3.1. Other parameters are given in the previous thermal evaluation of Projects W-320. The previous thermal analyses for Project WV-320 used a conservative fluffing factor of 2.0. A review of all available data resulted in a best estimate value of 1.4 (Reynolds 1997). Previous analyses used $241-\mathrm{C}-106$ heat loads ranging from 110,000 to $132,400 \mathrm{Btu} / \mathrm{hr}$. A best estimate value of 123,000 $\mathrm{Btu} / \mathrm{hr}$ was selected as a best estimate value. This is based upon a thermal evaluation the $24 \mathrm{l}-\mathrm{C}$ 1061994 process test (Fryer 1995), accounting for the radioactive decay from January 1994. The waste transferred from $241-\mathrm{C}-106$ was assumed to be homogenized, eliminating any layering.

Sathyanaryana et.al. 1997 describes three conduction models for a liquid/particle mixture. The most conservative of these is the series conductivity model. This model has been used for all Project W-320 thermal analyses. The best estimate thermal conductivity for $241-\mathrm{C}-106$ is based upon a liquid conductivity of $0.35 \mathrm{Btu} / \mathrm{hr} / \mathrm{f} /{ }^{\circ} \mathrm{F}$ and a solids conductivity ${ }^{\circ} \mathrm{F}$ of $5.0 \mathrm{Btu} / \mathrm{hr} / \mathrm{ft} /{ }^{\circ} \mathrm{F}$ which gives an overall sludge conductivity ( 6 foot transfer with waste homogenized with a fluffing factor of 1.4) of $0.41 \mathrm{Btu} / \mathrm{hr} / \mathrm{t} /{ }^{\circ} \mathrm{F}$. For a fluffing factor of 1 (current condition in 241-C-106) the conductivity is $0.44 \mathrm{Btu} / \mathrm{hr} / \mathrm{ft} /{ }^{/} \mathrm{F}$. This is in reasonable agreement with value of $0.5 \mathrm{Btu} / \mathrm{hr} / \mathrm{ft} /{ }^{\circ} \mathrm{F}$ which was used to match the temperature data for tank 241-C-106 during the post process test evaluations (Thurgood 1995). Reynolds 1997 suggest that the liquid thermal conductivity may be lower at a value of $0.28 \mathrm{Btu} / \mathrm{hr} / \mathrm{ft} /{ }^{\circ} \mathrm{F}$. Using the series conductivity model, the conductivity of the sludge for a full waste transfer would be $0.33 \mathrm{Btu} / \mathrm{hr} / \mathrm{f} /{ }^{\circ} \mathrm{F}$. Based upon the thermal evaluation of the 1994 process test, the value of $0.35 \mathrm{Btu} / \mathrm{hr} / \mathrm{ft} /{ }^{\circ} \mathrm{F}$ was selected for the best estimate thermal conductivity of liquid. However, sensitivity analyses for thermal conductivity were performed using a value of 0.33 (Section 4.2.3)

All analyses presented in this report were performed with the Project W-030 primary system configuration. This system provides $100 \mathrm{cfm}$ inlet air and $400 \mathrm{cfm}$ recirulation flow. The combined flow was modeled as $500 \mathrm{cfm}$ at $76^{\circ} \mathrm{F}$ and $75 \%$ humidity. 
HNF-SD-W320-ER-004 REV 0

Table 3.1 Best Estimate Parameters

\begin{tabular}{|c|c|}
\hline Best Estimate Parameters & $\begin{array}{l}\text { Best Estimate } \\
\text { Value }\end{array}$ \\
\hline \multicolumn{2}{|l|}{ 241-C-106 Parameters } \\
\hline $\begin{array}{l}\text { Fluffing Factor } \\
2 \text { Sigma range }\end{array}$ & $\begin{array}{c}1.4 \\
1.0 \text { tol. } 8 \\
\end{array}$ \\
\hline Liquid Thermal Conductivity (Btu/hr-ft- ${ }^{\circ}$ F) & 0.35 \\
\hline Particle Thermal Conductivity (Btu/hr- $\left.\mathrm{At}-{ }^{\circ} \mathrm{F}\right)$ & 5.0 \\
\hline Liquid Heat Capacity $\left(B t u / \mathrm{b}_{\mathrm{m}}-{ }^{-} \mathrm{F}\right)$ & 0.8 \\
\hline Particle Heat Capacity $\left(B t u / \mathrm{lb}_{\mathrm{m}}{ }^{\circ} \mathrm{F}\right)$ & 0.2 \\
\hline Total Heat Load (Btu/hr) & 123,000 \\
\hline $\begin{array}{l}\text { C-106 Heat Load Distribution (Btu/hr) } \\
0 \text { to } 2 \text { feet } \\
2 \text { to } 6 \text { feet }\end{array}$ & $\begin{array}{c}17,670 \\
105,300\end{array}$ \\
\hline \multicolumn{2}{|l|}{ 241-AY-102 Parameters } \\
\hline Sludge Thermal Conductivity (Btu/hr-ft- ${ }^{\circ} \mathrm{F}$ ) & 0.35 \\
\hline Sludge Heat Capacity $\left(\mathrm{Btu} / \mathrm{lb}_{\mathrm{m}}-{ }^{\circ} \mathrm{F}\right)$ & 0.8 \\
\hline $\begin{array}{c}\text { AY-102 Heat Load (Btu/hr) } \\
0 \text { to } 1 \text { foot } \\
1 \text { to } x \text { feet }\end{array}$ & $\begin{array}{c}33,000 \\
\text { homogenized } \\
\text { from C-106 }\end{array}$ \\
\hline
\end{tabular}




\section{HNF-SD-W320-ER-004 REV 0}

\subsection{PROCESS CONTROL ANALYSES}

Analyses were performed and documented in Sathyanaryana et.al. 1997 to evaluate the expected thermal behavior of tanks 241-C-106 and 241-AY-102 during and following sluicing. This evaluation contributed to the process control strategy for both tanks. These analyses have been further refined through the use of the best estimate parameters presented in the previous section. These best estimate steady state analyses are presented in sections 4.1 and 4.2 .

The previous thermal study included an evaluation of the sluicing process in 241-C-106. The thermal model has since been improved, providing a better determination of the sluicing increments and subsequent hold periods required to maintain maximum waste subcooling throughout the sluicing process. These updated analyses are presented in section 4.3.

The analyses were performed both with the 1-D HUB and the 1-D GOTHIC models described in Section 2.0. The results were compared and in good agreement. All the result in the following sections, with the exception of the steam bump and 241-C-106 sluicing analyses, were performed with the 1-D GOTHIC model.

Waste Tank Technical Safety Requirement (TSR) Controls (WHC-SD-WM-BIO-001, REV E) for Double Shell Tanks (DST's) specify that the waste temperature remain below $215^{\circ} \mathrm{F}$ in the bottom 15 feet of waste. This is $30^{\circ} \mathrm{F}$ subcooling at the tank bottom. This control is intended to prevent the occurance of a steam bump. The Operational Safety Requirements (OSD's) will be revised to reflect this TSR. The discussion in the following sections assumes that a $30^{\circ} \mathrm{F}$ subcooling margin will be incorporated into a future OSD revision and refers to the OSD subcooling limit. However, it should be noted that a subcooling margin does not currently exist in the OSD's.

\subsection{STEADY STATE BEST ESTIMATE ANALYSES}

An analyses of the steady state thermal behavior of tank 241-AY-102 following a transfer of two feet of waste from 241-C-106 is shown in Figure 4.1. The figure shows the waste temperature distribution. A value of 1 represents the bottom of the tank and 0 the top of the sludge (Some figures in the report include one foot of supernate so that 0 is one foot into the supernatant pool. These will be obvious because of the small temperature gradient in the pool). The maximum sludge temperature without any annulus slot flow is less than $180^{\circ} \mathrm{F}$. This provides a subcooling margin (local saturation temperature - maximum waste temperature) of more than $60^{\circ} \mathrm{F}$ with the system in its minimum configuration (no annulus flow). The Operational Safety Documents (OSD) limit is a minimum of $30^{\circ} \mathrm{F}$. With wall annulus blockage, $250 \mathrm{cfm}$ slot flow could be provided which significantly increases the available cooling margin. The heat removal is distributed as follows:

$$
\text { Primary sensible heat }=16 \%
$$




\section{HNF-SD-W320-ER-004，REV 0}

Primary evaporation $=74 \%$

Primary soil conduction $=10 \%$

Thus, evaporation is the dominate heat removal mechanism. Figure 4.1 represents the base case for a 2 foot transfer, using the best estimate parameters, and will be referred to throughout the report.

A best estimate analyses of the steady state thermal behavior of tank 241-AY-102 following a full retrieval from $241-\mathrm{C}-106$ is shown in Figure 4.2. The independent axis includes 1 foot of supernatant. The analyses assumed the primary system was operated with the Project W030 configuration $\left(500 \mathrm{~cm}, 76^{\circ} \mathrm{F}\right.$ inlet temperature at $75 \%$ relative humidity) and the secondary at $2000 \mathrm{cfm}$ with $40^{\circ} \mathrm{F}$ chilled air. The maximum waste temperature is about $212^{\circ} \mathrm{F}$ which just provides the minimum required subcooling of $30^{\circ} \mathrm{F}$. Notice that the maximum waste temperature occurs near the center axial location. For this configuration the energy balance is :

$\begin{array}{ll}\text { Primary sensible heat }= & 9 \% \\ \text { Primary evaporation }:= & 40 \% \\ \text { Primary conduction }=: & 5 \% \\ \text { Annulus system }= & 46 \%\end{array}$

The majority of the heat is removed by evaporative cooling and the annulus ventilation system. Figure 4.2 represents the base case for a 6 foot transfer.

The annulus system chiller can be eliminated by increasing the annulus slot flow. Figure 4.3 shows the waste temperature distribution using the best estimate parameters with no chiller and the annulus flow increased to $3000 \mathrm{cfm}$. The maximum waste temperature is just below the minimum OSD subcooling margin $\left(\sim 211^{\circ} \mathrm{F}\right)$.

The minimum configuration for the secondary annulus system is wall blockage and operation at high annulus vacuum (annulus system vacuum exceeds the primary system) or an inlet fan, without an annulus chiller. Assuming best estimate parameters the minimum annulus slot flow needed to maintain the required subcooling margin exceeds $2000 \mathrm{cfm}$. This slot flow is probably not achievable through high annulus vacuum alone, but would require an inlet fan (Sathyanaryana et.al. 1997). However, fluffing factors lower than 1.4 are very possible which would reduce the secondary cooling requirement. Figure 4.4 shows the waste temperature distribution for a 6 foot transfer with optimistic values of fluffing factor (1.0) and thermal conductivity $\left(0.44 \mathrm{Btu} / \mathrm{hr}-\mathrm{ft}-{ }^{\circ} \mathrm{F}\right)$. The annulus ventilation flow is $1200 \mathrm{cfm}$ which is achievable through high annulus vacuum and no inlet fan. The maximum waste temperature is only 5 to 10 ${ }^{\circ} \mathrm{F}$ below the OSD limit. Thus, a complete transfer of $241-\mathrm{C}-106$ waste may be achievable with a minimal modifications to the existing ventilation system given optimistic but possible thermal parameters and some relaxation in the subcooling margin. 
HNF-SD-W320-ER-004 REV 0

Figure 4.1 Best Estimate Steady State Analyses for 2 Foot Transfer.

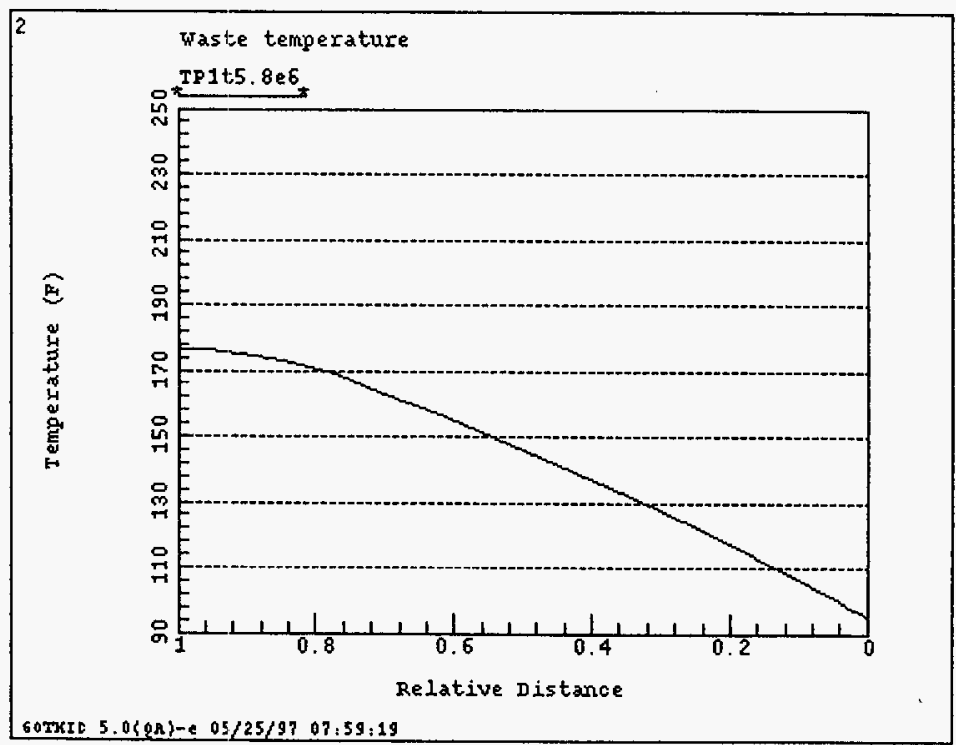




\section{HNF-SD-W320-ER-004 REV 0}

Figure 4.2 Best Estimate Steady State Analyses for 6 Foot Transfer.

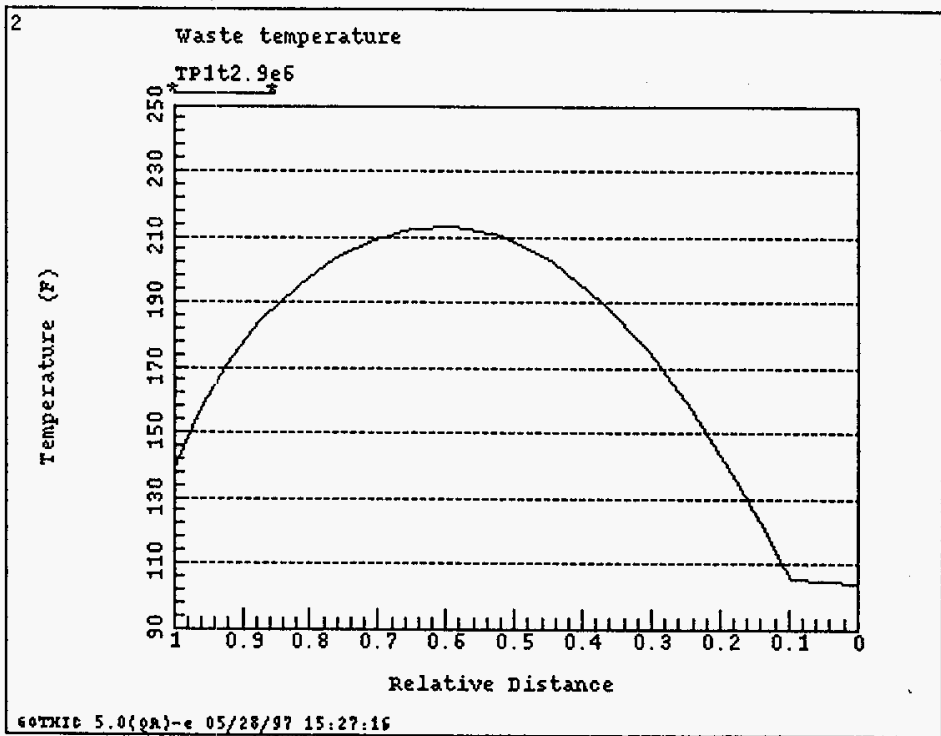


Figure 4.3 Best Estimate Steady State Analyses for 6 foot Transfer without Chilling.

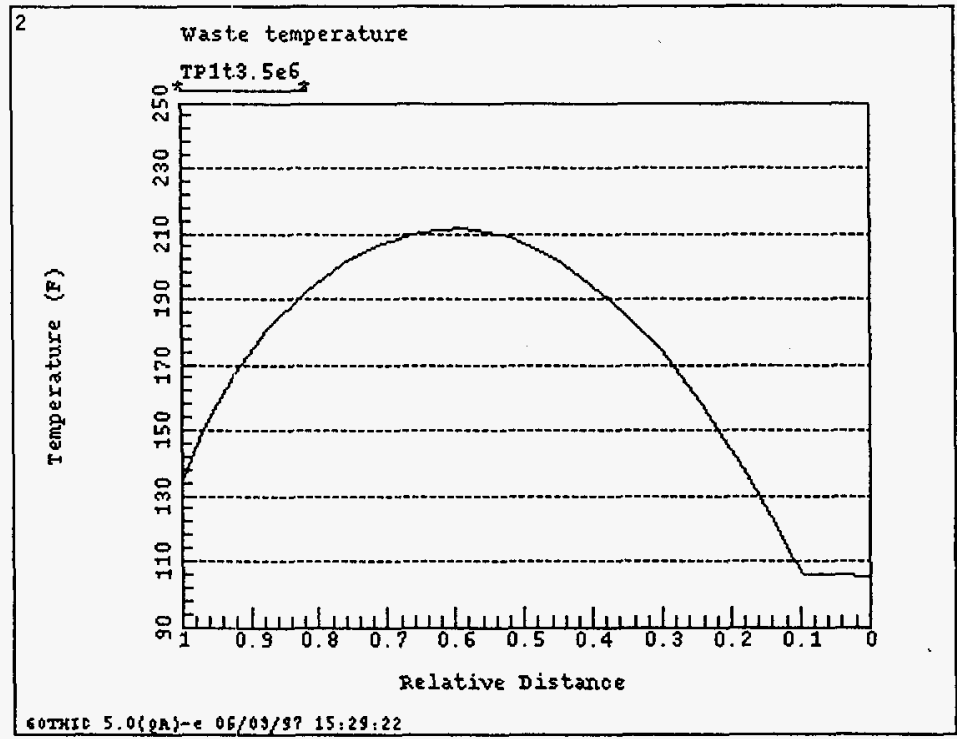




\section{HNF-SD-W320-ER-004 REV 0}

Figure 4.4 Steady State Temperature for 6 Foot Transfer with Optimistic Fluffing Factor.

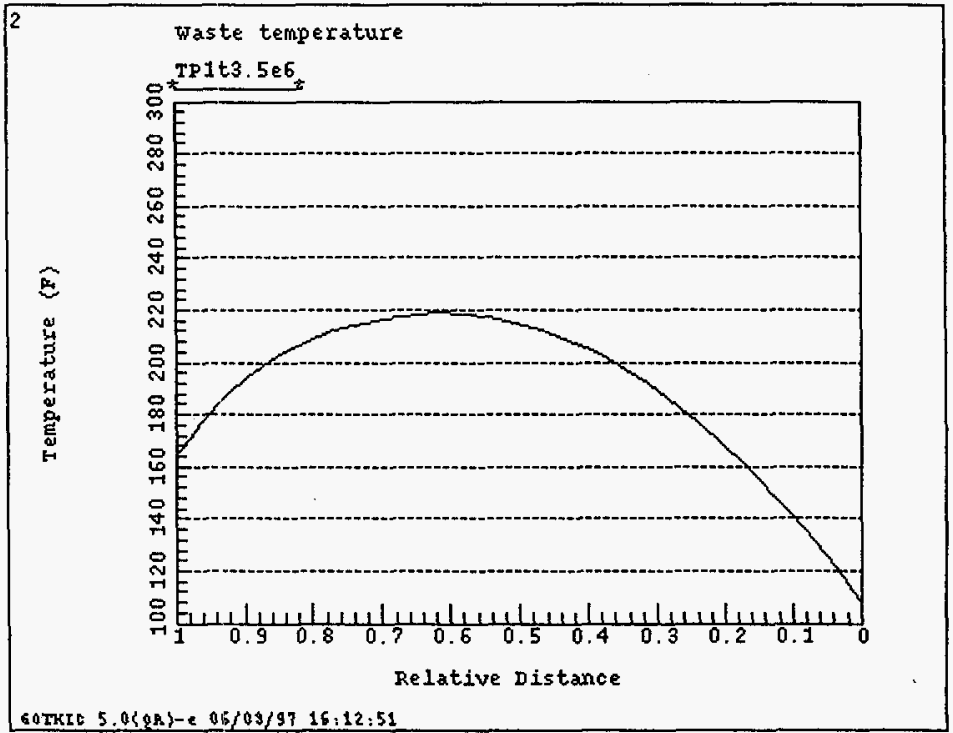




\section{HNF-SD-W320-ER-004 REV 0}

\subsection{PARAMETER SENSITIVITY}

The 241-C-106 retrieval will be performed incrementally with hold periods for evaluation. The purpose of this incremental sluicing is to allow cooling in 241-C-106 prior to supernatant removal and to evaluate the actual in-tank values of physical parameters important to the thermal behavior in 241-AY-102. These include total power and power distribution; waste fluffing factor and waste thermal conductivity. A series of steady state parametric analyses were performed to evaluate uncertainty in the predicted maximum waste temperature given the uncertainty in these parameters.

\subsubsection{Heat Load Distribution}

The best estimate heat load for 241-C-106 $(123,00 \mathrm{Btu} / \mathrm{hr})$ and heat load distribution is based upon tank thermo couple data and thermal modeling (Fryer 1995) of the 1994 241-C-106 Process Test. This value is also consistent with grab sample analyses of the 241-C-106 waste, although there is a significant amount of uncertainty in the grab sample data. It is very likely that the sluicing process will tend to homogenies the waste from 241-C-106, minimizing the uncertainty in the heat load distribution. However, an axially varying heat load distribution in the transferred waste in 241-AY-102 is possible.

There is currently a one foot layer of 241-AY-102 waste with an estimated heat load of $33,000 \mathrm{Btu} / \mathrm{hr}$. This was accounted for in all previous analyses. Table 4.1 shows the axial variation in heat in 241-C-105 based upon a review of the waste transfer records (Agnew 1996). This Hanford Waste Model predicts a heat load of nearly $47,000 \mathrm{Btu} / \mathrm{hr}$ in the first two feet of 241-C-106 waste. The best estimate heat load is about $18,000 \mathrm{Btu} / \mathrm{hr}$ in the same two feet. Analyses were performed using the heat load distribution of Table 4.1 for 241-AY-102 (in reverse order). All other parameters were best estimate.

Note that the total heat load predicted by the Agnew model is in excellent agreement with the best estimate value (Section 3.0). 
HNF-SD-W320-ER-004 REV 0

Table 4.1 Heat Load Distribution for 241-C-106 Based Hanford Waste Model.

\begin{tabular}{|c|c|c|c|c|c|c|}
\hline $\begin{array}{l}\text { Waste } \\
\text { Type }\end{array}$ & $\begin{array}{l}\text { Volume } \\
\text { (gallons) }\end{array}$ & $\begin{array}{l}\text { Waste } \\
\text { Helght } \\
\text { (inches) }\end{array}$ & $\begin{array}{l}\text { कo } \\
\text { Date Added }\end{array}$ & $\begin{array}{l}\text { Predicted Cs-137 } \\
\text { Concentration } \\
\text { (uCV }\end{array}$ & $\begin{array}{l}\text { Predicted Sr-90 } \\
\text { Concentration } \\
\text { (uCV/mi) }\end{array}$ & $\begin{array}{l}\text { Predicted } \\
\text { Heat load } \\
\text { (Btuhr) }\end{array}$ \\
\hline supernate & variable & 69 & & $3 \times 10^{4}$ & 5.35 & negligible \\
\hline $\begin{array}{l}\text { unknown } \\
\text { (B plant \& } \\
\text { AR vault) }\end{array}$ & 64,000 & 44 to 69 & & $\begin{array}{l}\text { average of } B \text { plant } \\
\text { and AR vault } \\
\text { layers }\end{array}$ & $\begin{array}{l}\text { average of } B \\
\text { plant and } A R \\
\text { vault layers }\end{array}$ & 46,970 \\
\hline B Plant & 20,000 & 37 to 44 & 1974 to 1977 & 0 & 4,734 & 8,210 \\
\hline AR Vault & 64,000 & 13 to 37 & 1969 to 1972 & 506 & 11,834 & 67,590 \\
\hline $\begin{array}{l}\text { PUREX } \\
\text { cladding } \\
\text { removal }\end{array}$ & 34,000 & 11013 & 1958 to 1965 & 2.9 & 2.5 & 13 \\
\hline $\begin{array}{l}\text { Urauium } \\
\text { Recoveny }\end{array}$ & 15,000 & $\begin{array}{l}-12 \text { to } 1 \\
\text { (dis:hed } \\
\text { bottom) }\end{array}$ & 1954 & 10.3 & 5.1 & 16 \\
\hline \multicolumn{6}{|r|}{ Total Heat Load } & 122,800 \\
\hline
\end{tabular}

The predicted steady state temperature for a full waste transfer using the heat load distribution of Table 4.1 is shown in Figure 4.5. The analyses used the base case configuration (Section 4.1, Project W-030 primary ventilation and $2000 \mathrm{cfm}$ chilled annulus flow). The maximum waste temperature is increased by about $30^{\circ} \mathrm{F}$ and approaches the local saturation temperature. The minimum subcooling margin is not maintained. A comparison with Figure 4.2 shows that the maximum power layer is located where the waste temperature is a maximum and heat removal the most difficult.

A second analyses was performed with an increased annulus ventilation flow. The flow was increased to $3000 \mathrm{cfm}$. As shown in Figure 4.6, the temperature increase is only partially mitigated through the use of excess cooling margin provided by an upgraded annulus ventilation system. A full waste transfer may not be possible given this conservative power distribution. However, more favorable values for fluffing factor or thermal conductivity would probably compensate for Agnew power distribution, allowing complete waste transfer.

The power distribution of Table 4.1 was used for a 2 foot transfer. The $46,970 \mathrm{Btu} / \mathrm{hr}$ of the first layer was added to the 33,000 Btu/hr already in 241-AY-102. No credit was taken for annulus ventilation flow. The predicted steady state temperature shown in Figure 4.7. The temperature is over $60^{\circ} \mathrm{F}$ above the base case (Figure 4.1). The OSD limit $\left(-215^{\circ} \mathrm{F}\right)$ is exceeded by a few degrees. There will be nearly $250 \mathrm{cfm}$ annulus flow available after wall blockage is 


\section{HNF-SD-W320-ER-004 REV 0}

complete. This will provide excess cooling to compensate for uncertainties if thermal parameters. Figure 4.8 shows the temperature distribution for the same power distribution with $150 \mathrm{cfm}$ annulus slot flow. The temperature increase is completely mitigated. Only a fraction of this flow would be needed to maintain the minimum required subcooling $(-50 \mathrm{~cm})$. The analyses of the 2 foot transfer with the Agnew power distribution indicates that an adverse power distribution can be mitigated through the use of excess cooling capacity in the annulus ventilation system.

The evaluation of the 6 foot waste transfer indicates that a heat load distribution which places a high power layer (Agnew distribution) at the location of the maximum waste temperature will significantly increase the maximum waste temperature for a full 6 foot transfer. Increase annulus flow can only partially compensate for this adverse power distribution. The sluicing method will however most likely tend to homogenies the waste resulting in an averaging of the heat load. Reduced fluffing factor would also compensate. During the process of incremental sluicing, the actual power distribution in 241-AY-102 will be determined. If an adverse distribution of power is identified, a waiting period to allow for waste consolidation (lowering the fluff factor) may allow a full transfer to be completed. 
HNF-SD-W320-ER-004 REV 0

Figure 4.5 Heat Load Distribution Analyses, 6 Foot Transfer.

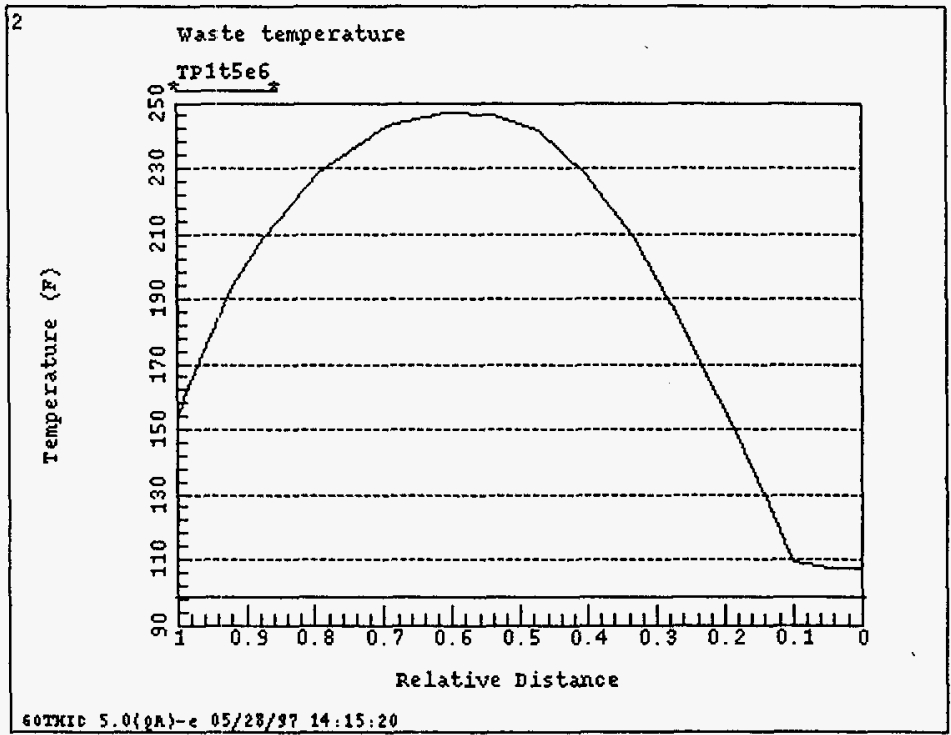




\section{HNF-SD-W320-ER-004 REV 0}

Figure 4.6 Heat Load Distribution Analyses, 6 Foot Transfer with Increased Annulus Flow.

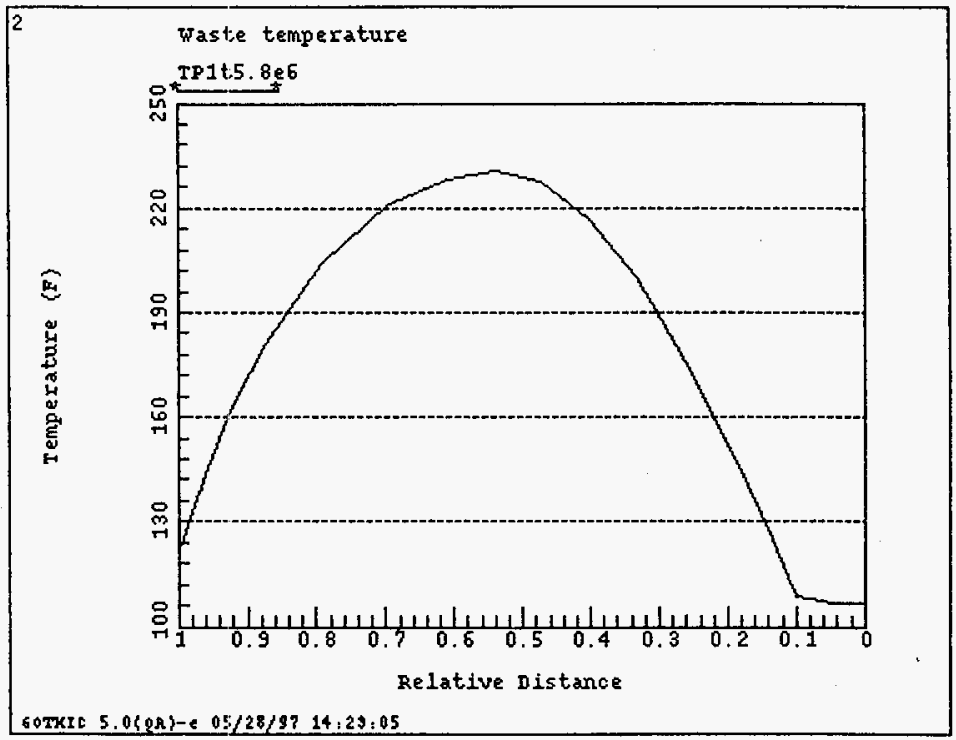


HNF-SD-W320-ER-004 REV 0

Figure 4.7 Heat Load Distribution Analyses, 2 Foot Transfer.

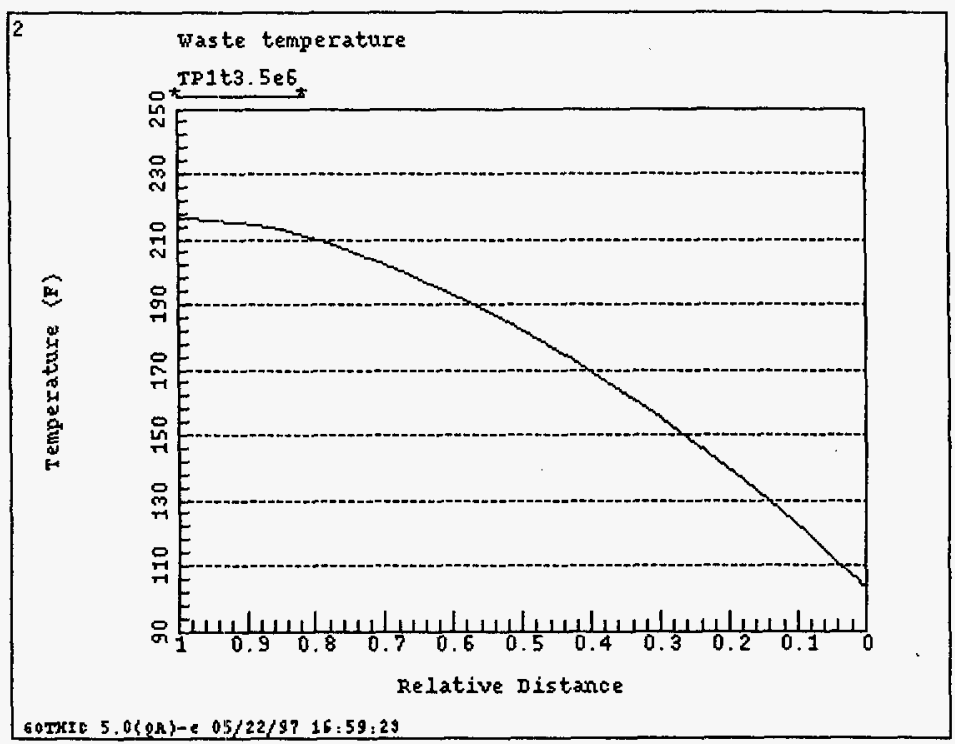


Figure 4.8 Heat Load Distribution Analyses, 2 Foot Transfer With Annulus Flow.

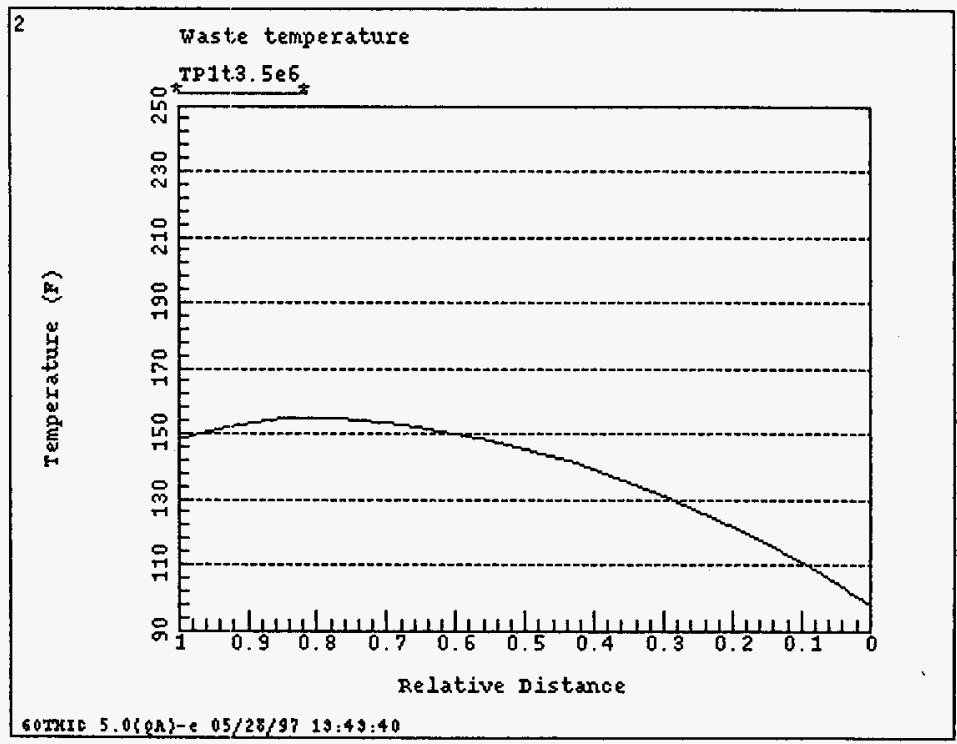




\section{HNF-SD-W320-ER-004 REV 0}

\subsubsection{Fluffing Factor}

The fluffing factor is the ratio of the volume of waste in 241-C-106 prior to sluicing to the volume of the same waste in 241-AY-102 after sluicing. The maximum waste temperature is very sensitive to this parameter since the waste temperature is a function of the square of the conduction distance. A value of 1.4 was chosen for the best estimate fluffing factor. Steady State parametric analyses were performed for fluffing factors of 1.7 and 1 .

The waste temperature distribution for a 6 foot waste transfer with a fluffing factor of 1.7 is shown in Figure 4.9. The maximum waste temperature increases to near the local saturation temperature for the base case configuration of the primary and annulus ventilation systems. This is not surprising since the total waste depth has increased from 9.4 feet for a fluffing factor of 1.4 to 11.2 feet for a fluffing factor of 1.7. Figure 4.10 shows that same case with an annulus ventilation flow of $3300 \mathrm{cfm}$. Temperature is reduced to below the saturation temperature, giving over $15^{\circ} \mathrm{F}$ subcooling margin through the use of available cooling margin in the annulus system. However, the full $30^{\circ} \mathrm{F}$ is not recovered

It is possible that the fluffing factor following waste retrieval from $241-\mathrm{C}-106$ will be less than the best estimate value. This is particularly true following a period of consolidation. Figure 4.11 shows the temperature distribution for a full 6 foot waste transfer with a fluffing factor of 1 and the base case configuration. The maximum waste temperature is $190^{\circ} \mathrm{F}$. This is more than $50^{\circ} \mathrm{F}$ of subcooling margin. This illustrates the need to monitor the in-tank data during and following retrieval. Given actual tank fluffing factor data, the uncertainty in the thermal analyses will be significantly reduced and the maximum waste transfer achieved.

Parametric analyses were also performed for a 2 foot waste transfer with the base case configuration (no annulus flow). There is also sensitivity to fluffing factor for this case. Figure 4.12 shows the steady state temperature distribution for the 2 foot case. The temperature increases by more than $20^{\circ} \mathrm{Fi}$ but does not exceed the OSD limit. The annulus ventilation is required to maintain the required subcooling. Figure 4.13 shows the temperature distribution with $150 \mathrm{cfm}$ floor annulus flow. The temperature increase is completely eliminated.

The fluffing factor may also be lower than the best estimate value of 1.4. Figure 4.14 shows the steady state temperature distribution for a fluffing factor of 1.0 (no annulus ventilation). The maximum waste temperature is only $131^{\circ} \mathrm{F}$ which is nearly $50^{\circ} \mathrm{F}$ lower than the base case with a fluffing factor of 1.4. The observed waste temperature following the first 2 foot transfer may be quite low. It is important however to be careful about extrapolating these conditions to the full waste transfer. Incremental sluicing should be continued through the complete waste transfer. This will allow evaluation of the thermal parameters for each incremental retrieval and identify any layering effects. 


\section{HNF-SD-W320-ER-004 REV 0}

Figure 4.9 Fluffing Factor Sensitivity, 6 Foot Transfer, Increased Fluffing Factor.

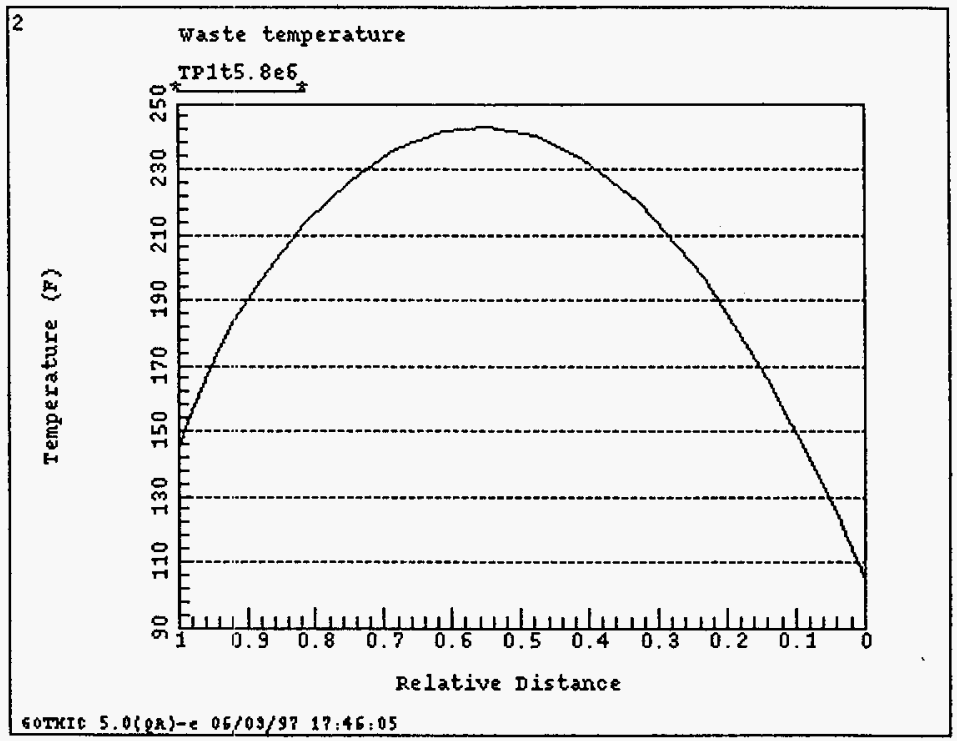




\section{HNF-SD-W320-ER-004 REV 0}

Figure 4.10 Fluffing Factor Sensitivity, 6 Foot Transfer, Increased Annulus Flow.

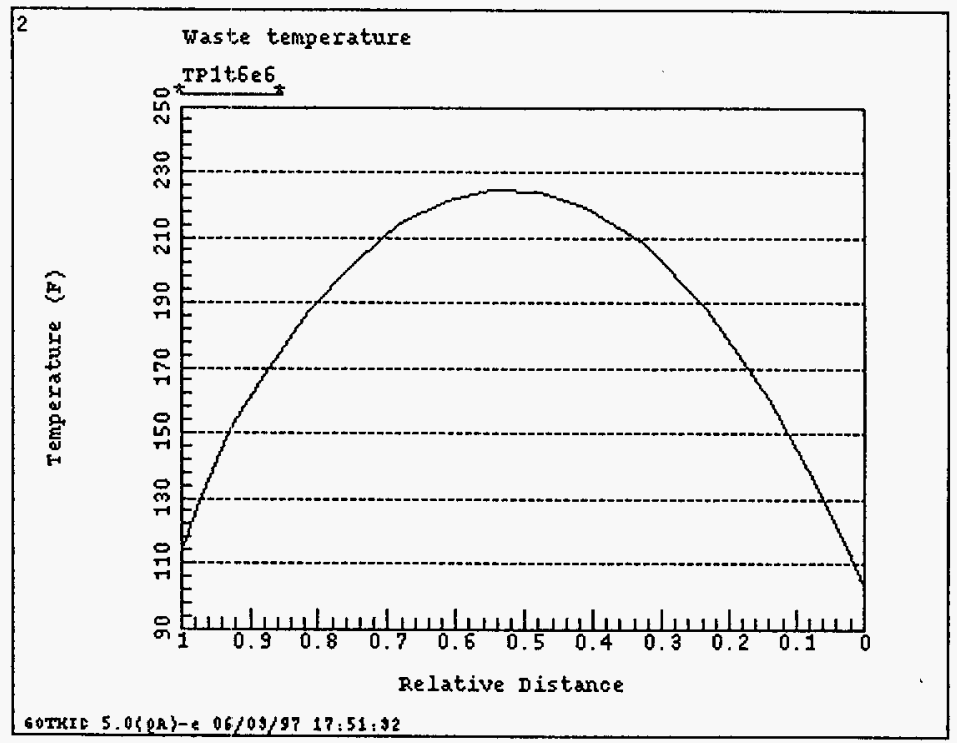


HNF-SD-W320-ER-004 REV 0

Figure 4.11 Fluffing Factor Sensitivity, 6 Foot Transfer, Decreased Fluffing Factor.

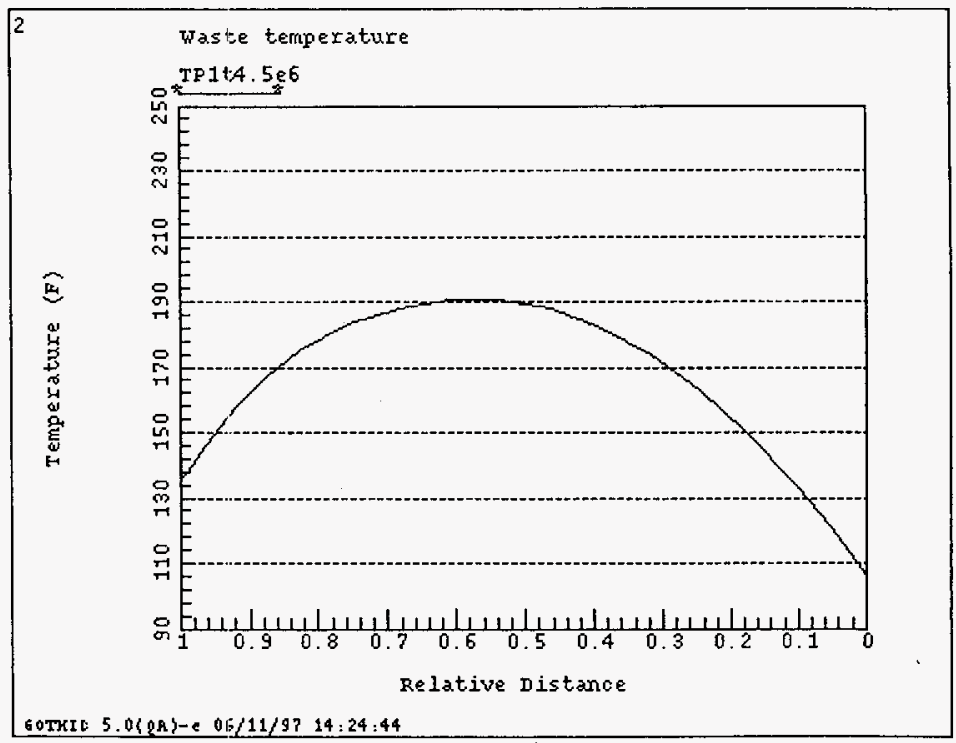




\section{HNF-SD-W320-ER-004 REV 0}

Figure 4.12 Fluffing Factor Sensitivity, 2 Foot Transfer, Increase Fluffing Factor.

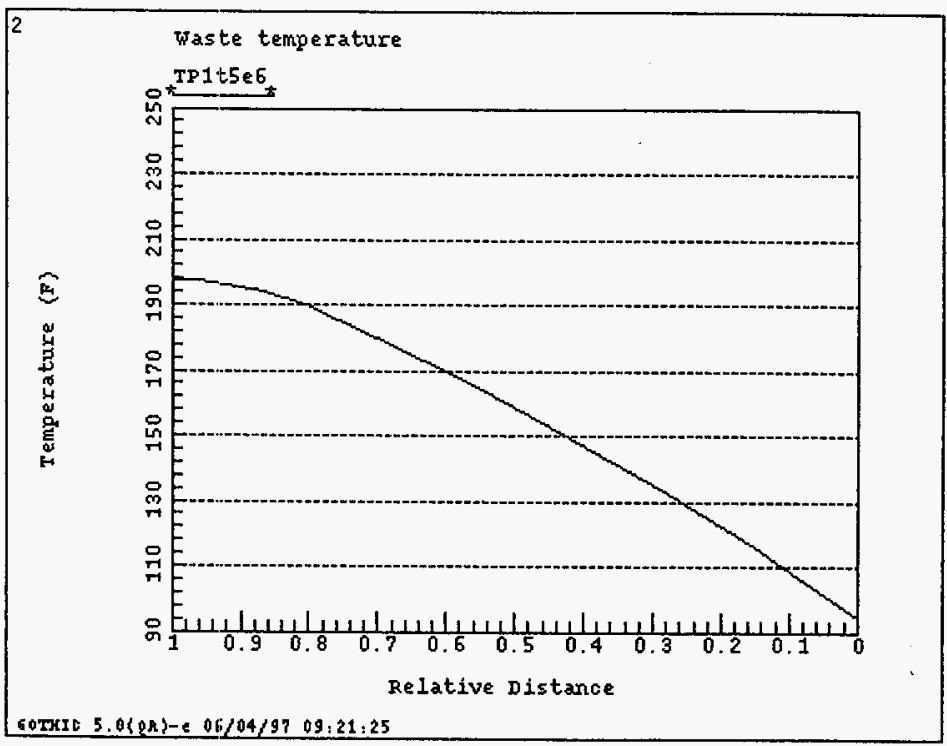




\section{HNF-SD-W320-ER-004 REV 0}

Figure 4.13 Fluffing Factor Sensitivity, 2 Foot Transfer, With Annulus flow.

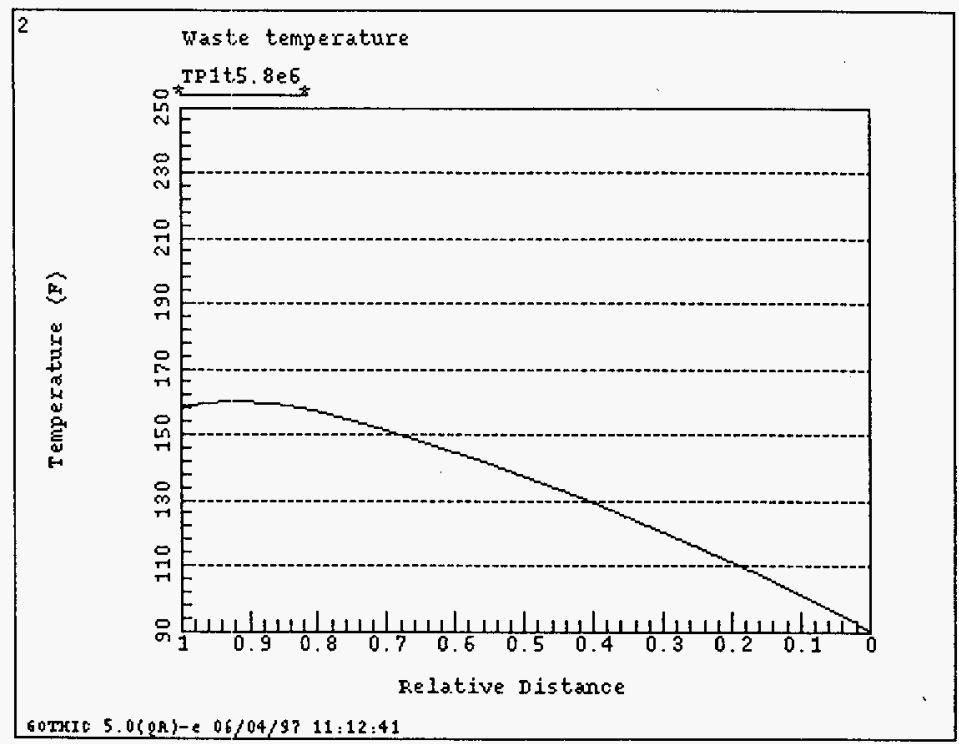




\section{HNF-SD-W320-ER-004 REV 0}

Figure 4.14 Fluffing Factor Sensitivity, 2 Foot Transfer, Decreased Fluffing Factor.

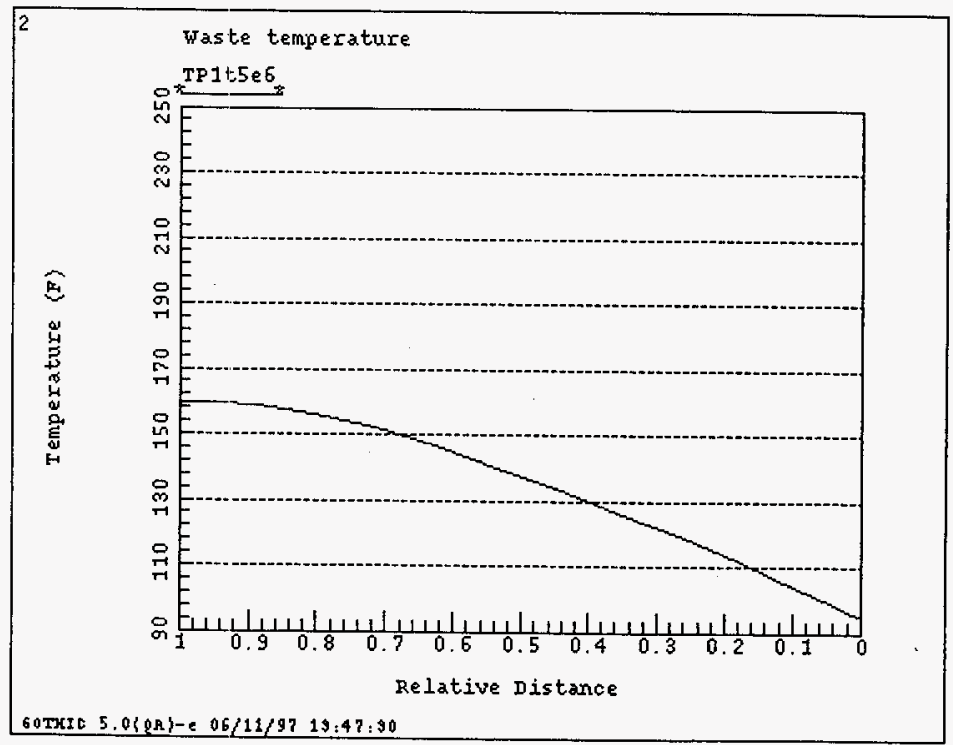




\section{HNF-SD-W320-ER-004 REV 0}

\subsubsection{Thermal Conductivity}

Sathyanaryana et.al. 1997 describes three conduction models for a liquid/particle mixture. The most conservative of these is the series conductivity model. This model has been used for all Project W-320 thermal analyses. The best estimate thermal conductivity (Section 3.0) is based upon a liquid conductivity of $0.35 \mathrm{Btu} / \mathrm{hr} / \mathrm{ft} /{ }^{\circ} \mathrm{F}$ and a solids conductivity of $5.0 \mathrm{Btu} / \mathrm{hr} / \mathrm{ft} /{ }^{\circ} \mathrm{F}$ which gives an overall sludge conductivity ( 6 foot transfer with waste homogenized with a fluffing factor of 1.4) of $0.41 \mathrm{Btu} / \mathrm{hr} / \mathrm{ft} /{ }^{\circ} \mathrm{F}$. For a fluffing factor of 1 the conductivity is $.44 \mathrm{Btu} / \mathrm{hr} / \mathrm{ft} /{ }^{\circ} \mathrm{F}$. This is in reasonable agreement with value of $0.5 \mathrm{Btu} / \mathrm{hr} / \mathrm{ft} /{ }^{\circ} \mathrm{F}$ which was used to match the temperature data for tank 241-C-106 during the post process test evaluations (Thurgood 1995). Reynolds 1997 suggest that the liquid thermal conductivity may be lower at a value of $0.28 \mathrm{Btu} / \mathrm{hr} / \mathrm{ft} /{ }^{\circ} \mathrm{F}$. Using the series conductivity model, the conductivity of the sludge for a full waste transfer would be 0.33 . Sensitivity analyses for thermal conductivity were performed using a value of 0.5 and 0.33 . For the two foot transfer, the particle loading is smaller and the conductivity is very close to the water conductivity. Sensitivity analyses for the 2 foot transfer case was performed using a lower liquid conductivity of $\left(1.28 \mathrm{Btu} / \mathrm{hr} / \mathrm{ft} /{ }^{\circ} \mathrm{F}\right.$.

The sensitivity analyses for a full 6 foot transfer with decreased thermal conductivity is shown in Figure 4.15. The maximum waste temperature is $230^{\circ} \mathrm{F}$. While the OSD limit $(\sim 211$ ${ }^{\circ} \mathrm{F}$ ) is exceeded, there is still a $10^{\circ} \mathrm{F}$ subcooling margin. The maximum temperature is not as sensitive to thermal conductivity as fluffing factor sensitivity or power distribution seen in the previous sections.

Figure 4.16 shows the calculated steady state temperature for the decreased thermal conductivity using available cooling margin in an upgraded annulus ventilation system. An annulus slot flow of $3000 \mathrm{cfn}$ was used. The increased flow reduces the maximum waste temperature to $216^{\circ} \mathrm{F}$, nearly completely mitigating the effects of the decreased thermal conductivity.

There is also a chance the thermal conductivity will be higher than the best estimate value. This is particularly true in view of the thermal evaluation of the 1994 241-C-106 process test which resulted in conductivities in excess of $0.5 \mathrm{Btu} / \mathrm{hr}-\mathrm{ft}-{ }^{\circ} \mathrm{F}$. The sensitivity to increased thermal conductivity, using a value of $0.5 \mathrm{Btu} / \mathrm{hr}-\mathrm{ft}-{ }^{\circ} \mathrm{F}$ is shown in Figure. 4.17. The maximum waste temperature decreases as expected. The maximum temperature of $200^{\circ} \mathrm{F}$ increases the subcooling margin by about $10^{\circ} \mathrm{F}$. It should be noted that improvement in some thermal parameters relative to the best estimate values will help offset degraded values in other parameters. Combined with the excess available cooling, a full transfer of 241-C-106 waste is very probable.

The uncertainty in thermal parameters is less important for a 2 foot transfer because of the excess of cooling available through the annulus ventilation system. However, a sensitivity analyses was performed for a 2 foot transfer with a thermal conductivity of $0.3 \mathrm{Btu} / \mathrm{hr}-\mathrm{ft}-{ }^{\circ} \mathrm{F}$. The 


\section{HNF-SD-W320-ER-004 REV 0}

steady state temperature is shown in Figure 4.18. The maximum waste temperature is $194^{\circ} \mathrm{F}$, which is over $20^{\circ} \mathrm{F}$ below the OSD limit. As seen in the other sensitivity analyses for a 2 foot transfer, the use of a small annulus slot flow will completely mitigate the increased temperature. 
Figure 4.15 Thermal Conductivity Sensitivity, 6 Foot Transfer, Decreased K.

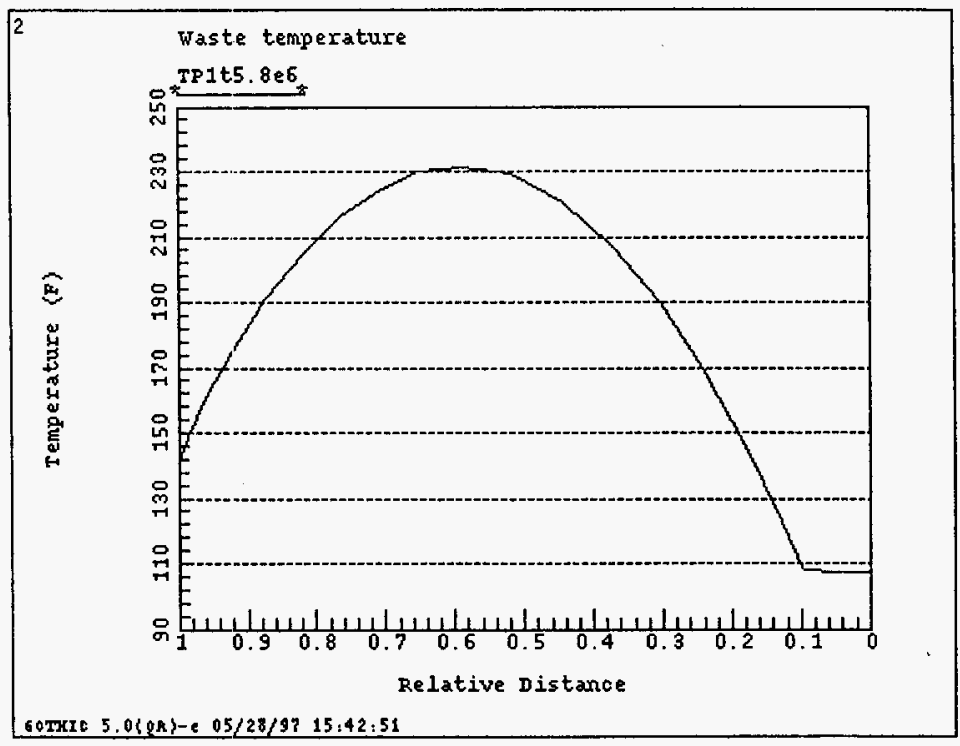




\section{HNF-SD-W320-ER-004 REV 0}

Figure 4.16 Thermal Conductivity Sensitivity, 6 Foot Transfer, Increased Annulus Flow.

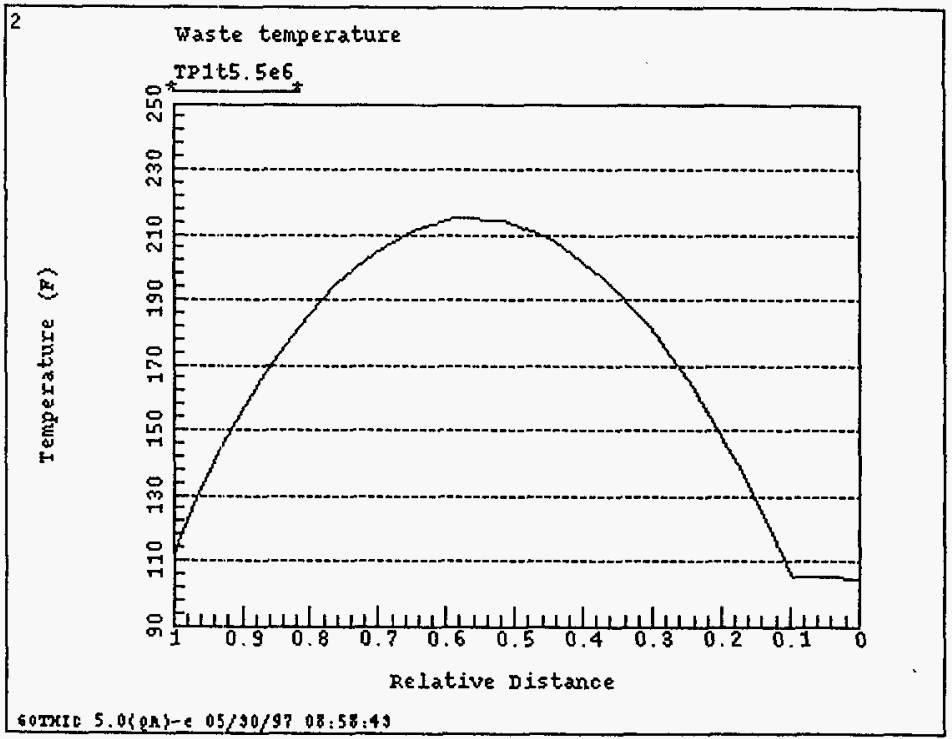


Figure 4.17 Thermal Conductivity Sensitivity, 6 Foot Transfer, Increased K.

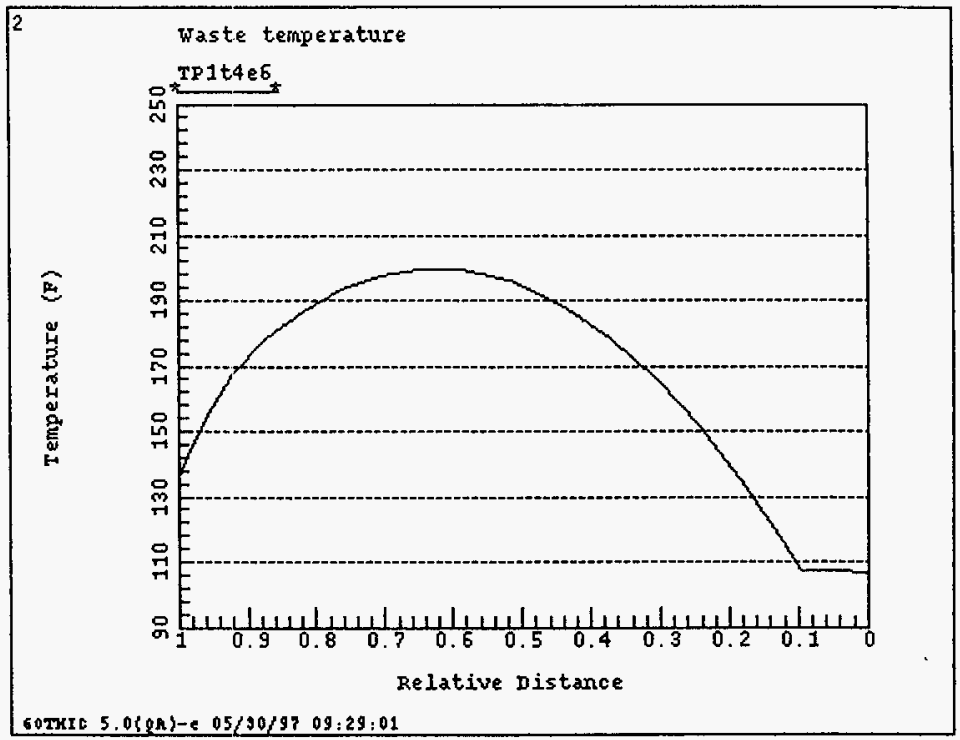


HNF-SD-W320-ER-004 : REV 0

Figure 4.18 Thermal Conductivity Sensitivity, 2 Foot Transfer, Decreased K.

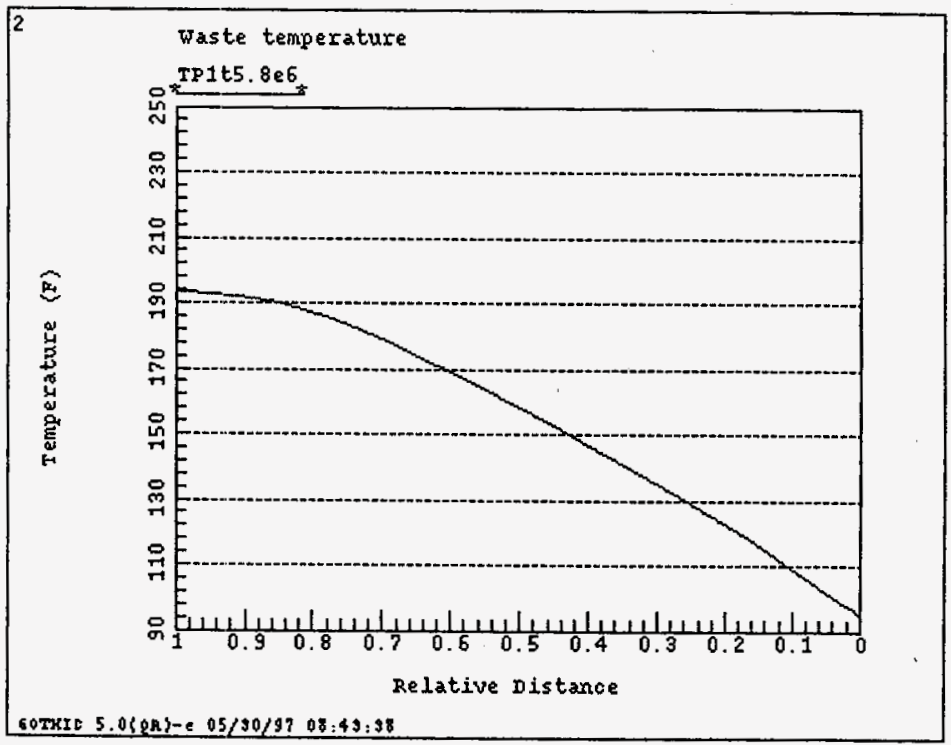




\section{HNF-SD-W320-ER-004 REV 0}

\subsubsection{Tank Heat Load}

Sensitivity analyses for the heat load distribution in 241-C-106 was presented in Section 4.2.1. Sensitivity analyses were also performed for the total tank heat load for 241-C-106. The best estimate value is $123,000 \mathrm{Btu} / \mathrm{hr}$. This value is consistent with tank thermo couple data, tank grab sample and as discussed in Section 4.2.1, it is also in agreement with the waste transfer records. However, there probably exists a 5 to $10 \%$ uncertainty in this heat load estimate. Analyses of the waste temperature distribution were performed for a $10 \%$ higher and lower heat load

Figure 4.19 shows the $241-\mathrm{AY}-102$ waste temperature distribution assuming a full 6 foot transfer from 241-C-106 with a tank heat load of $135,300 \mathrm{Btu} / \mathrm{hr}$ and a total heat load in $24 \mathrm{I}-\mathrm{AY}$ 102 of $168,300 \mathrm{Btu} / \mathrm{hr}$. The maximum waste temperature is $223^{\circ} \mathrm{F}$ which leaves over a $15^{\circ} \mathrm{F}$ subcooling margin. The effect of increased heat load is about the same magnitude as the increase in thermal conductivity discussed in Section 4.2.3 and much less than the heat load distribution sensitivity discussed in Section 4.2.1. As seen in Figure 4.16 for the thermal conductivity sensitivity, increasing the anrulus ventilation flow to $3000 \mathrm{cfm}$ will nearly mitigate a maximum waste temperature increase of $15^{\circ} \mathrm{F}$. Thus the effect of the higher power can be mitigated with the excess cooling capacity of the annulus ventilation system.

Figure 4.20 shows the steady state waste temperature distribution for a total tank heat load in 241-C-106 of $110,700 \mathrm{Btu} / \mathrm{hr}(143,700 \mathrm{Btu} / \mathrm{hr}$ in AY-102), which is $10 \%$ lower than the best estimate value. The maximum temperature is $199^{\circ} \mathrm{F}$. The subcooling margin is increased by $15^{\circ} \mathrm{F}$. A lower power would help offset increased temperatures from other parameters.

\subsubsection{Summary of Parametric Analyses}

The results of the parametric analyses are summarized in Table 4.2. The table is sorted by the waste transfer ( 2 or 6 feet). The first case for both the 2 and 6 foot transfer is the base case. The sensitivity analyses can be compared to these cases. 


\section{HNF-SD-W320-ER-004 REV 0}

Table 4.2. Summary of Parametric Analyses.

\begin{tabular}{|c|c|c|c|c|c|c|c|c|c|c|c|}
\hline 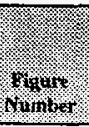 & 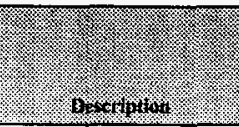 & 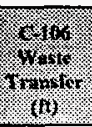 & (ton & 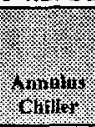 & 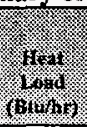 & 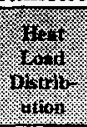 & 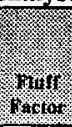 & 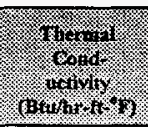 & 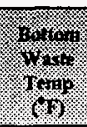 & $\frac{.}{4+4}$ & 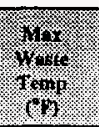 \\
\hline 4.1 & Base Case $2 \mathrm{ft}$ transfer & 2 & 0 & no & 50.670 & BE & 1.4 & 0.37 & 177 & 96 & 177 \\
\hline 4.2 & Base Case $6 \mathrm{fl}$ transfer & 6 & 2000 & yos & 156.000 & $\mathrm{BE}$ & 1.4 & 0.41 & 140 & 104 & 214 \\
\hline 4.3 & Best Estimate W/O chilling & 6 & 3000 & no & 156,000 & $\mathrm{BE}$ & 1.4 & 0.41 & 137 & 104 & 212 \\
\hline 4.4 & Optimistic parameters & 6 & 1200 & no & 156,000 & $\mathrm{BE}$ & 1.0 & 0.44 & 164 & 110 & 220 \\
\hline 4.5 & Agnew heat distribution & 6 & 2000 & yes & 156.000 & Agnew & 1.4 & 0.41 & 154 & 110 & 247 \\
\hline 4.6 & Above with $>$ siot flow & 6 & 3000 & yes & 156,000 & $\mathrm{BE}$ & 1.4 & 0.41 & 124 & 108 & 233 \\
\hline 4.7 & Agnew Hcat Distribution & 2 & 0 & no & 79.970 & Agnew & 1.4 & 0.37 & 217 & 104 & 217 \\
\hline 4.8 & Above with annulus flow & 2 & 150 & no & 79.970 & Agnew & 1.4 & 0.37 & 149 & 98 & 149 \\
\hline 4.9 & Increased nuff factor & 6 & 2000 & yes & 156,000 & $\mathrm{BE}$ & 1.7 & 0.38 & 146 & 105 & 242 \\
\hline 4.10 & Above with $>$ slot flow & 6 & 3300 & yes & 156,000 & $\mathrm{BE}$ & 1.7 & 0.38 & 115 & 104 & 225 \\
\hline 4.11 & Decreased fluff factor & 6 & 2000 & yes & 156.000 & $\mathrm{BE}$ & 1 & 0.44 & 137 & 105 & 190 \\
\hline 4.12 & Increased fluff factor & 2 & 0 & no & 50.670 & $\mathrm{BE}$ & 1.7 & 0.35 & 197 & 96 & 197 \\
\hline 4.13 & Above with annulus flow & 2 & 150 & no & 50,670 & $\mathrm{BE}$ & 1.7 & 0.35 & 158 & 96 & 158 \\
\hline 4.14 & Decreased fluff factor & 2 & 0 & no & 50.670 & $\mathrm{BE}$ & 1 & 0.37 & 131 & 90 & 131 \\
\hline 4.15 & Decreased $\mathrm{K}$ & 6 & 2000 & yes & 156.000 & $\mathrm{BE}$ & 1.4 & 0.33 & 142 & 108 & 230 \\
\hline 4.16 & Above with $>$ slot flow & 6 & 3000 & $y e s$ & 156.000 & $\mathrm{BE}$ & 1.4 & 0.33 & 113 & 104 & 216 \\
\hline 4.17 & Increased $\mathrm{K}$ & 6 & 2000 & yes & 156,000 & $B E$ & 1.4 & 0.5 & 137 & 104 & 200 \\
\hline 4.18 & Decreased K & 2 & 0 & yes & 50.670 & $\mathrm{BE}$ & 1.4 & 0.3 & 194 & 96 & 194 \\
\hline 4.19 & Increased power & 6 & 2000 & $\mathrm{yes}$ & 168.300 & $B E$ & 1.4 & 0.41 & 146 & 106 & 223 \\
\hline 4.20 & Decreased power & 6 & 2000 & ves & 143,700 & BEE & 1.4 & $0.4 !$ & 132 & 100 & 199 \\
\hline
\end{tabular}




\section{HNF-SD-W320-ER-004. REV 0}

Figure 4.19 Waste Temperature Distribution for $10 \%$ Increase in Heat Load.

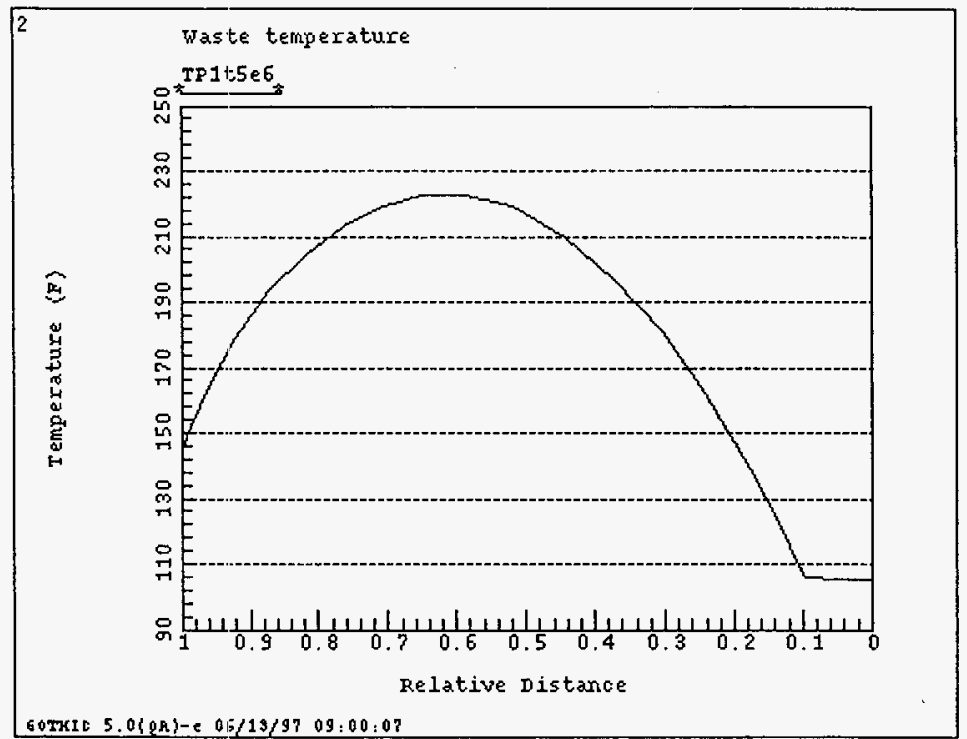


Figure 4.20 Waste Temperature Distribution for $10 \%$ Decrease in Heat Load.

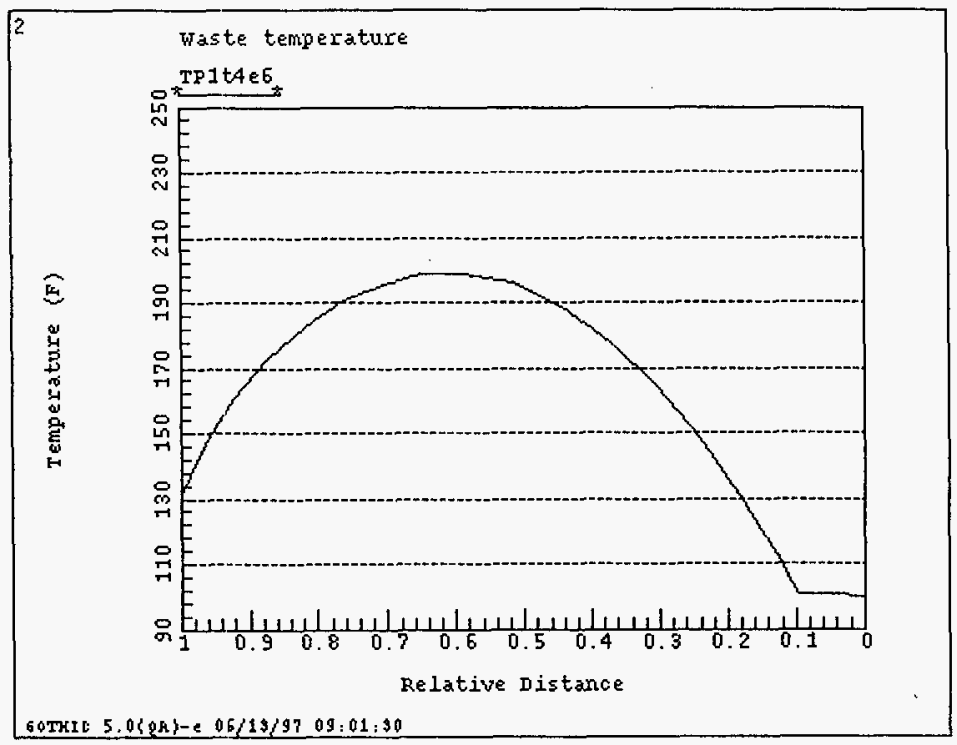




\section{HNF-SD-W320-ER-004 REV 0}

\subsection{TANK 241-C-106 SLUICING EVALUATION}

During sluicing in $241-\mathrm{C}-106$, the waste level will be decrease through the pumping of slurry to 241-AY-102. This will decrease the tank bottom saturation pressure and temperature Without proper process control, the saturation temperature may decrease to the local waste temperature, creating a potential for a steam bump. The process control strategy for 241-C-106 sluicing is incremental sluicing followed by hold periods for waste cooling as discussed in Sathyanaryana et.al. 1997. Following sluicing, but before removal of the supernatant, the conduction heat transfer will be improved through a reduced conduction length due to waste removal. During the hold period the waste temperature will therefore decrease. The length of the hold period must allow adequate cooling so that supernate reduction will not decrease the margin of subcooling. Analyses presented in Sathyanaryana et.al. 1997 showed that a period of 5 days was the minimum period needed for cooling. Those analyses were performed with a 1 foot incremental sluicing. The actual increments may be as small as 0.5 feet. Additional analyses were performed to assess the effect of smaller sluicing increment. The sluicing analyses were performed with the GOTH code using the 1 dimensional model presented in Section 2.5 .

Figure 4.21 shows the waste saturation temperature and the maximum waste temperature for a 0.5 foot incremental sluicing. The problem was initialized with a 90 day period of maximum summer conditions followed by an 83 day of inlet chiller operation. This lowers the waste temperature to near winter conditions. The analyses modeled a 5 hour sluicing period, followed by a 5 day hold period for cooling, followed by a 1 hour period of supernate reduction of 0.5 feet. The waste level shown in Figure 4.21 indicates the level reduction. There is a corresponding drop in saturation temperature due to the loss of hydrostatic head. The maximum waste temperature decreases slowly at first, but rapidly after several sluicing increments as the conduction heat transfer improves. The subcooling margin, indicated by the difference between saturation and waste temperatures, increases. With a hold period of 5 days, the subcooling margin is maintained or increased. Thus the reduction in the sluicing increment size from 1 foot to 0.5 feet did not change the length of the required hold period of 5 days.

During the sluicing operation, the ventilation system for $241-\mathrm{C}-106$ will be configured in a recirculation mode with the chiller on the recirculation line for defogging purposes. The tank inlet flow will decrease from over $2000 \mathrm{cfm}$ to just over $200 \mathrm{cfm}$. This will significantly diminish the cooling capacity of the system. The analyses describe above accounts for the heat removal capacity. If the ventilation system is reconfigured for sluicing and sluicing is delayed, the waste temperature will begin to increase, reducing the subcooling margin. An analysis was performed to determine the heat up rate of the waste. Figure 4.22 shows the temperature of the waste and the waste saturation temperature. As seen in the figure, the waste temperature will approach saturation temperature within 90 to 100 days. Therefore it is important that the ventilation system remain in its current configuration with inlet chiller until sluicing can be initiated. 
HNF-SD-W320-ER-004 .REV 0

Figure 4.21 Waste Temperature During Sluicing for 241-C-106.

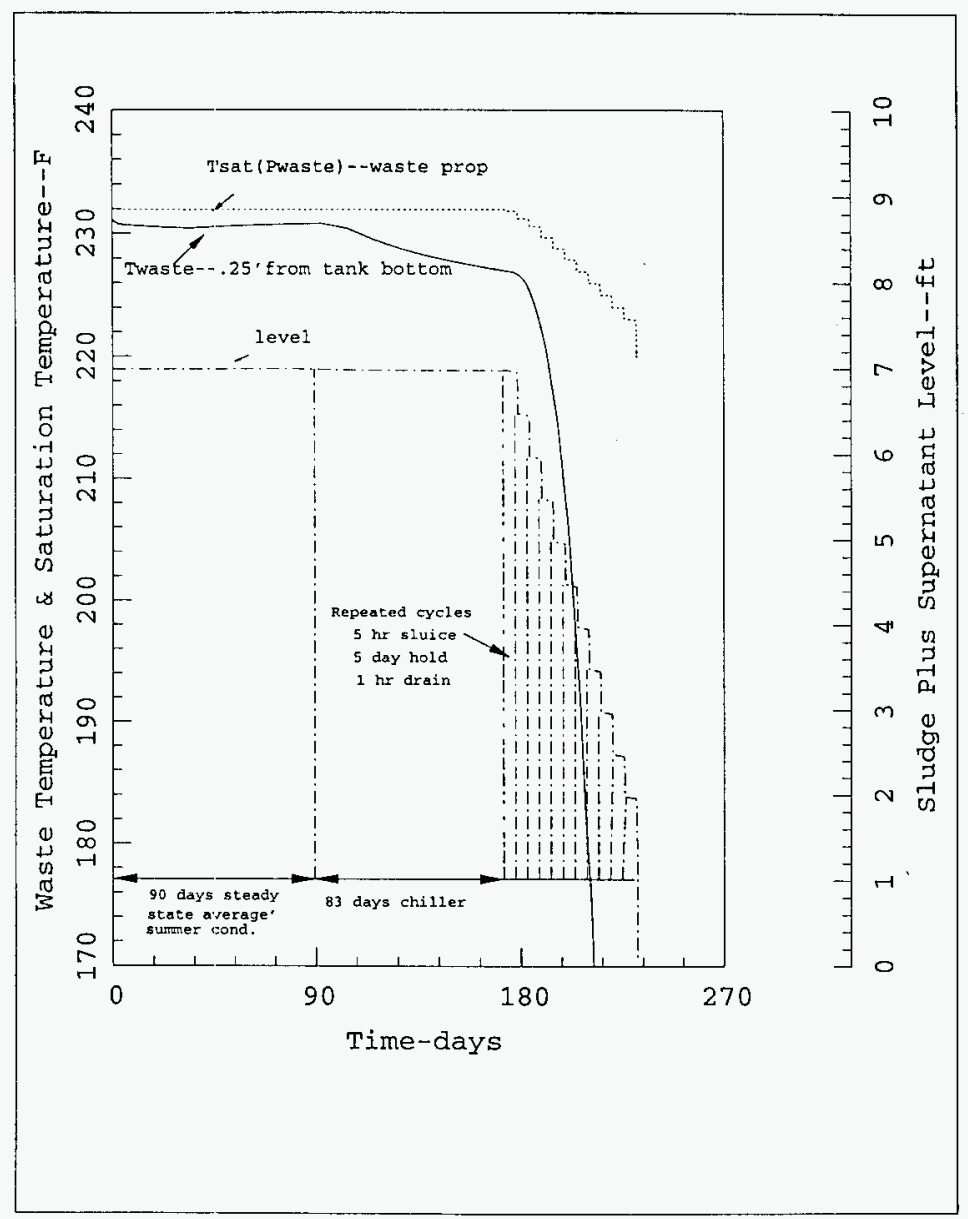




\section{HNF-SD-W320-ER-004 REV 0}

Figure 4.22 Waste Temperature for 241-C-106 for Sluicing Ventilation System.

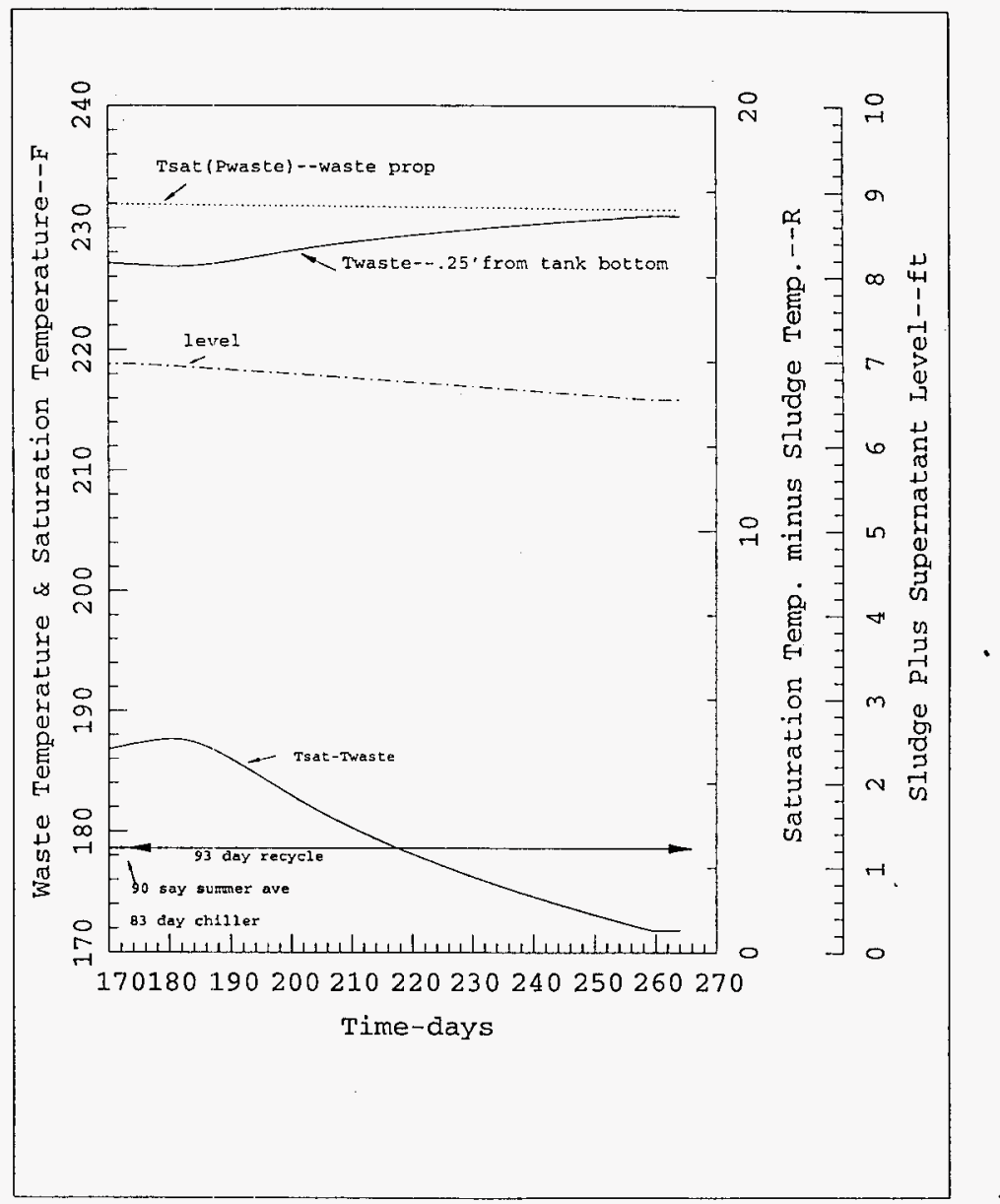




\section{HNF-SD-W320-ER-004 REV 0}

\subsection{SAR ANALYSIS}

The analyses discussed in the previous sections and in Sathyanaryan 1997 were primarily steady state analyses, evaluating thermal behavior of 241-AY-102 and 241-C-106 during normal operation or retrieval. Analyses have also been performed to support the Safety Analyses for Project W-320. These are time transient analyses of off normal events. An evaluation of loss of ventilation, loss of evaporation and loss of secondary chiller are provided in the following sections. These analyses were performed with the 1-D GOTHIC model and 2-D GOTH model discussed in Section 2.0.

\subsection{LOSS OF VENTILATION}

Loss of primary or secondary (annulus) ventilation will result in a general tank heat up. If the maximum waste temperatures reach local saturation temperatures, steam will form in the waste. If this occurs after a period of waste consolidation, the strength of the waste can trap the steam, increasing the buoyancy of the waste. This could result in a spontaneous steam release and water flashing which is generally referred to as a "steam bump". The objective the loss of ventilation analyses is to determine the available time following the loss of ventilation to recover ventilation and therefore mitigate the potential for a steam bump. Analyses were performed for a 2 foot and 6 foot transfer using the best estimate parameters presented in Section 3.0. The analyses assumed a full 20 foot supernatant pool. Analyses for reduced supernatant pools are presented in Section 6.2.

The analyses documented in sections 5.1.1 through 5.1.3 were performed for a full 6 foot waste transfer. The loss of ventilation for a 2 foot waste transfer with a 20 foot supernatant pool is discussed in Section 5.1.4.

\subsubsection{Loss of Primary and Secondary Ventilation}

The supernatant pool heat up following a total loss of ventilation (primary and secondary) is shown in Figure 5.1. The transient calculation was initiated at $3 \mathrm{e}^{6}$ seconds. The pool heat up is slow, less than 1 degree per day $\left(0.25^{\circ} \mathrm{F} /\right.$ day $)$. The transient waste temperature distribution is shown in Figure 5.2. The lower curve ( $\mathrm{t}=2.9 \mathrm{e} 6 \mathrm{~seconds})$ is the steady state temperature profile. As discussed in Section $4.1, \sim 46 \%$ of the heat generated by the waste is taken out by the annulus ventilation system. When ventilation is loss, the lower half of the waste begins heating immediately as seen in the figure. The top portion of the waste during normal ventilation operation is cooled by the primary ventilation system. After loss of ventilation, the supernatant pool with a large heat capacity still provides a significant heat sink, which continues to provide cooling for the top half of the waste. Thus the temperatures in the top half of the waste increase slowly, following the pool temperature increases. Saturation temperature is reached at the bottom of the waste in $\mathbf{3 1}$ days. This should provide adequate time to recover ventilation. 


\section{HNF-SD-W320-ER-004 REV 0}

Because the maximum waste temperature occurs at the tank bottom, recovery of the annulus ventilation system will immediately begin reducing waste temperatures. The pool temperature for a loss of ventilation (at $3 \mathrm{e} 6$ seconds) with ventilation recovery when the waste temperatures reach saturation ( $6 \mathrm{e} 6 \mathrm{~seconds}$ ) is illustrated in Figures 5.3. The rate of rise in temperature is immediately reduced. However, it will not decrease until most of the energy stored in the waste as a result of the ventilation outage is removed. The waste temperature distribution is shown in Figure 5.4. The bottom waste temperature is reduced by over $70^{\circ} \mathrm{F}$ in 12 days (le 6 seconds). The location of the maximum temperature shifts back toward the original position. Complete recovery as indicated by the waste temperature will required many months.

\subsubsection{Loss of Secondary Ventilation}

The transient waste temperature distribution for a loss of secondary or annulus ventilation is shown in Figure 5.5. The time to saturation remains the same at 31 days. Up to 20 days, the heat up of the lower half of the waste is nearly adiabatic since the temperature is lower than the maximum temperature near the middle of the waste. After approximately 20 days, a negative temperature gradient is established which allows conduction of heat to the pool to begins. As a result, the time to saturation is not greatly influenced by the pool or primary ventilation system. If the normal operating waste temperature was further from saturation (for example, a partial retrieval from 241-C-106), the temperature gradient to the pool would be established will before the waste temperature reached saturation and then the pool would greatly influence the waste heat up.

The transient pool ternperature is shown in Figure 5.6. The pool does not begin to heat up until the peak temperature inireases at about 12 days (le 6 seconds). At this point, the temperature gradient in the top of the waste increases, increasing the flow of energy to the pool.

\subsubsection{Loss of Primary Ventilation}

The transient waste temperature distribution for a loss of primary ventilation is shown in Figure 5.7. The waste heat up occurs more slowly, taking over 250 days to reach saturation. This is because the maximum waste temperature for the 6 foot transfer is strongly affected by the annulus ventilation system which continues to provide cooling during this event. With loss of primary ventilation, the heat capacity of the supernatant pool becomes much more important. This results in a slow thermal heat up. Without mitigation, waste saturation temperatures will be reached.

The supernatant pool temperature is shown in Figure 5.8. This event is characterized by a slow, long heat up.

\subsubsection{Loss of Primary Ventilation - 2 Foot Transfer}

Figure 5.9 shows the supernatant pool temperature for a loss of primary ventilation with a 


\section{HNF-SD-W320-ER-004 REV 0}

2 foot transfer. The heat up rate is skomewhat slower than the 6 foot transfer. However, the waste heatup rates are significantly lower as shown in Figure 5.10 shows the waste temperature distribution. The waste temperature has not exceeded the OSD temperature limit 185 days after the loss of ventilation. 


\section{HNF-SD-W320-ER-004 REV 0}

Figure 5.1 Loss of Ventilation, Pool Temperature.

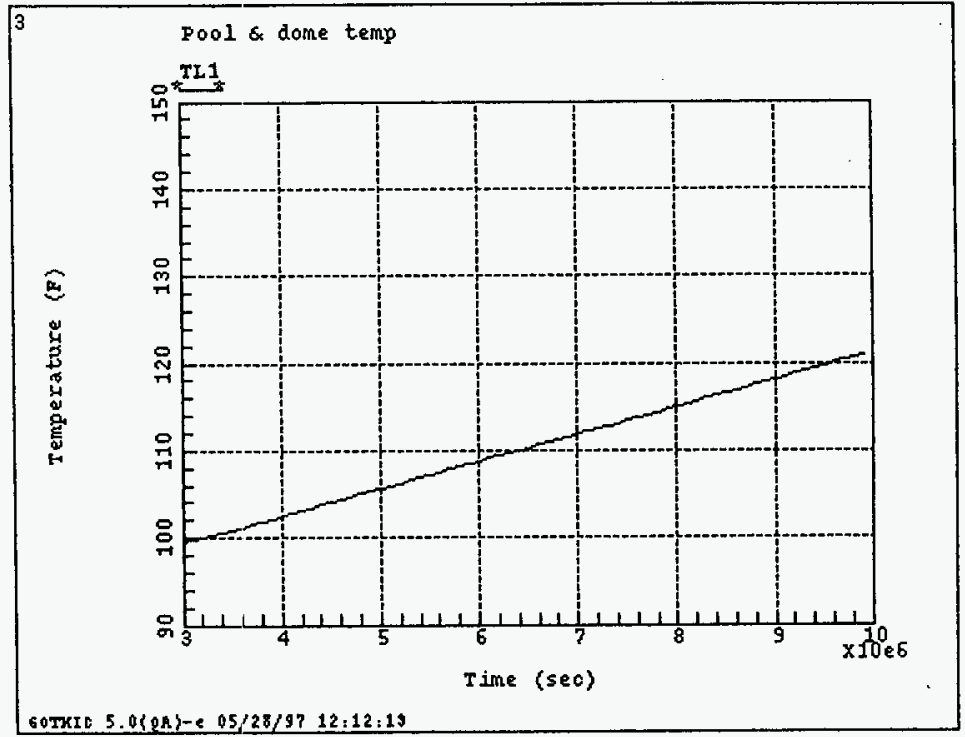




\section{HNF-SD-W320-ER-004 REV 0}

Figure 5.2 Loss of Ventilation, Transient Temperature Distribution.

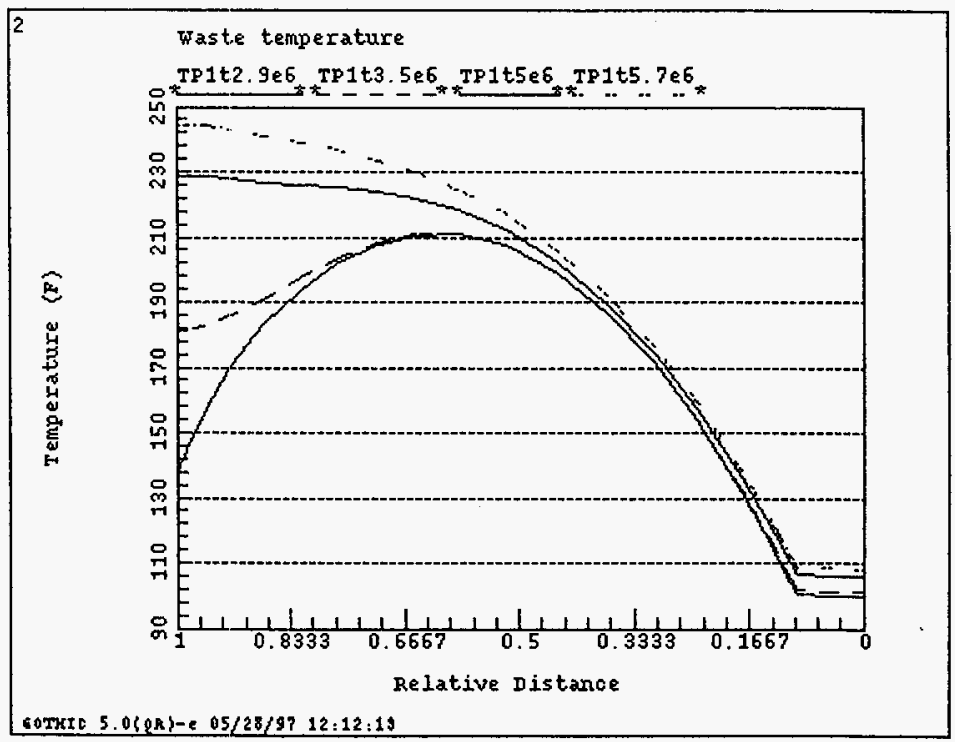




\section{HNF-SD-W320-ER-004 REV 0}

Figure 5.3 Loss of Ventilation with Recovery, Pool Temperature.

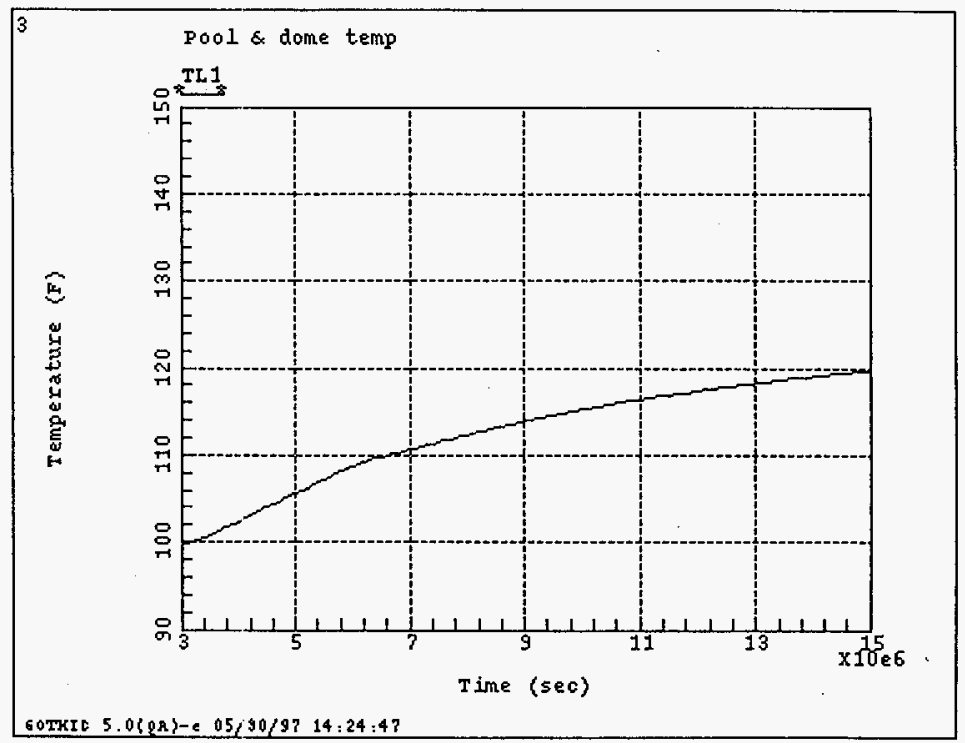




\section{HNF-SD-W320-ER-004 REV 0}

Figure 5.4 Loss of Ventilation with Recovery, Transient Temperature Distribution.

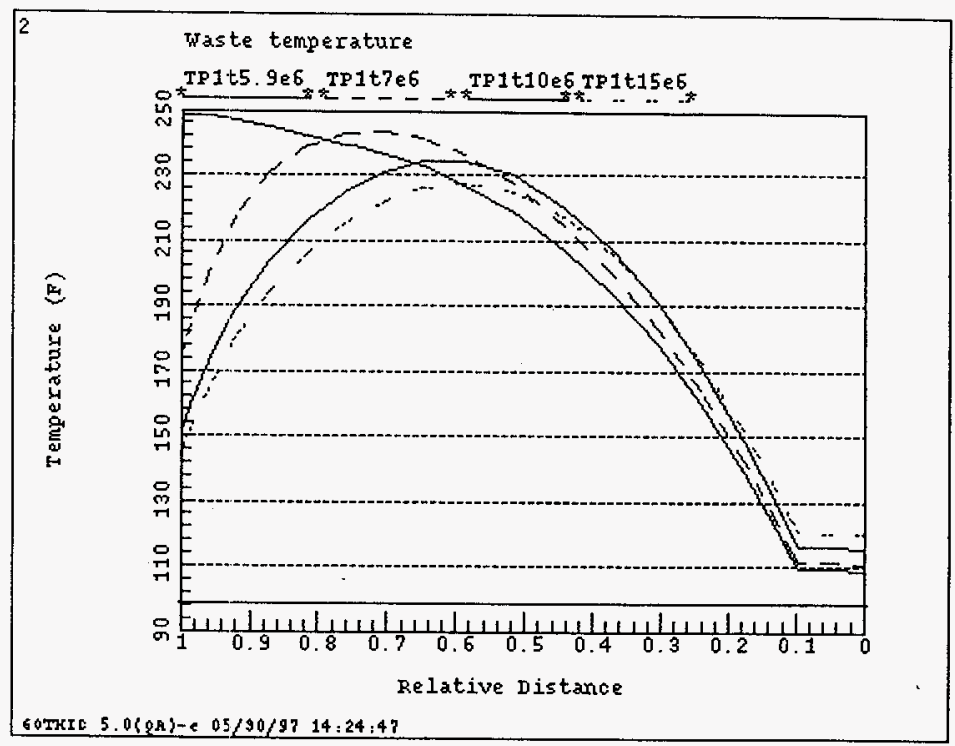


HNF-SD-W320-ER-004 REV 0

Figure 5.5 Loss of Secondary Ventilation, Transient Temperature Distribution.

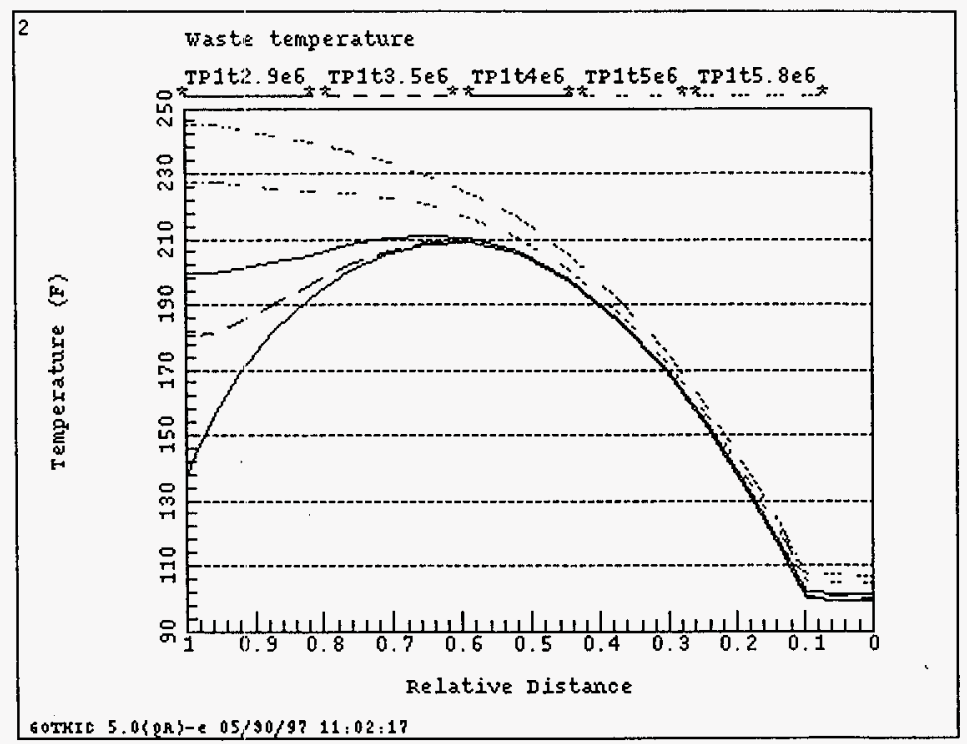




\section{HNF-SD-W320-ER-004 REV 0}

Figure 5.6 Loss of Secondary Ventilation, Transient Pool Temperature.

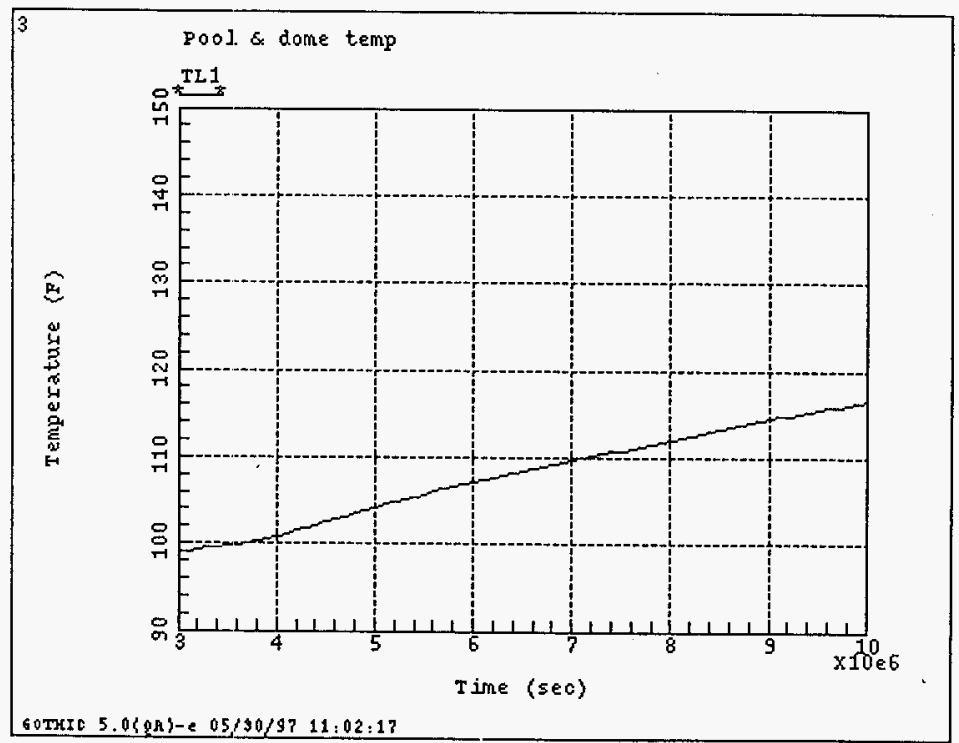


Figure 5.7 Loss of Primary Ventilation, Transient Temperature Distribution.

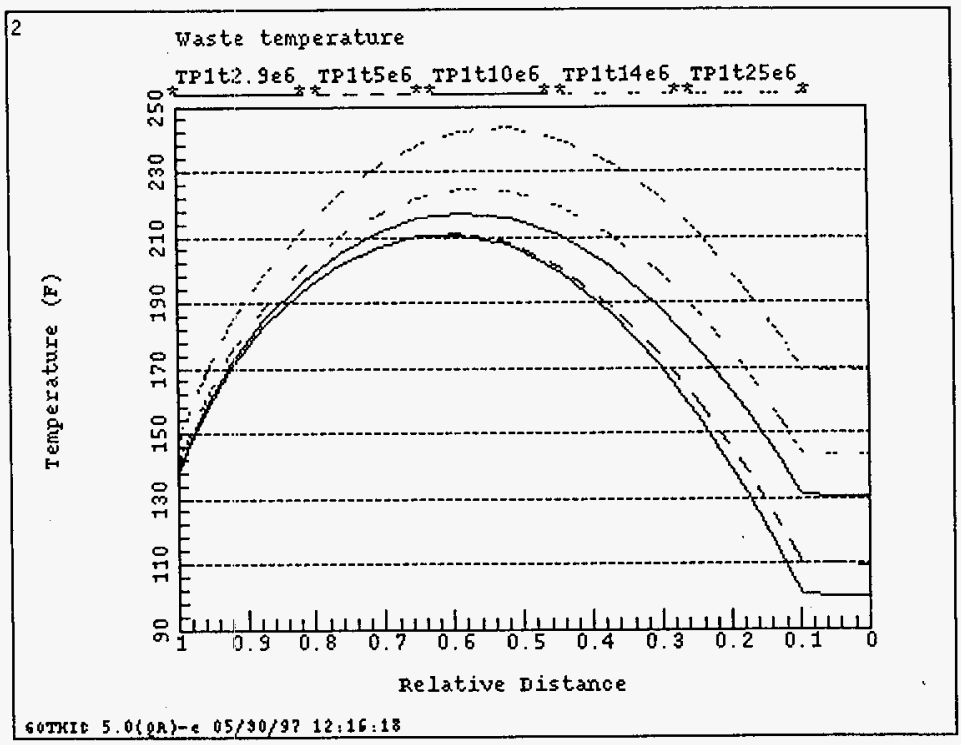


HNF-SD-W320-ER-004: REV 0

Figure 5.8 Loss of Primary Ventilation, Pool Temperature.

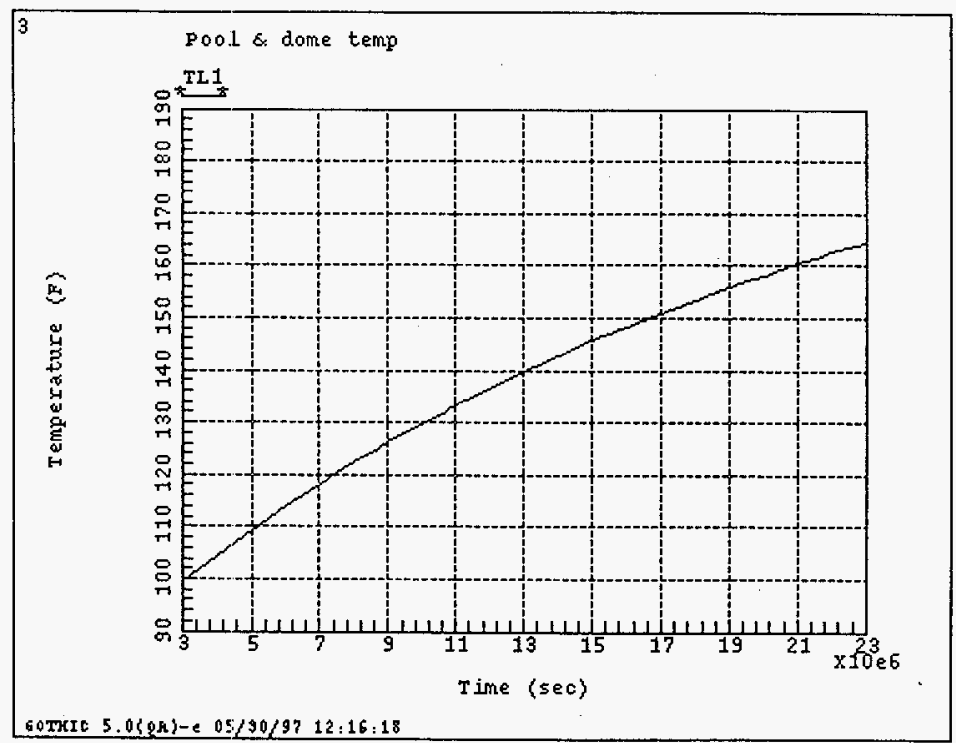




\section{HNF-SD-W320-ER-004 REV 0}

Figure 5.9 Loss of Primary Ventilation, 2 Foot Transfer, Pool Temperature.

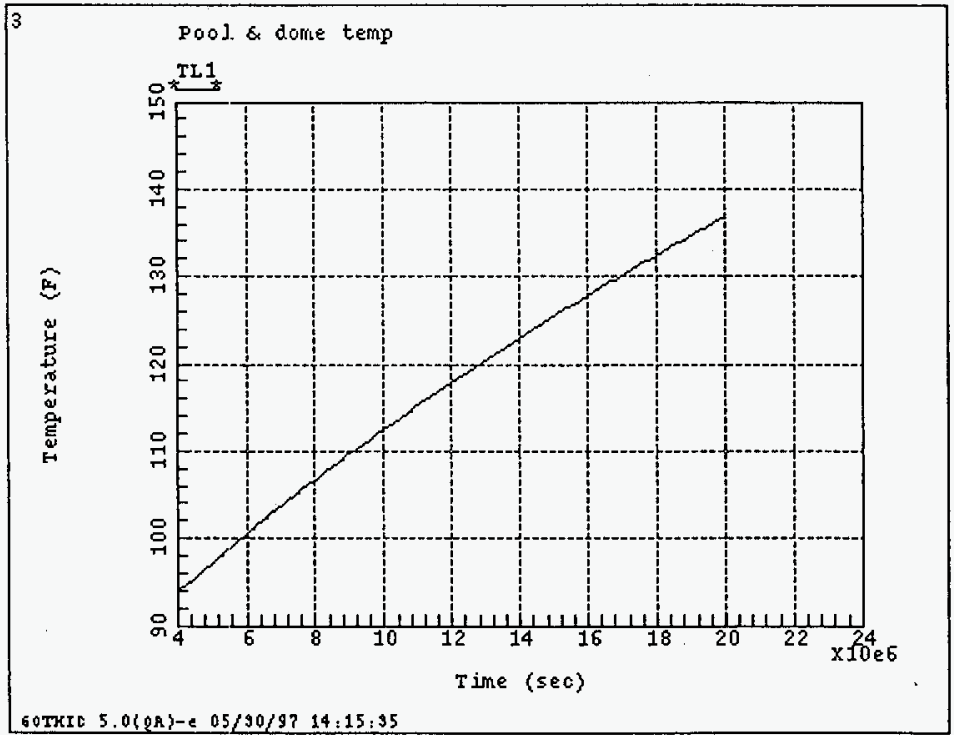




\section{HNF-SD-W320-ER-004 REV 0}

Figure 5.10 Loss of Primary Ventilation, 2 Foot Transfer, Waste Temperature Distribution.

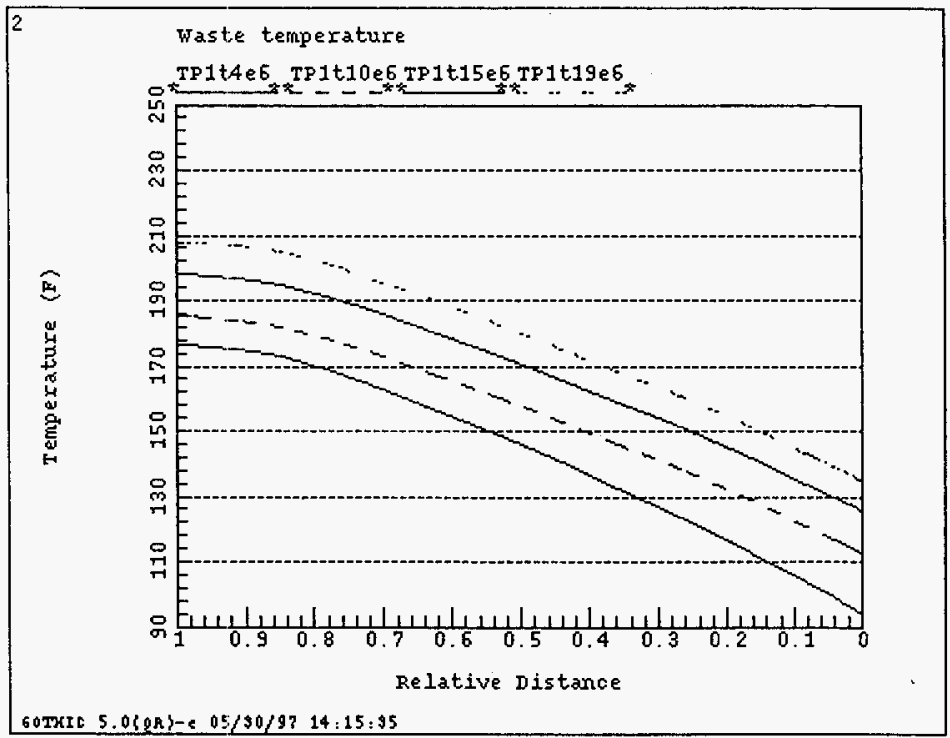




\section{HNF-SD-W320-ER-004 REV 0}

\subsection{LOSS OF EVAPORATION}

The sluicing of waste from $241-\mathrm{C}-106$ could result in the separation of an organic component which would locati on the surface of the supernatant pool. If this were to occur, the evaporation would be severely limited or completely eliminated. Analyses were performed for 2 foot and 6 foot waste transfers with a loss of evaporation cooling. Only sensible heat removal (convection) and soil conduction remain from the primary system. All analyses were performed with the best estimate parameters of Section 3.0 .

\subsubsection{Six Foot Transfer}

The steady state waste temperature distribution for a full 6 foot waste retrieval with a loss of ventilation is shown in Figure 5.11. The maximum waste temperature $\sim 246^{\circ} \mathrm{F}$, which exceeds the saturation temperature $\left(-242^{\circ} \mathrm{F}\right)$. As discussed in Section 4.1, evaporation accounts for nearly $40 \%$ of the normal heat removal. With the loss of evaporation, the bottom sludge temperature increases only a small amount, increasing the heat removal by the secondary by only $2 \%$. Thus $38 \%$ of the heat load must be removed by increasing the dome space temperature to increase convection and soil conduction heat removal. This results in over a $60^{\circ} \mathrm{F}$ dome space temperature increase (see Figure 5.11).

If an organic layer forms, it should do so shortly after retrieval. However, if it forms after the waste has reached a steady state temperature, the transient response will be very slow. Figure 5.12 shows the supernatant pool temperature starting from a pool temperature of $130^{\circ} \mathrm{F}$. It takes about 200 days to reach the new steady state temperature.

The excess cooling capacity of the upgraded annulus ventilation system can be used to help mitigate the effects of lost evaporation. Figure 5.13 shows the waste temperature distribution for a loss of evaporation with the annulus slot flow increased to $3300 \mathrm{cfm}$. The maximum waste temperature is decreased to $226^{\circ} \mathrm{F}$. This provides about half the required $30^{\circ} \mathrm{F}$ subcooling.

\subsubsection{Two Foot Transfer}

The base case configuration for the 2 foot waste transfer does not include annulus ventilation cooling. In this configuration, evaporative cooling accounts for nearly $75 \%$ of the heat removal. With loss of evaporation, the dome temperature must increase significantly to remove the total heat load by convection and conduction. Figure 5.14 shows the waste temperature distribution for a 2 foot transfer with loss of evaporation. The maximum waste temperature has increased by over $40^{\circ} \mathrm{F}$, just exceeding the OSD limit.

With the 2 foot transfer, annulus ventilation flow is not required (best estimate parameters). With wall annulus blockage, $250 \mathrm{cfm}$ annulus slot flow is available as excess 


\section{HNF-SD-W320-ER-004 REV 0}

cooling. Figure 5.15 shows the waste temperature distribution for a loss of evaporation with 150 cfm slot flow. The maximum waste temperature has decreased will below the OSD limit. Only a fraction of this flow would be required to maintain the waste temperature at the OSD limit. 
Figure 5.11 Loss of Evaporation, 6 Foot Transfer, Waste Temperature.

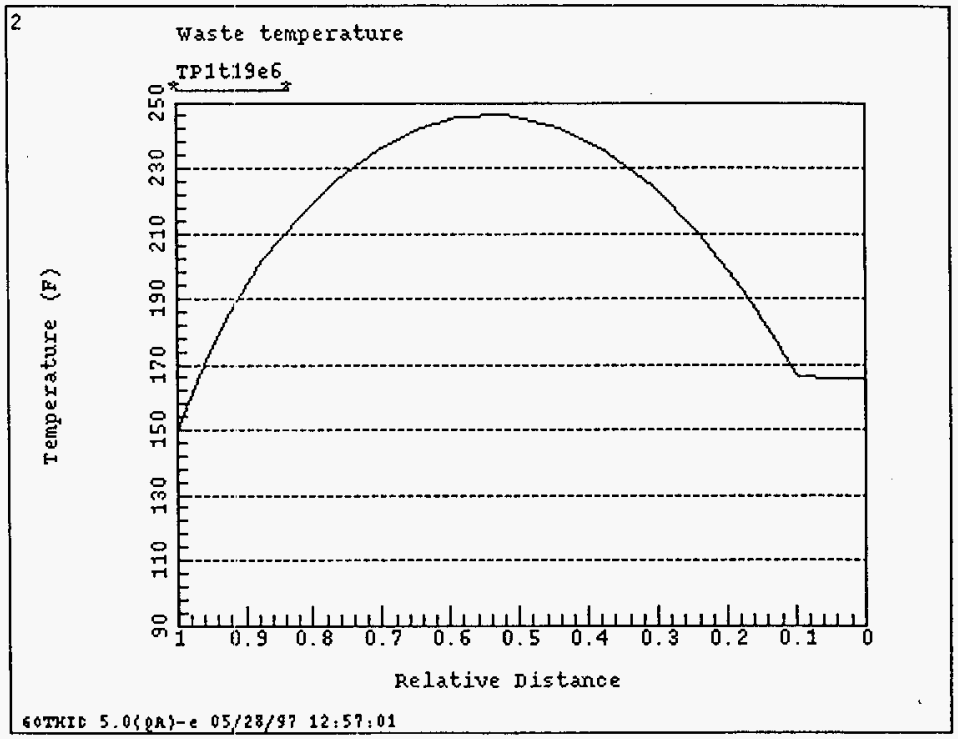




\section{HNF-SD-W320-ER-004 . REV 0}

Figure 5.12 Loss of Evaporation, 6 Foot Transfer, Pool Temperature.

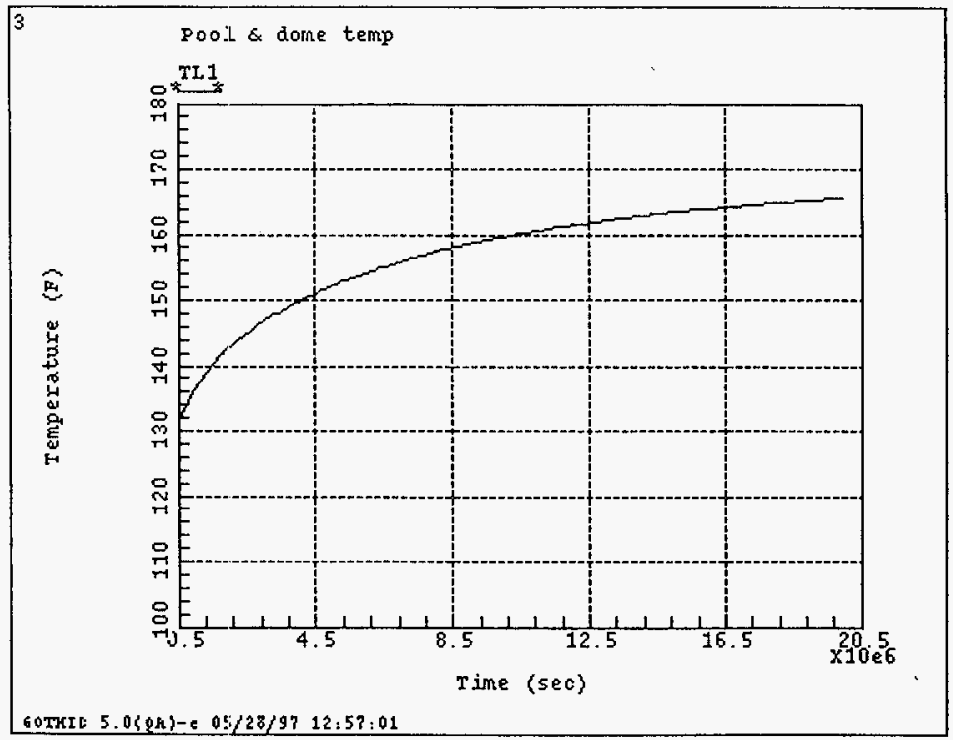


Figure 5.13 Loss of Evaporation, 6 Foot Transfer, With Increased Annulus Flow, Waste Temperature.

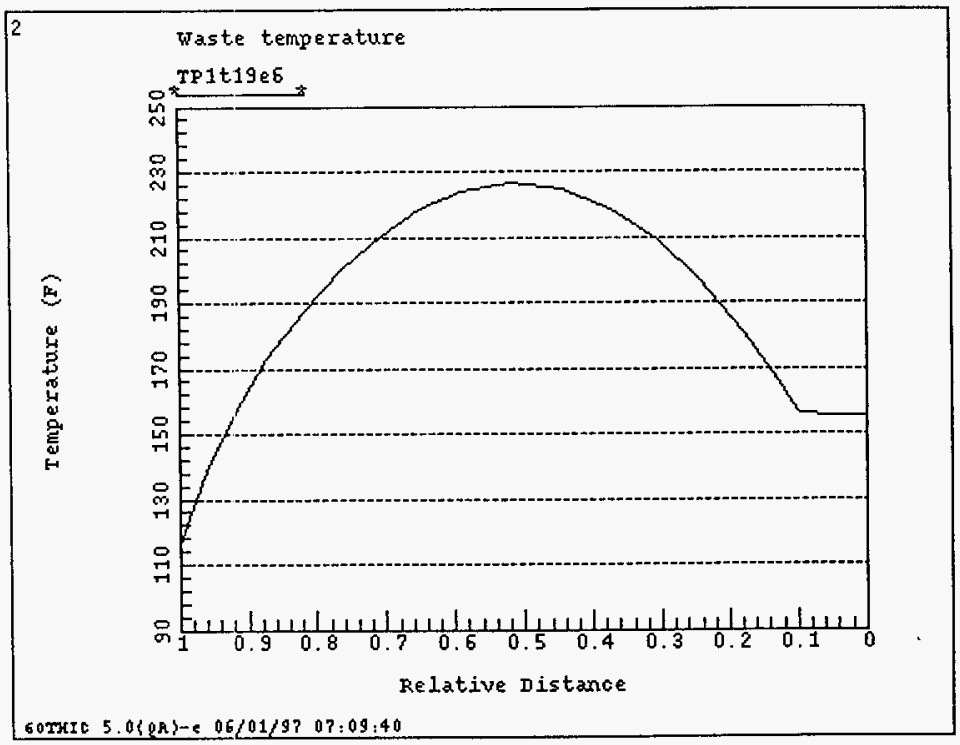




\section{HNF-SD-W320-ER-004 REV 0}

Figure 5.14 Loss of Evaporation, 2 Foot Transfer, Waste Temperature.

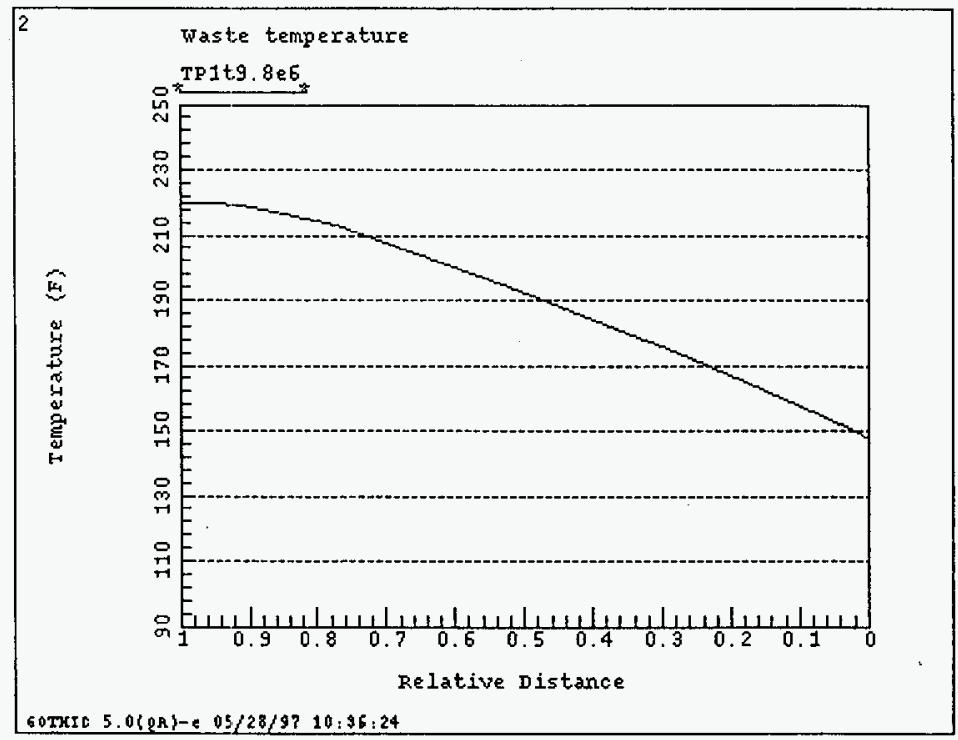


Figure 5.15 Loss of Evaporation, 2 Foot Transfer, With Annulus Flow, Waste Temperature.

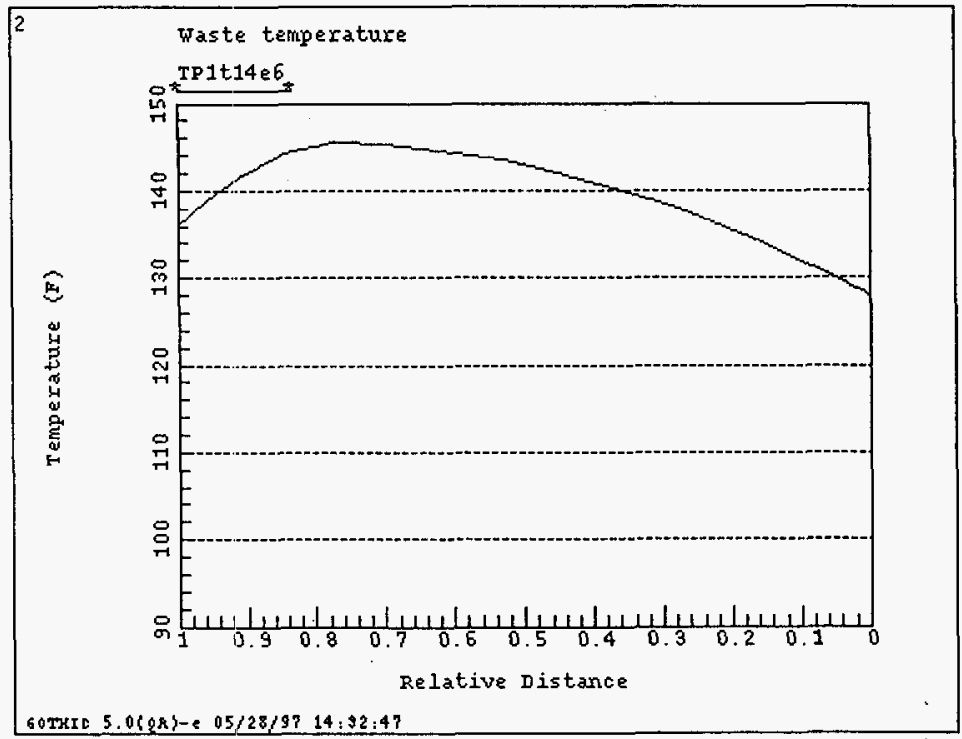




\section{HNF-SD-W320-ER-004 REV 0}

\subsection{LOSS OF CHILLER}

Sathyanaryana et.al. 1997 considered a range of options for increasing the annulus system cooling capacity. The primary improvements results from blockage of the wall annulus flow and either operating the system at high annulus vacuum or providing an inlet fan. Chilling of the inlet annulus air was shown to have a smaller, but important effect. The base case presented in Section 4.1 included $40^{\circ} \mathrm{F}$ chilled annulus inlet air. Analyses were performed to evaluate an off normal event resulting from the loss of the chiller.

The waste temperature distribution for a 6 foot waste transfer with loss of annulus chiller is shown in Figure 5.16. The transient temperature leading to the new steady state temperature without the chiller is shown in the figure. The maximum temperature is just over $230^{\circ} \mathrm{F}$. This leaves about an $11^{\circ} \mathrm{F}$ subcooling margin. The increased bottom waste and supernatant temperature of more than $20^{\circ} \mathrm{F}$, compensates for the loss of the chiller. The supernatant pool temperature is shown in Figure 5.17. The loss of chiller results in a slow transient. It takes over 200 days to reach the new steady state temperature.

Excess cooling of the annulus ventilation system can compensate for the loss of chiller. Figure 5.18 shows the waste temperature distribution for a loss of chiller with the annulus slot flow increased from 2000 to $3000 \mathrm{cfm}$. The increase in maximum waste temperature is completely mitigated by the increased annulus flow. 
HNF-SD-W320-ER-004 REV 0

Figure 5.16 Loss of Chiller, 6 Foot Transfer, Waste Temperature.

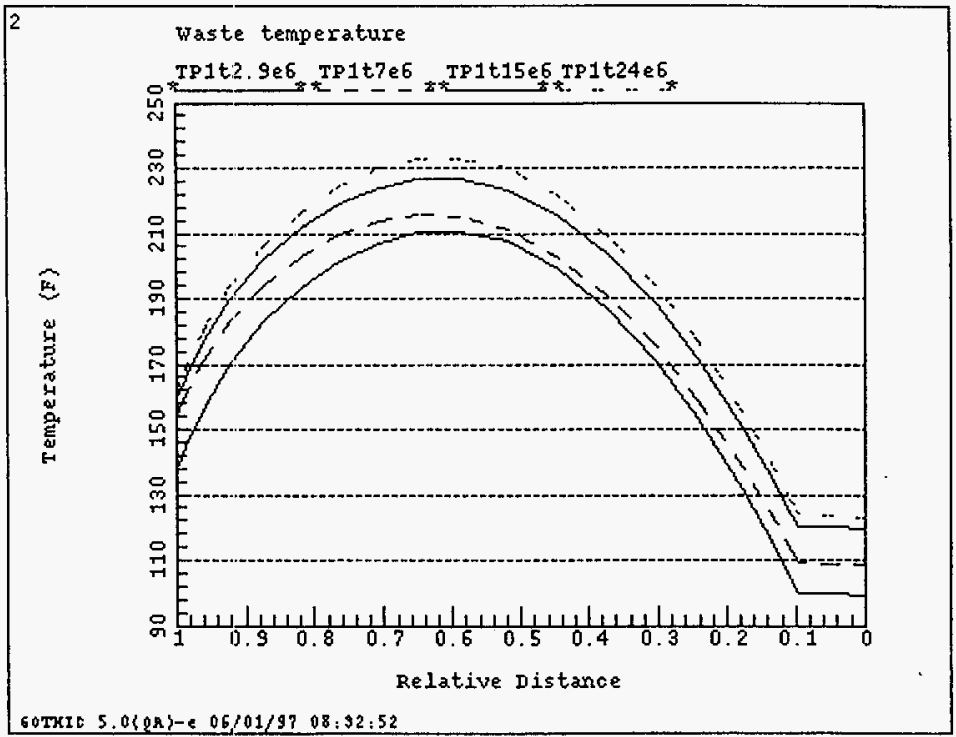




\section{HNF-SD-W320-ER-004 REV 0}

Figure 5.17 Loss of Chiller, 6 Foot Transfer, Pool Temperature.

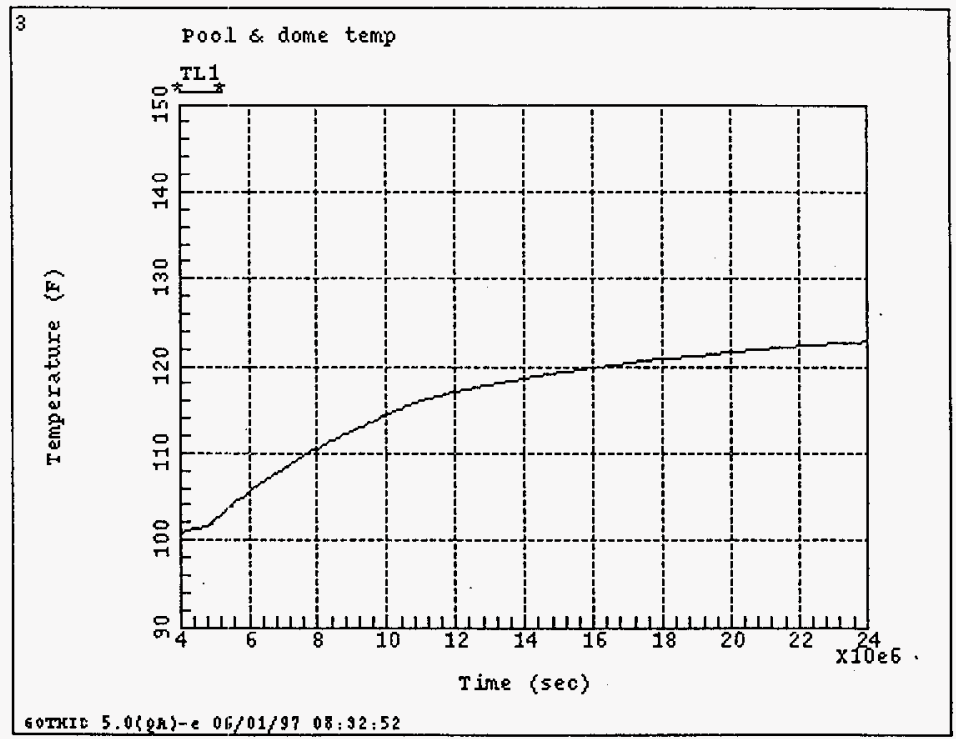




\section{HNF-SD-W320-ER-004 REV 0}

Figure 5.18 Loss of Chiller, 6 Foot Transfer, Increased Annulus Flow, Waste Temperature.

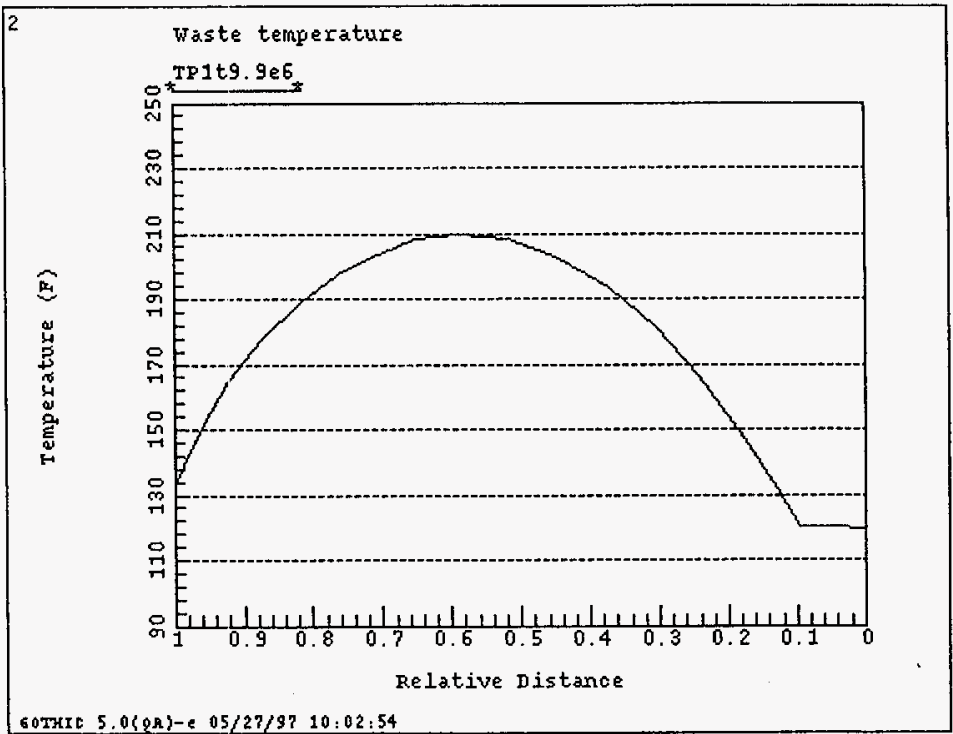


HNF-SD-W320-ER-004 REV 0

\subsection{SUPERNATANT REDUCTION EVALUATION}

The Project W-320 flammable gas control strategy for tank 241-AY-102 includes the possible reduction of the supernatant depth from nearly 20 feet to between 1 and 8 feet (Pasamehrnetoglu 1997). The purpose of the reduction is to limit the magnitude of a possible spontaneous Gas Release Event (GRE) in 241-AY-102. This supernatant reduction influences the thermal response of tank 241-AY-102 for certain off normal events. A thermal evaluation was performed for the most limiting off normal events, loss of ventilation and steam bump events.

\subsection{STEAM BUMP EVALUIATION}

The Safety Analyses Report (HNF-SD-WM-TSR-006) requires that during normal operation the waste temperature remain $30^{\circ} \mathrm{F}$ below the local saturation temperature. This $30^{\circ} \mathrm{F}$ subcooling provides a margin of safety for steam bump event. If the waste temperature reaches the local saturation temperature, steam will be generated and trapped in the waste. Buoyancy forces can result in waste plume rising into the supernatant pool. Because of the decreasing pressure, the fluid with a temperature above the local saturation temperature flashes to steam resulting in a rapid dome pressure increase which can result in unfiltered release of radioactive material (Bendixsen 1990).

Steam bump events for aging waste tanks has been evaluated using the GOTH model described in Section 2.4 (Sathyanaryana et.al. 1996). The magnitude of the steam release from a steam bump is proportional to the size of the waste plume and the difference between the tank bottom saturation temperature and the dome space saturation temperature. Lowering the supernatant level will decrease both the plume size and bottom saturation temperature and thus should reduce the consequence of the steam bump.

Steam bump analyses were performed for a 6 foot transfer of waste. The analyses were initiated with a loss of ventilation. The initial waste temperature profile for the steam bump analyses is provided in Section 6.1.1. The steam bump event for a 1 foot and 8 foot supernatant pool was compared with a full 20 foot pool case.

\subsubsection{Initial Temperature Distribution}

The loss of ventilation for a full 6 foot waste transfer was presented in Section 5.1. The transient waste temperature distribution in the axial direction is shown in Figure 6.1. Because of the loss of annulus slot flow, there will not be a radial temperature gradient. The temperature distribution at 23 days ( $5 \mathrm{e} 6$ seconds on graph) was used for the steam bump analyses. As discussed in Section 6.2, this would be the temperature distribution when the waste reaches local saturation temperatures at the bottom if the tank is operated with reduced subcooling margin after lowering the supernatant level to 1 foot (i.e. no measures are taken to increase cooling to provide the full $30^{\circ} \mathrm{F}$ margin of subcooling). This temperature profile is some what conservative for the 8 foot and 20 foot supernatant cases. 


\section{HNF-SD-W320-ER-004 REV 0}

Figure 6.1 Waste Temperature Distribution Following a Loss of Ventilation.

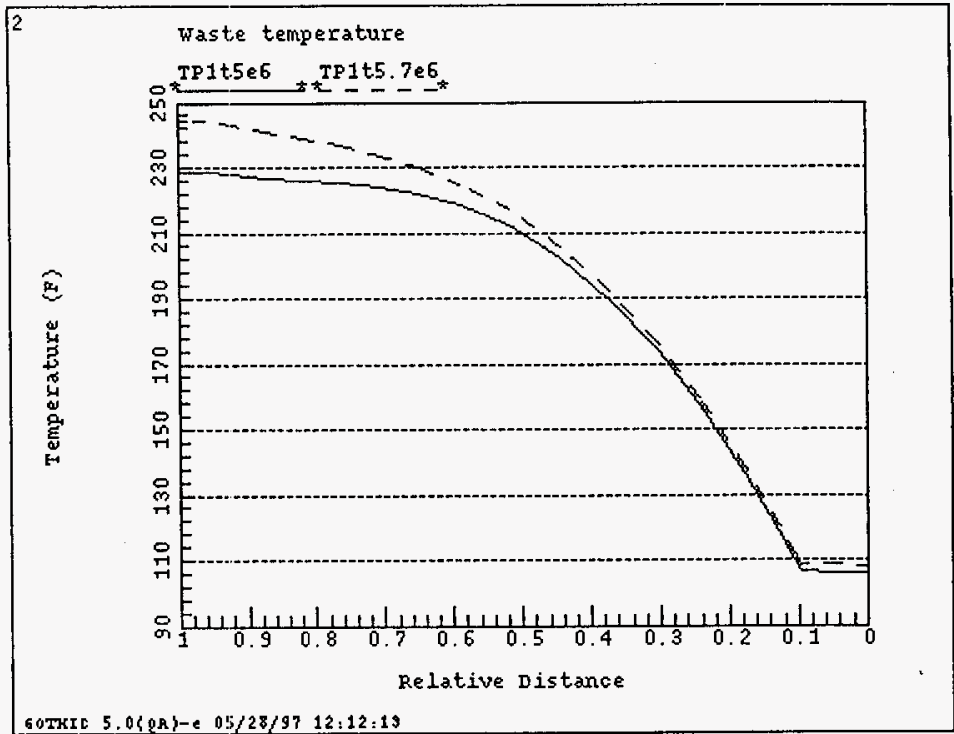




\section{HNF-SD-W320-ER-004 REV 0}

\subsubsection{Steam Vent Paths}

Three vent paths were modeled for the steam bump analyses. The ventilation inlet filter was assumed to be blown out by the over pressure providing a 6 inch diameter vent path. The outlet filter was assumed to be blown out by the over pressure providing a 20 inch diameter vent path. In addition, the cover blocks from a single bump pit were assumed to be open (through the over pressurization) providing a vent path through the drain lines equivalent to 1 foot in diameter.

\subsubsection{Pool Condensation}

During steam bump, a portion of the steam generated by the flashing waste will be condensed in the supernatant pool. The consequence of the bump is strongly dependent upon the heat transfer between the rising plume and the supernatant. Bench marking of the GOTH model against historic tank bumps may determine the extent of this heat transfer and condensation. This benchmark has not been performed to date. Because of the uncertainty in this pool quenching phenomenon, the current analyses conservatively bound the problem by assuming no condensation of steam occurs in the supernatant pool.

\subsubsection{Full Supernatant Pool}

The dome space pressure for the 20 foot pool steam bump is shown in Figure 6.2. There was a small initial bump followed by a large steam bump. The figure shows the bottom saturation pressure and the dome pressure. The dome pressure can not exceed the initial bottom saturation pressure because steam flashing will stop at this pressure. The dome pressure reaches the initial tank bottom saturation pressure. This is followed by a period of pressure decay. The integrated steam flow from the three vent paths discussed in the previous section is shown in Figure 6.3. The pressure decay is a result of the decreasing steam flow with time. Steam generation continues until the temperature of the displaced fluid and particles are cooled through mixing and steam flashing to the local saturation temperature.

Figure 6.4 shows the steam volume fraction contours near 35 seconds for the first smaller steam bump. The rising of the waste plume into the supernatant pool can be seen. The vapor velocity contours are shown in Figure 6.5. The eruption caused by the rising plume flashing results in vapor velocities exceeding 20 to $30 \mathrm{ft} / \mathrm{s}$. The vapor fraction contour for the second steam bump near 70 seconds is shown in Figure 6.6. While the first bump occurred near the tank center, the second bump occurred mid way to the tank wall. Given the axi-symetric model, the volume of material involved in the second bump is larger, contributing to the higher dome pressure. 


\section{HNF-SD-W320-ER-004 REV 0}

As the waste plume rises and flashes, liquid and particles are carried out the vent paths. Figure 6.7 shows the integrated liquid mass expelled through the three vent paths. The total liquid mass is approximately $5 \%$ of the total liquid in the tank. The integrated particle mass expelled through the vent paths is shown in Figure 6.8 . 
HNF-SD-W320-ER-004 REV 0

Figure 6.2 Saturation and Dome Pressure, 20 Foot Pool.

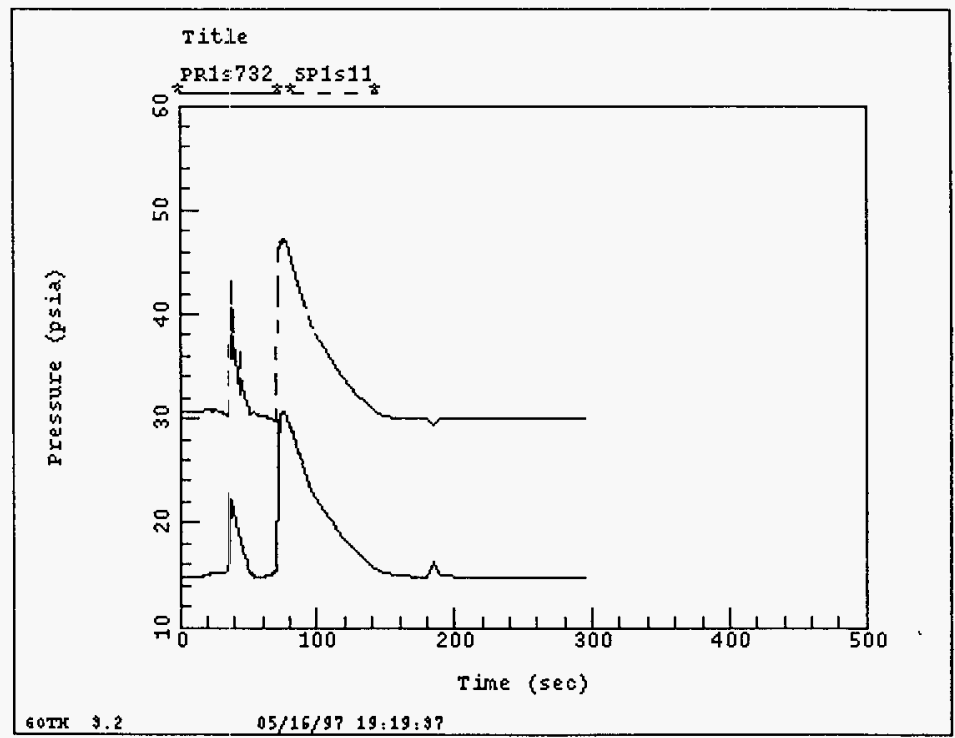




\section{HNF-SD-W320-ER-004 , REV 0}

Figure 6.3 Integrated Vapor flow Through Vent Paths, 20 Foot Pool.

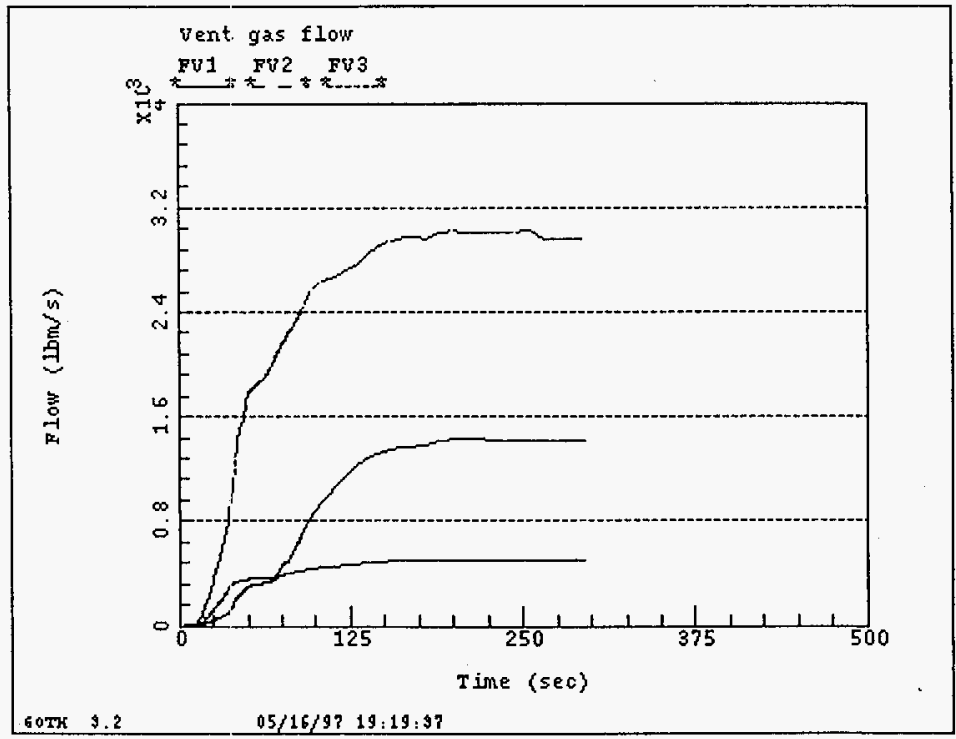


HNF-SD-W320-ER-004 REV 0

Figure 6.4 Vapor Fraction Contour at 35 Seconds, 20 Foot Pool.

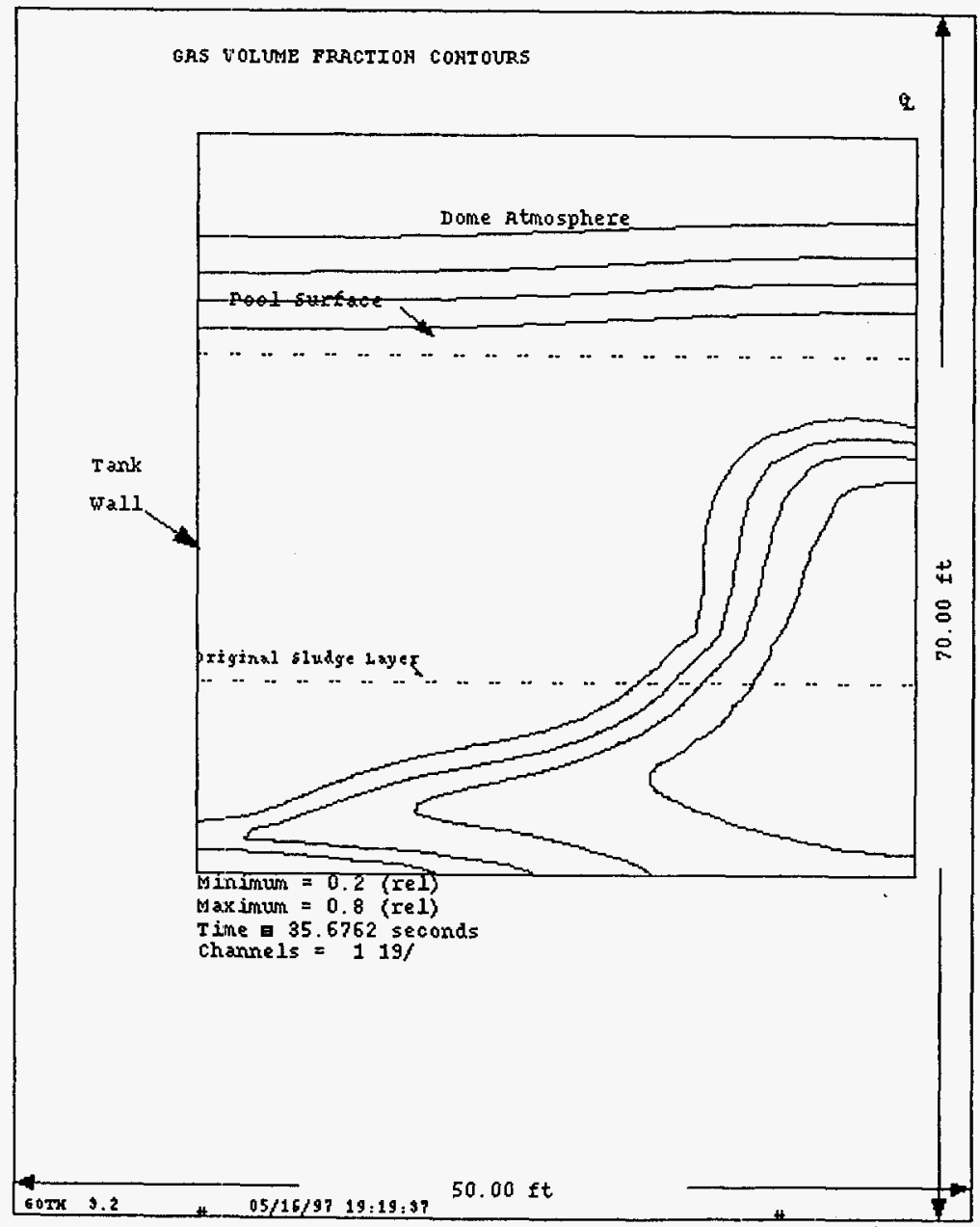




\section{HNF-SD-W320-ER-004 REV 0}

Figure 6.5 Vapor Velocity Contours at 35 Seconds, 20 Foot Pool.

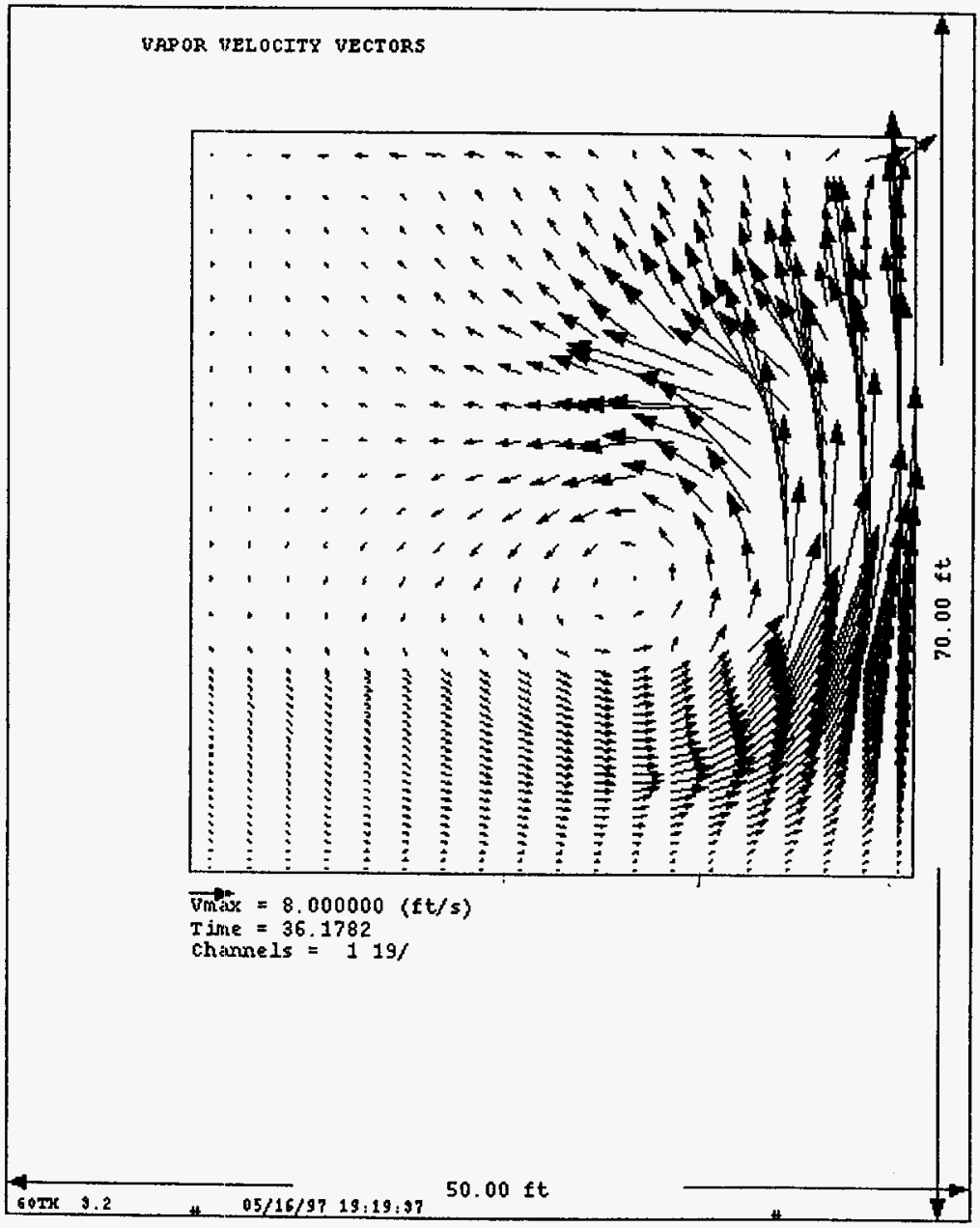




\section{HNF-SD-W320-ER-004 REV 0}

Figure 6.6 Vapor Volume Fraction Contours at 72 Seconds, 20 Foot Pool.

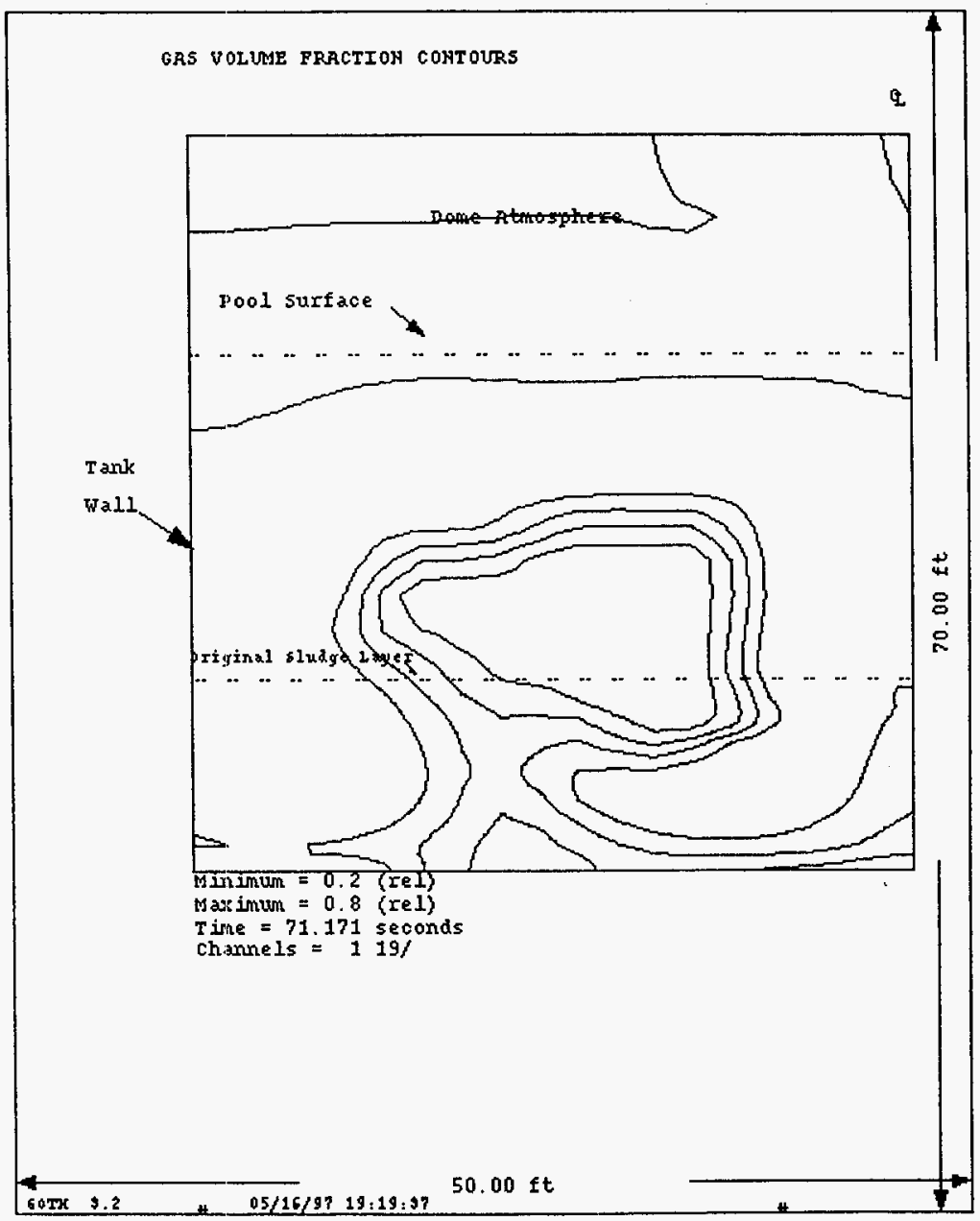




\section{HNF-SD-W320-ER-004 REV 0}

Figure 6.7 Integrated Liquid Flow Through Vent Paths, 20 Foot Pool.

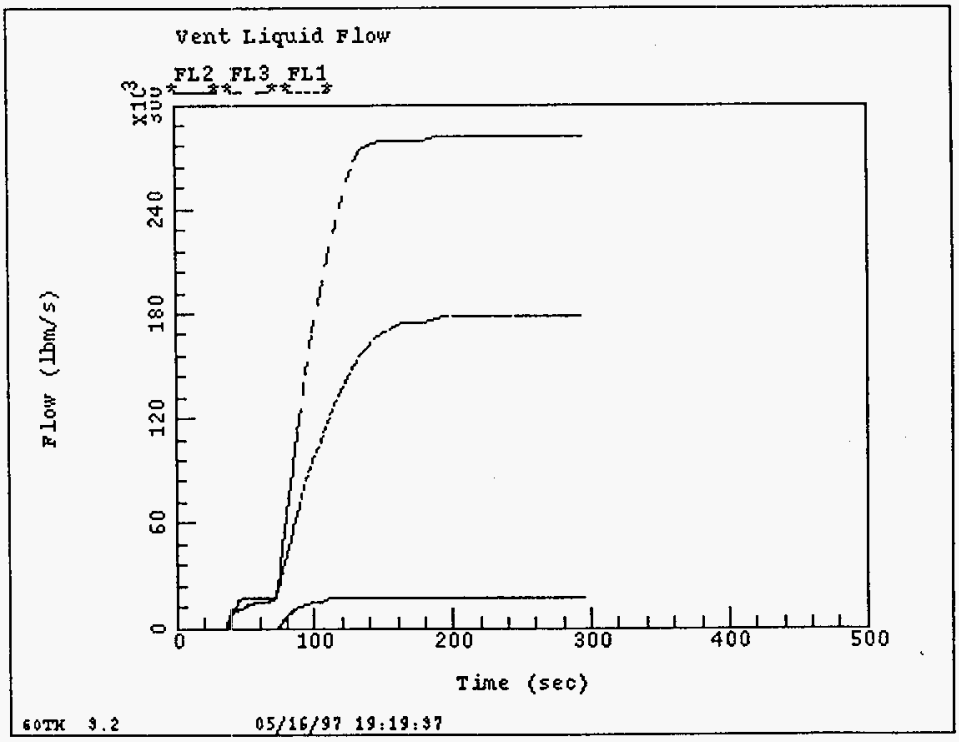




\section{HNF-SD-W320-ER-004 REV 0}

Figure 6.8 Integrated Particle Mass Through Vent Paths, 20 Foot Pool.

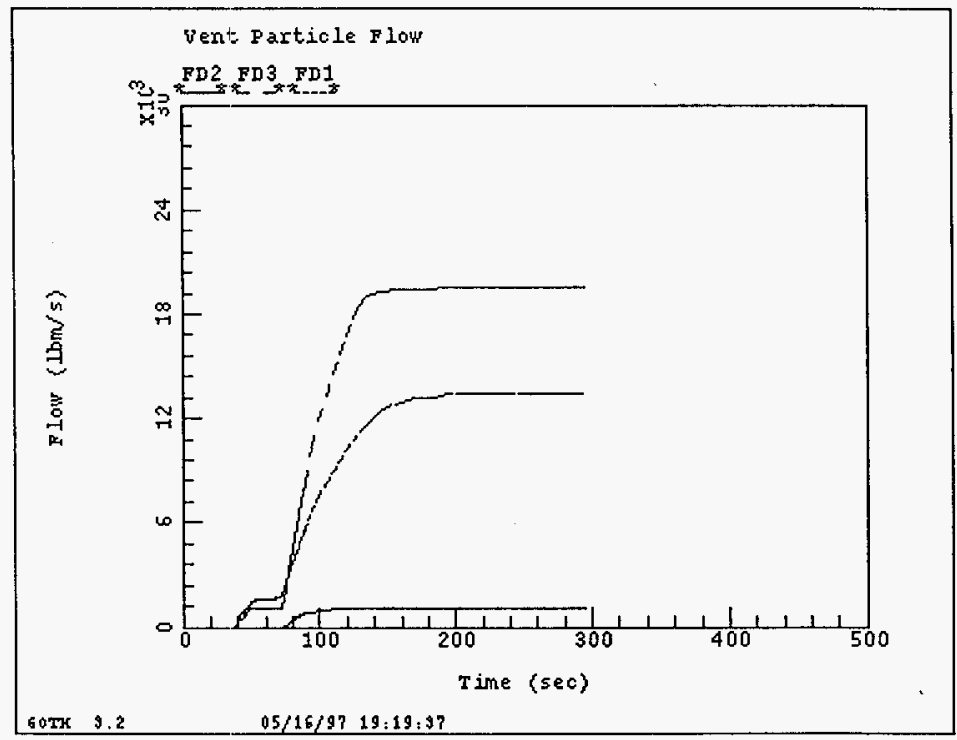




\section{HNF-SD-W320-ER-004 REV 0}

\subsubsection{Maximum Supernatant Removal}

Analyses were performed for a 1 foot supernatant pool. This represents a minimum pool level required to provide evaporative cooling. The bottom saturation and dome pressures are shown in Figure 6.9. While the dome pressure for the 20 foot pool reached the initial tank bottom pressure, the maximum dome pressure for the reduced supernatant is only about $80 \%$ of the maximum possible pressure (jnitial tank bottom pressure).

The vapor fraction contour is shown in Figure 6.10. There is not a significant supernatant pool to allow the development of a waste plume. Instead the waste surface tilts as the steam void grows in the center of the tank. This results in a local eruption shown in the vapor velocity contour in Figure 6.11.

The integrated vapor mass flow through the vent paths is shown in Figure 6.12. The integrated vapor mass flow is nearly the same as the 20 foot pool case although released more slowly. In spite of the fact that a waste plume does not develop, the size of the effected waste volume is comparable to the 20 foot case. Therefore an equivalent amount of steam must be released to provide the needed cooling. However, without the reduced supernatant pool, there is little entrainment of liquid or particles. The integrated liquid flow out the vent paths is essentially zero as shown in Figure 6.13. Thus, while the total vapor flow through the vent paths is not significantly decreased, entrained liquid and particles has been essentially eliminated. 


\section{HNF-SD-W320-ER-004 REV 0}

Figure 6.9 Saturation and Dome Pressure, 1 Foot Pool.

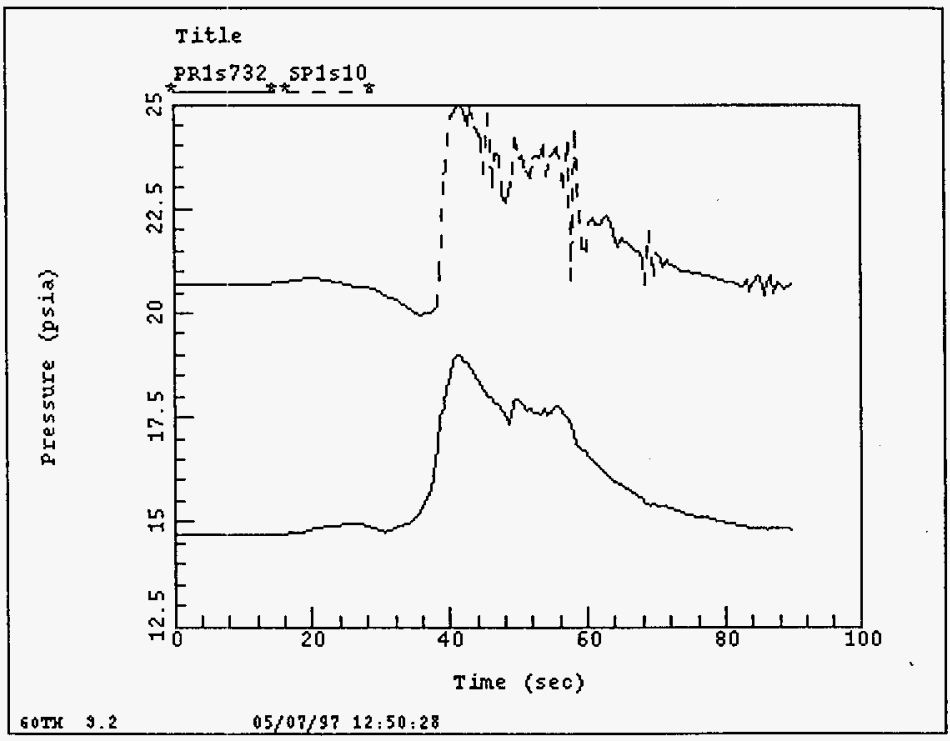


HNF-SD-W320-ER-004 REV 0

Figure 6.10 Vapor Fraction Contour, 1 Foot Pool.

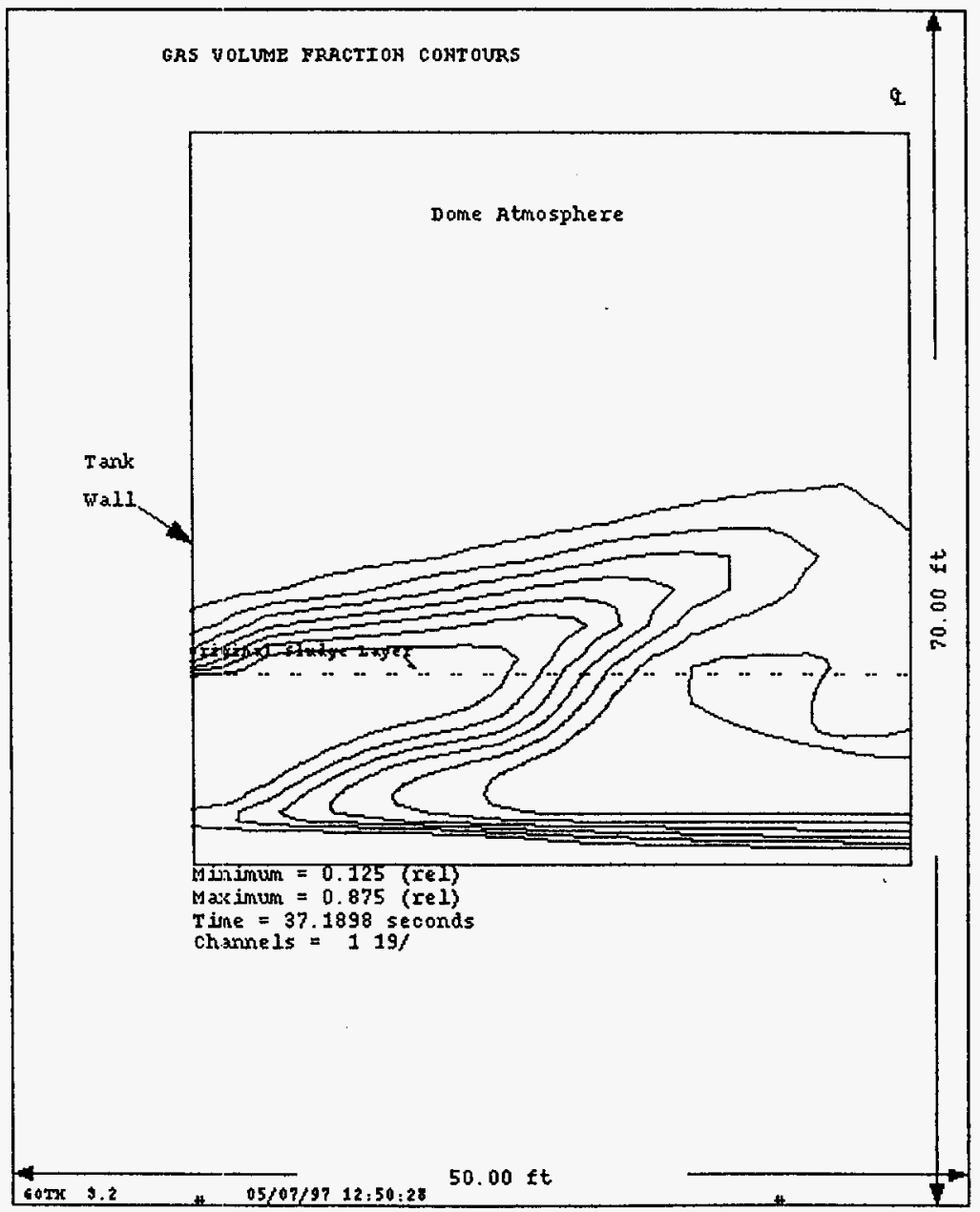




\section{HNF-SD-W320-ER-004 REV 0}

Figure 6.11 Vapor Velocity Contour, 1 Foot Pool.

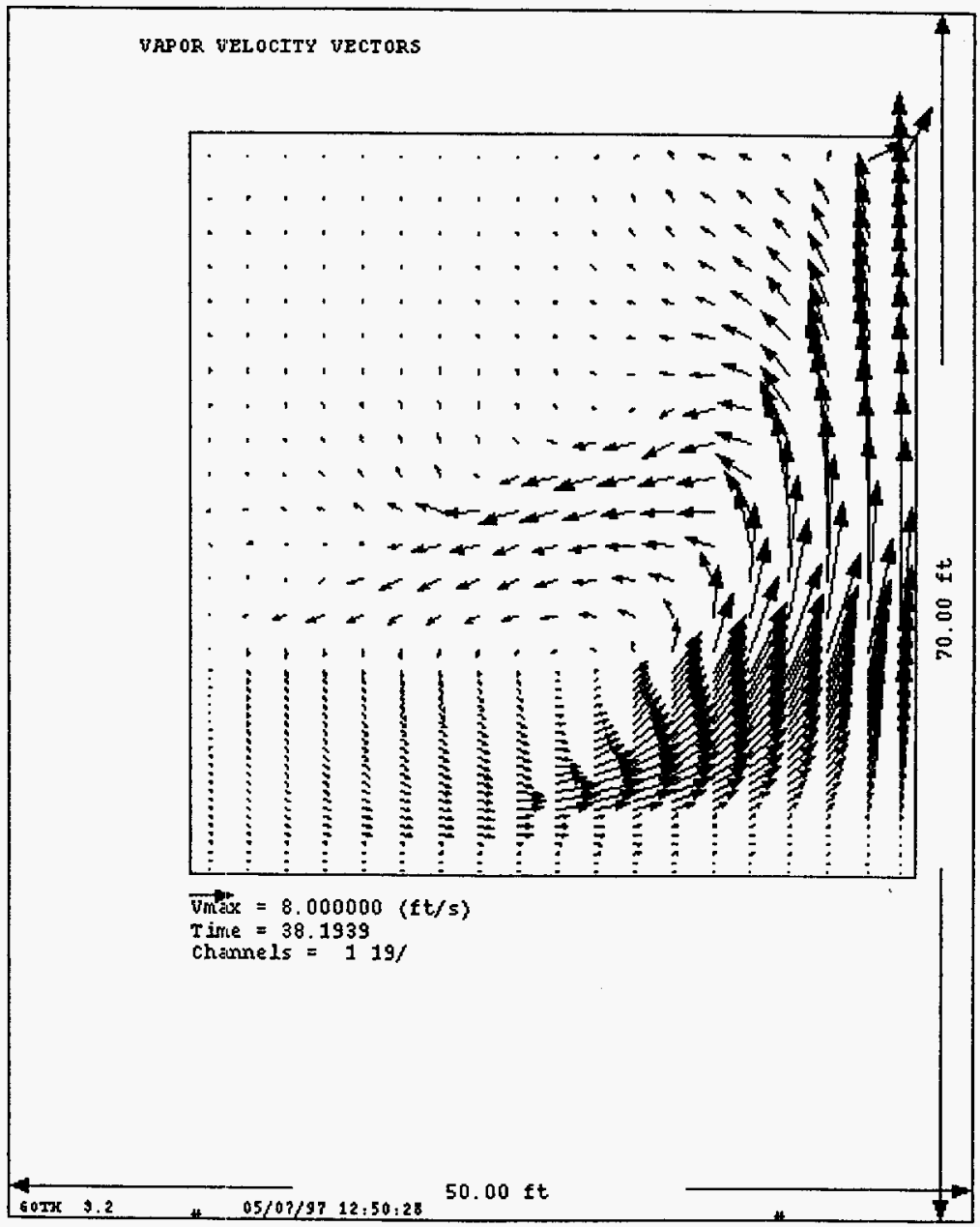




\section{HNF-SD-W320-ER-004 REV 0}

Figure 6.12 Integrated Vapor Flow Through Vent Paths, 1 Foot Pool.

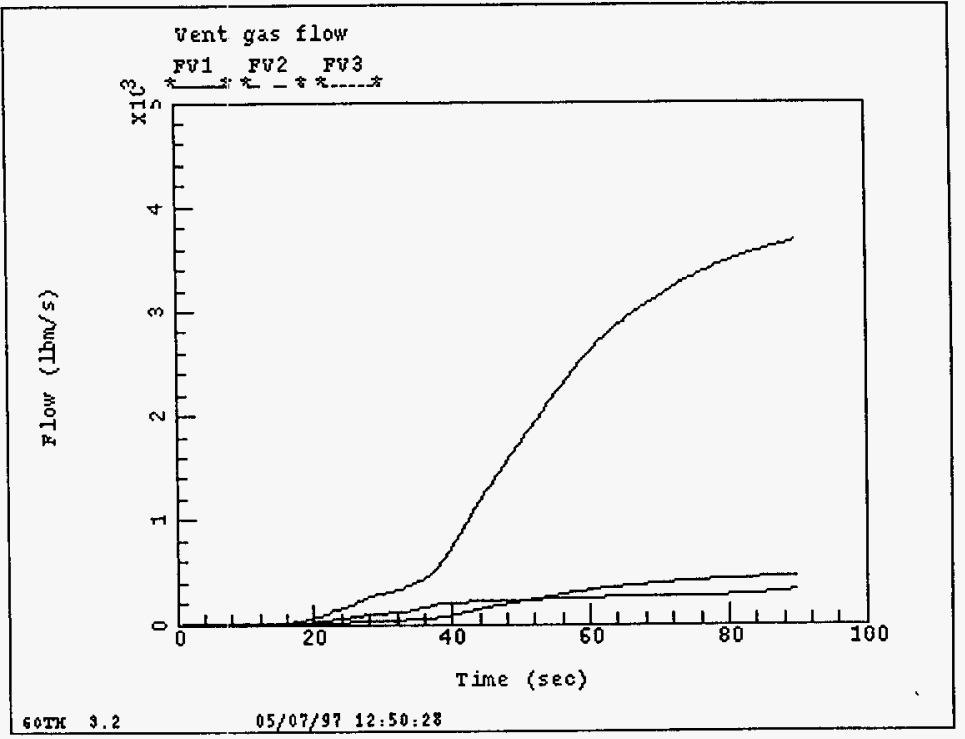




\section{HNF-SD-W320-ER-004 REV 0}

Figure 6.13 Integrated Liquid Flow Through vent Paths, 1 Foot Pool.

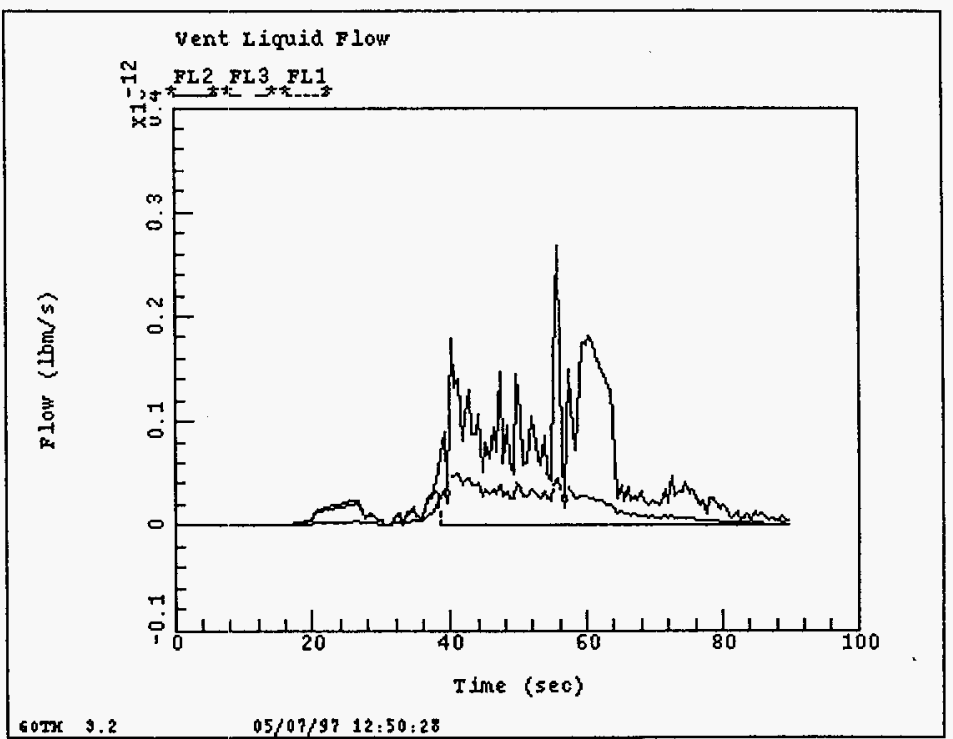




\section{HNF-SD-W320-ER-004 REV 0}

\subsubsection{Minimum Supernatant Removal}

The flammable gas topical report for Project W-320 (Pasamehmetoglu 1997) species that the supernatant should be lowered in the range of 7 to 8 feet to derive the desired benefit in reducing risk for a flammable igas release event. A steam bump evaluation was performed with this maximum pool depth for supernatant reduction.

The tank bottom saturation pressure and dome space pressures for the maximum supernatant case is shown in Figure 6.14. The dome pressure reaches $80 \%$ of the maximum possible pressure indicated by the initial tank bottom saturation pressure. The vapor fraction and vapor velocity contours are shown in Figures 6.15 and 6.16. With the 7 foot supernatant pool there is a more distinguishable waste plume, although it does not fully develop.

The vent path vapor and liquid integrated flows are shown in Figures 6.17 and 6.18. The total vapor flow is similar to the 1 foot and 20 foot pool cases. However, the early release is higher than the one foot pool but lower than the 20 foot pool. With the deeper supernatant pool more liquid is entrained out the vent paths. However, it is still several orders of magnitude less than for a full supernatant pool. The integrated particle flow out the vent paths is shown in Figure 6.19. Again, with the deeper pool, some particies are entrained out the vent paths, but much less than for the 20 foot pool. 


\section{HNF-SD-W320-ER-004 REV 0}

Figure 6.14 Bottom Saturation and Dome Pressures, 7 Foot Pool.

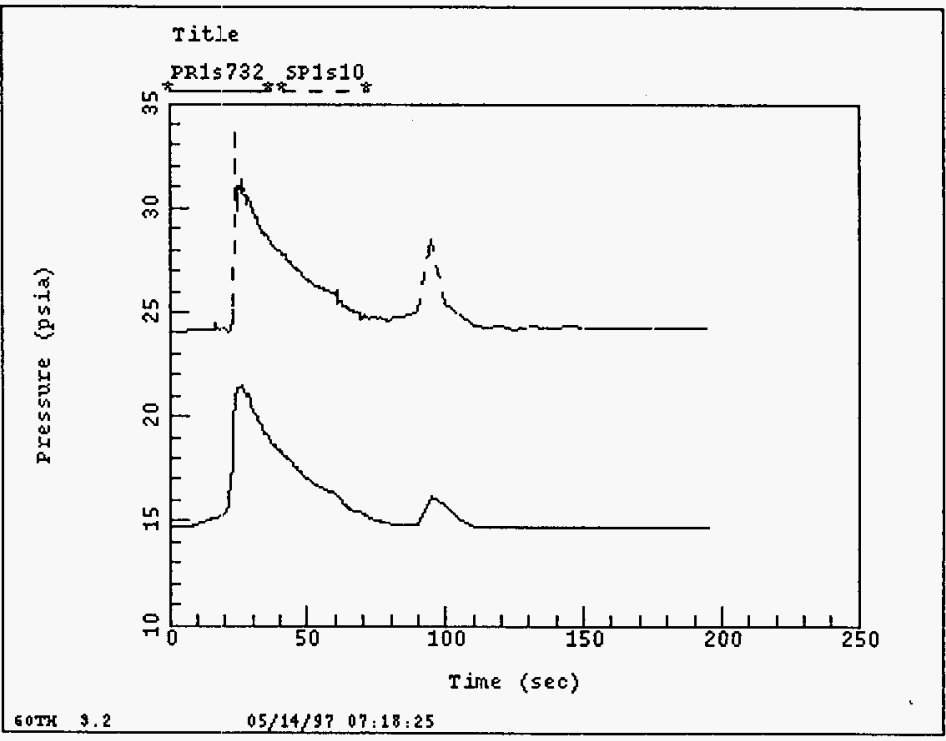




\section{HNF-SD-W320-ER-004 REV 0}

Figure 6.15 Vapor Fraction Contour, 7 Foot Pool.

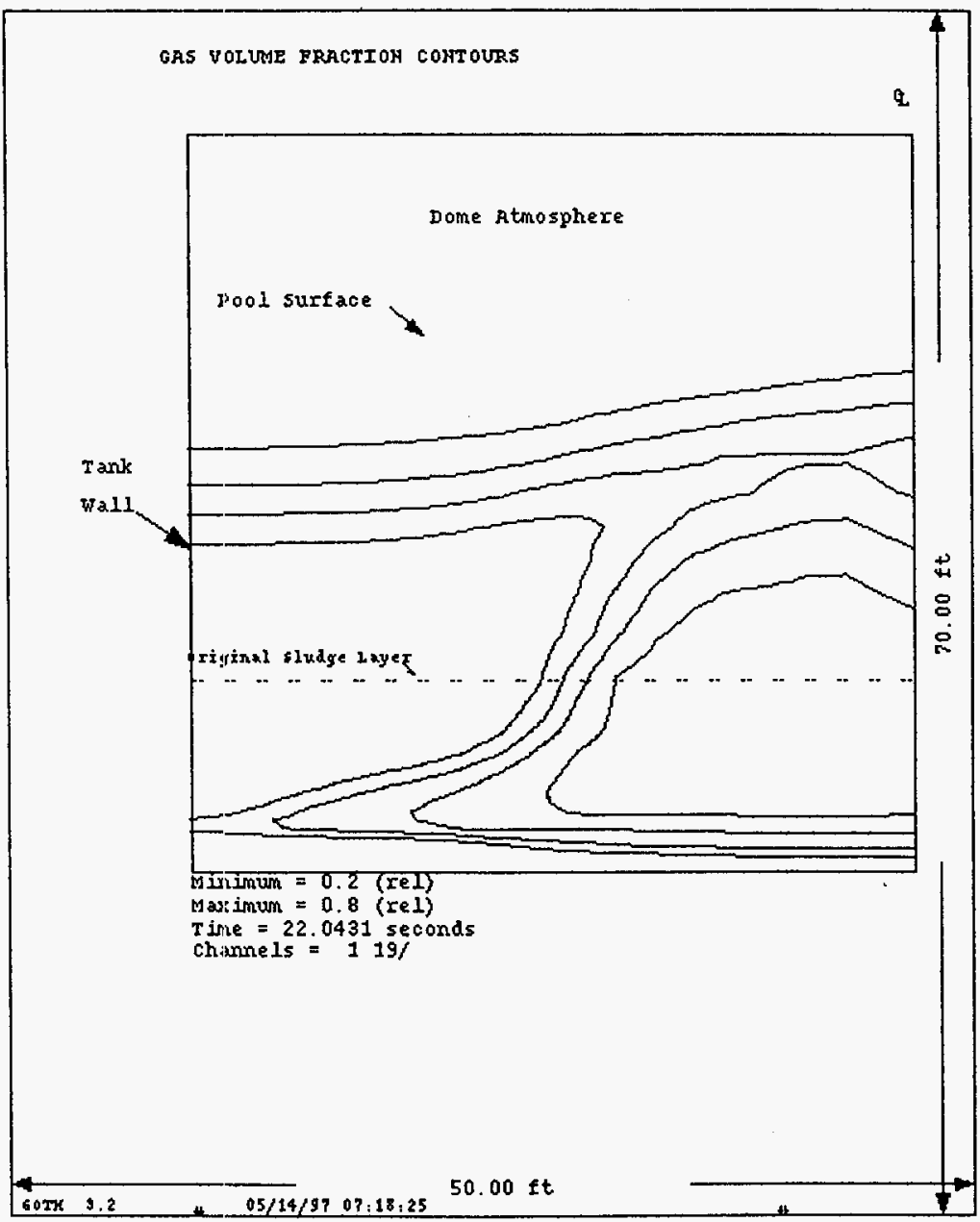




\section{HNF-SD-W320-ER-004. REV 0}

Figure 6.16 Vapor Velocity Contour, 7 Foot Pool.

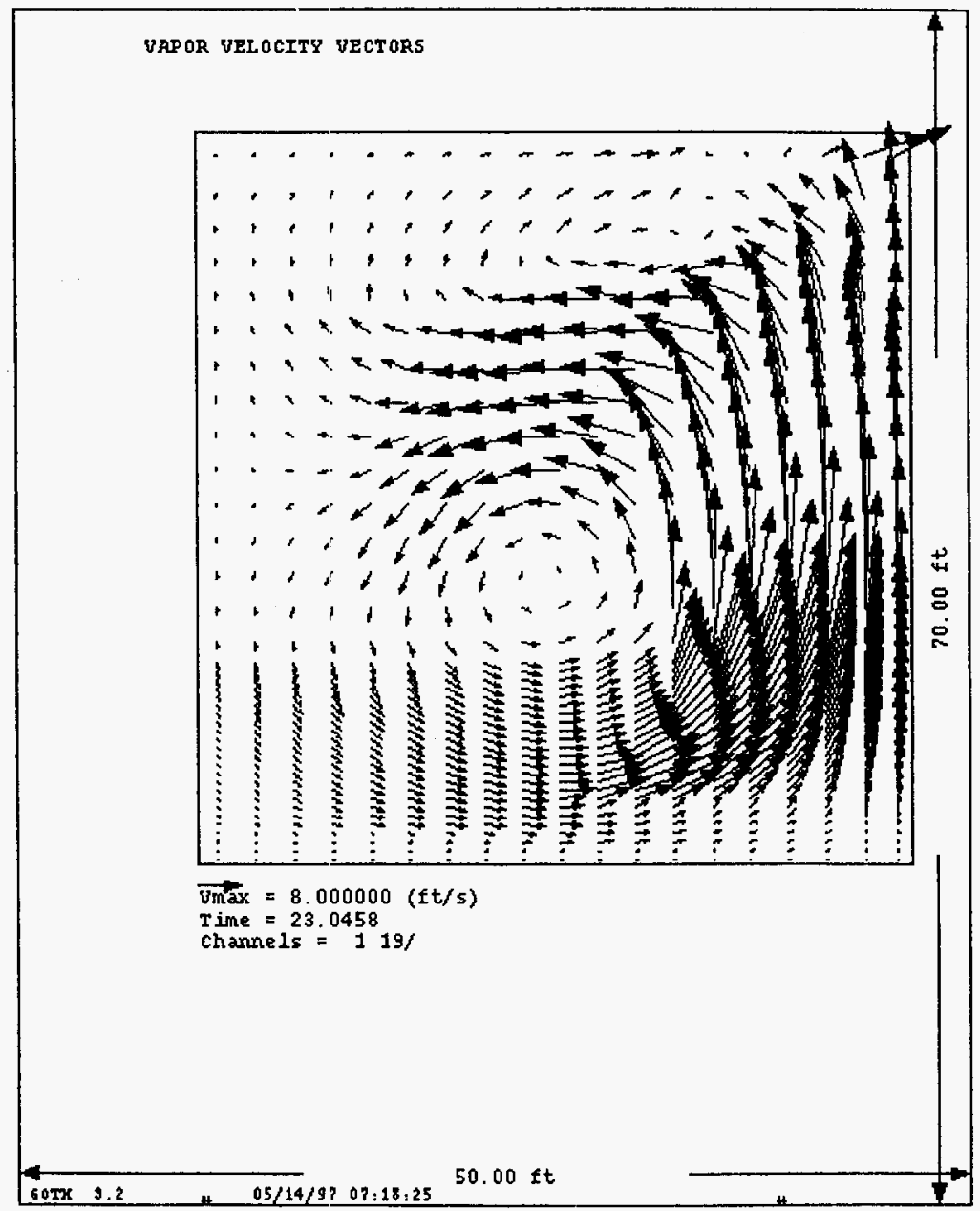




\section{HNF-SD-W320-ER-004 REV 0}

Figure 6.17 Integrated Vapor Flow Out the Vent Paths, 7 Foot Pool.

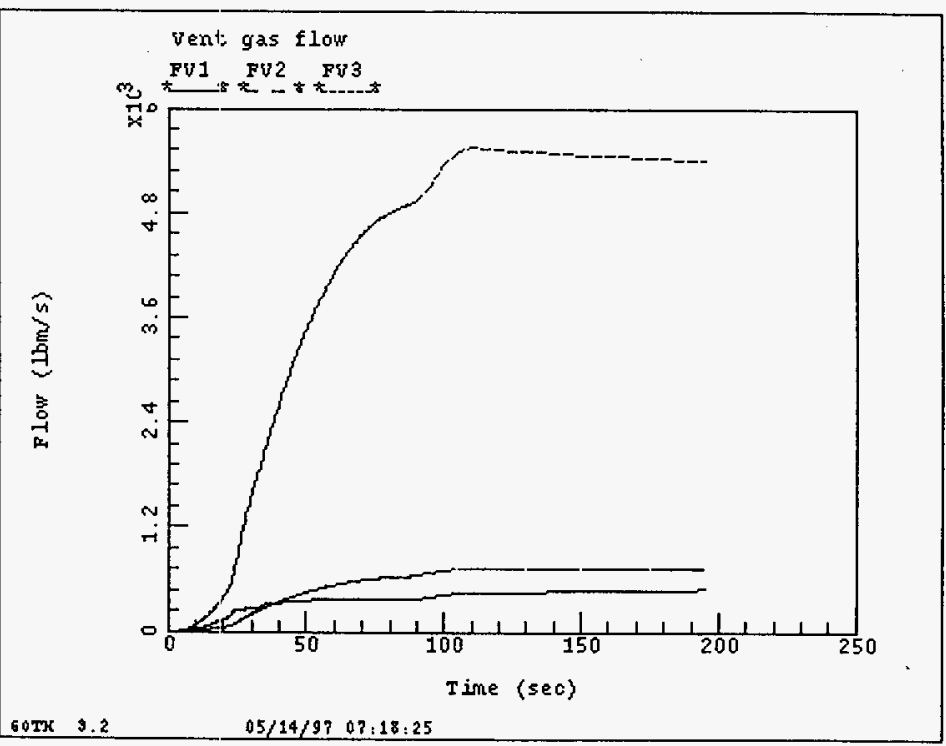




\section{HNF-SD-W320-ER-004 REV 0}

Figure 6.18 Integrated Liquid Flow Out the Vent Paths, 7 Foot Pool.

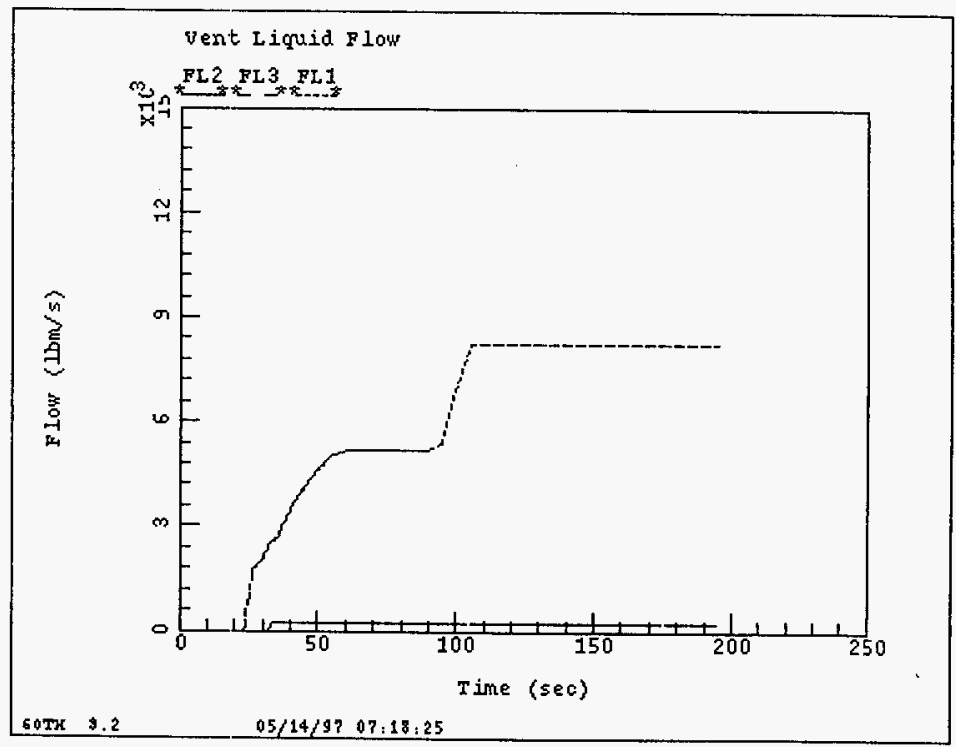




\section{HNF-SD-W320-ER-004 REV 0}

Figure 6.19 Integrated Particle Flow Out the Vent Paths, 7 Foot Pool.

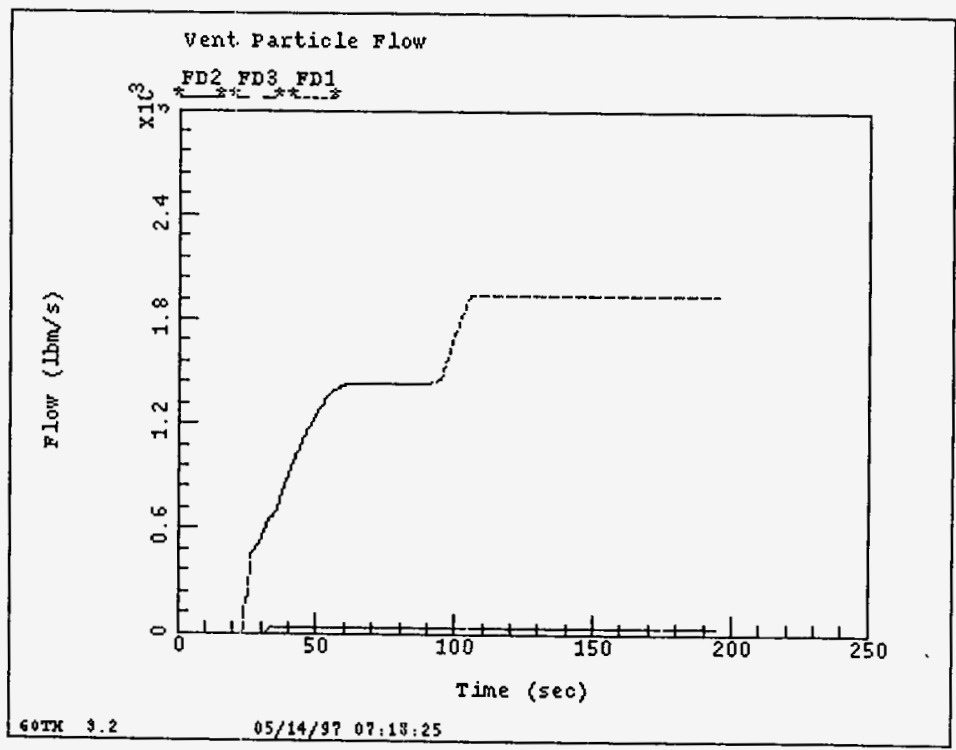




\section{HNF-SD-W320-ER-004 REV 0}

\subsection{OTHER OFF NORMAL EVENTS}

Lowering the supernatant level decreases the consequence of a steam vent accident described in the previous section. However, the decreased supernatant will effect other off normal events which must be evaluated. The depth of the pool does not affect the evaporation rate. Also, because of convection within the pool, the temperature difference from waste surface to pool surface is small and not significantly affected by the pool depth. However the full supernatant pool provides a large thermal mass which can affect the transient time of some off normal events. There were three off normal events evaluated in Section 5.0, loss of ventilation, loss of evaporation and loss of chiller. The loss of ventilation was shown to be the most limiting of these events. Thus only the loss of ventilation is evaluated in the following section.

\subsubsection{Loss of Ventilation for 6 Foot Transfer}

The waste temperature distribution following a loss of primary and secondary ventilation is shown in Figures 6.20 through 6.21 for 8 foot and 2 foot supernatant pools. The temperature distribution for a 20 foot pool is shown in Figure 5.2. These analyses were performed for a full 6 foot waste transfer. In all three cases the time to reach saturation temperature for a 20 foot pool $\left(-248^{\circ} \mathrm{F}\right)$ is the same at about 31 days $(5.8 \mathrm{e} 6$ seconds $-3 \mathrm{e} 6$ seconds). As discussed in Section 5.1 , the bottom of the sludge heats up nearly adiabatically for over 23 days. The pool does not effect the heat up rate for the bottom of the sludge during this period and thus it is not sensitive to the pool depth. If the cooling is increased when the supernatant is lowered so that $30^{\circ} \mathrm{F}$ is maintained, then the time to saturation will not be affected by lowering the supernatant pool. If the supernatant is lowered to 2 foot, the saturation temperature will decrease by about $18{ }^{\circ} \mathrm{F}$. The analyses of Section 4.0 show that it probably is not possible to regain the $18{ }^{\circ} \mathrm{F}$ subcooling by increasing annulus ventilation flow. It may be necessary to operate with a smaller subcooling margin. The analyses shown in Figures 6.20 and 6.21 were performed with the reduced subcooling margin, i.e. no increase in cooling. The time to reach saturation temperature for the 8 foot and 2 foot supernatant cases is 27 and 23 days respectively. Thus, a minimum of 3 weeks is available for restoring ventilation for a reduced supernatant level.

\subsubsection{Loss of Ventilation for 2 Foot Transfer}

An analyses was performed for a loss of primary ventilation for a 2 foot transfer of waste with a 2 foot supernatant pool (annulus ventilation not needed for 2 foot transfer)The waste temperature distribution is shown in Figure 6.22. It would take 69 days to reach saturation temperatures at the bottom of the tank. Comparing with the same case with a 20 foot pool (Section 5.1.4), it can be seen that the reduced supernatant increases the heat up rate. However, there is still a substantial amount of time before saturation temperatures are reached. This case is still bounded by the total loss of ventilation for a full 6 foot transfer. 


\section{HNF-SD-W320-ER-004 REV 0}

Figure 6.20 Loss of Ventilation, 8 Foot Pool, 6 Foot Transfer, Waste Temperature.

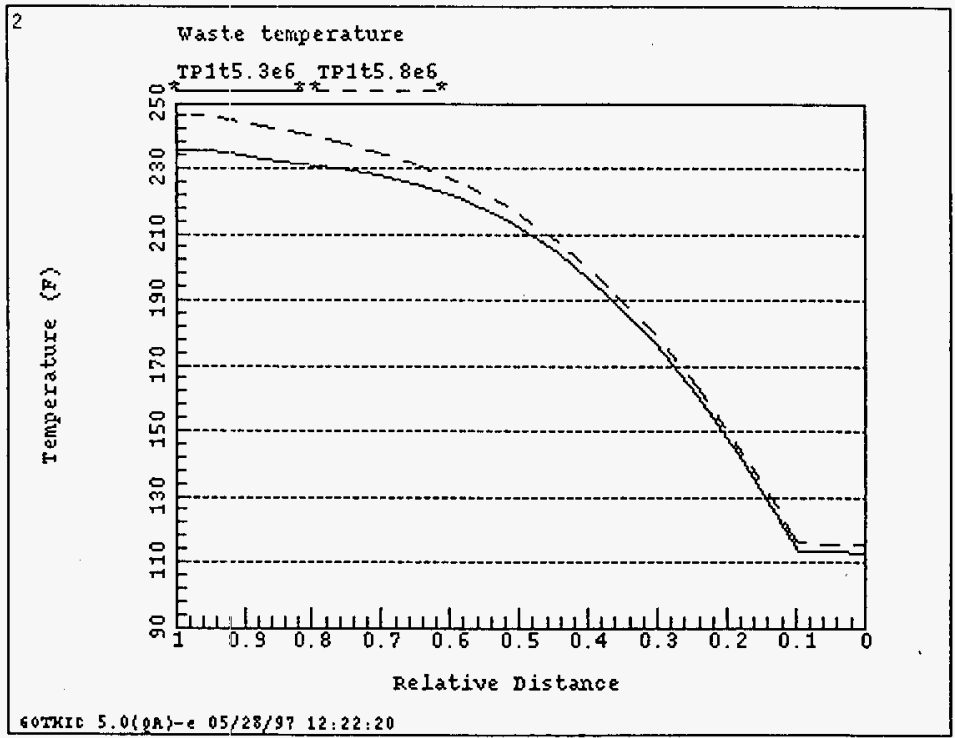




\section{HNF-SD-W320-ER-004 REV 0}

Figure 6.21 Loss of Ventilation, 2 Foot Pool, 6 Foot Transfer, Waste Temperature.

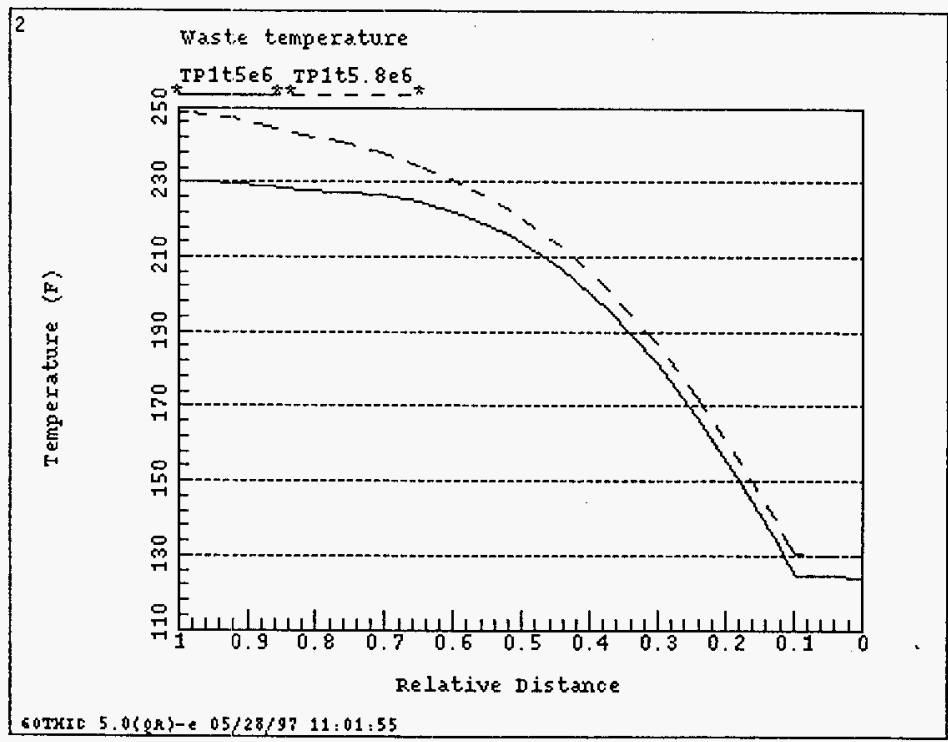


HNF-SD-W320-ER-004 REV 0

Figure 6.22 Loss of Ventilation, 2 Foot Pool, 2 Foot Transfer, Waste Temperature.

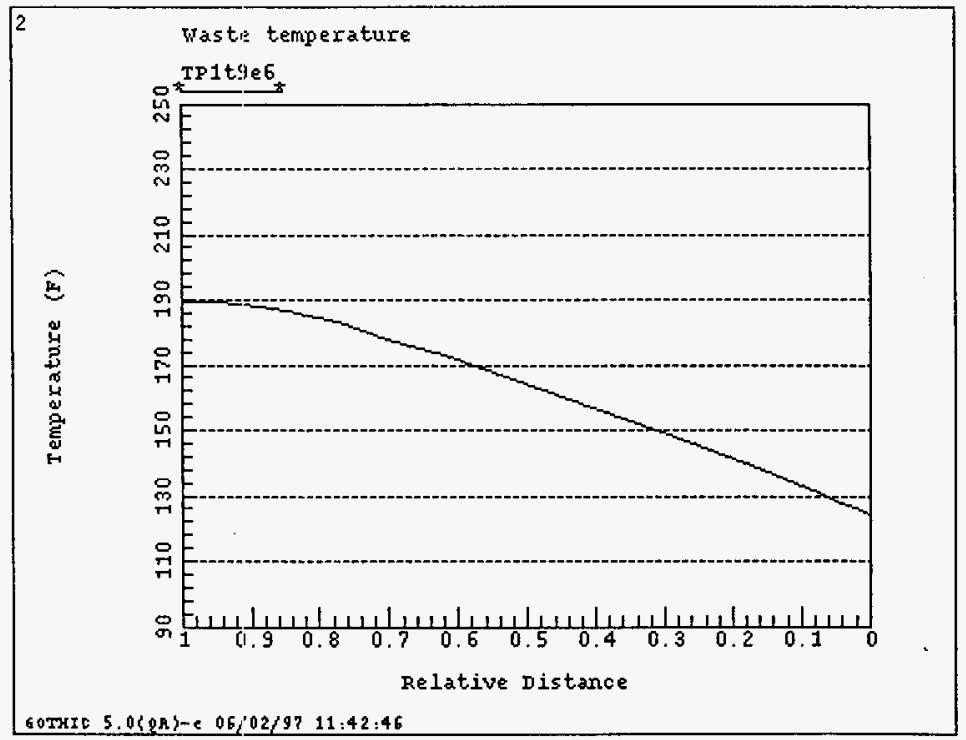




\section{HNF-SD-W320-ER-004 REV 0}

\subsection{CONCLUSIONS}

The following are conclusions resulting from the process control and safety analyses evaluations performed with best estimate parameters.

1. Primary ventilation (Projects W- 030 configuration) and no annulus ventilation flow will provide the required cooling for a 2 foot transfer from $241-\mathrm{C}-106$.

2. Project W-030 primary ventilation, $2000 \mathrm{cfm}$ annulus system slot flow and a $40^{\circ} \mathrm{F}$ annulus chiller will provide the minimum required cooling for a full 6 foot transfer of waste from 241-C106. The annulus chilier can be eliminated by increasing the annulus slot flow to $3000 \mathrm{cfm}$.

3. Stratification of the transfered waste into 241-AY-102, which places a high heat power layer near the center of the waste (axially), will significantly increase the waste temperature for a complete transfer from $\mathrm{C}-106$. Increased annulus flow and a reduction in the subcooling margin may still allow a complete transfer to occur.

4. There is a significant sensitivity to the fluffing factor for a full 6 foot transfer. Increased annulus slot flow will nearly eliminate the increased waste temperature.

5. The maximum waste temperature is less sensitive to thermal conductivity uncertainties than either heat load distribution or fluffing factor. Excess cooling capacity of the annulus system can mitigate the increased temperature.

6. The 241-C-106 total heat load sensitivity is on the same order as the thermal conductivity and significantly less than the heat load distibution.

7. The waste temperature for a complete loss of ventilation will reach saturation temperatures in about 30 days with a full 6 foot waste transfer.

8. The loss of evaporation for either a 2 foot or 6 foot transfer will decrease the subcooling margin, but will not raise the waste temperature to saturation temperatures. Excess cooling capacity for the annulus ventilation system will significantly mitigate the consequence for a full waste transfer and completely eliminate the temperature increase for partial retrievals.

9. The loss of annulus system chiller will cause a slow waste temperature increase, reducing the subcooling margin to $\sim 10^{\circ} \mathrm{F}$. Increased annulus flow can completely mitigate the event.

10. Reduction of the supernatant pool significantly reduces the consequence of a steam bump through a reduction in dome overpressure and a significant reduction in entrained liquid and particles out the vent paths. 


\section{HNF-SD-W320-ER-004 REV 0}

11. Reduction of the supernatant will shorten the time to saturation for a loss of ventilation to about 21 days and may require operation at a reduced subcooling margin. 


\section{HNF-SD-W320-ER-004 REV 0}

\subsection{REFERENCES}

Agnew, S.F., J. Boyer, R.A. Corbin, T.B. Duran, J.R. Fitzpatrick, K.A. Jurgensen, T.P. Oritz, and B.L. Young, 1996, Hanford Tank Chemical and Radionuclide Inventrories: HDW Model Rev. 3, LA-UR-96-858, Los Alamos National Laboratory, Los Alamos, New Mexico.

Boelter, Gordon, and Griffith, 1946. Rates of Evaporation of Water by Natural Convection, Industrial Engineering Chemistry, 38, 596.

Fryer, B.C. and Thurgood, M.J., Revised Tank Heat Loaed Estimate for the Process Test, JMIWT-002, John Marvin Inc., Richland, WA.

George, Thomas L., et. al., 1995, GOTHIC Containment Analyses Package User Manual, NAI 8907-02 Rev 6, Numerical Atpplications, Inc., Richland, Wa.

Hanlon, B.M., 1997, Waste Tank Summary Report, HNF-EP-0182-106, Lockheed Martin Hanford Corporation, Richland, Wa.

Reynolds, D. A., 1997, Chemical and Chemically Related Issues Associated with Sluicing Tank C-106 Waste to Tank Ay-102, HNF-SD-WM-TI-756 Rev. 2, Flour Daniel Company, Richland, Washington.

Sathyanaryana, K., Fryer, B.C. 1996a, Evaluation of Potential and Consequences of Steam Bump in High Heat Waste Tanks and Assemssment and Validation of GOTH Computer Code, WHCSD-WM-CN-022, Rev 0. Westinghouse Hanford Company, Richland, Washington.

Sathyanaryana, K., Fryer, BC, 1996b, Thermal Hydraulic Evaluation of Consolidating Tank C-106 Waste into Tank AY-102, WHC-SD-WM-ER-534, Rev. 0, Westinghouse Hanford Company, Richland, Washington.

Sathyanaryana, K, Ogden, DM, Fryer, BC, 1997, Project W-320 Thermal Evaluation, HNF-SDW320-ER-002, Rev. 0, Numatec Hanford Corporation, Richland, Washington.

Thurgood, M. J., et al., 19913, GOTHIC Containment Analysis Package, Version 3.4e, EPRI TR-103053, Electric Power Research Institute, Palo Alto, California. 


\section{HNF-SD-W320-ER-004 REV 0}

APPENDIX A GOTHIC Model Benchmark With HUB Model 


\section{HNF-SD-W320-ER-004 REV 0}

The GOTHIC 1-D tark model presented in Section 2.3 was benchmarked against the HUB model described in Section 2.1 and a closed form analytical solution. Analyses were performed for a 6 foot transfer with best estimate parameters (base case from Section 4.1). The annulus ventilation flow was $3000 \mathrm{cfm}$. A heat transfer coefficient for the annulus flow was adjusted to give an efficiency factor of 0.32. Figure A.1 shows the GOTHIC model prediction of the steady state waste temperature distribution. On the $\mathrm{x}$-axis 0 is the top of the waste and 0.9 the bottom. The maximum temperture is $204^{\circ} \mathrm{F}$ and occurs 4.3 feet up from the bottom of the waste. The pool temperature is $106^{\circ} \mathrm{F}$ and the bottom sludge temperature is $120^{\circ} \mathrm{F}$.

The HUB temperature distribution for the same case is shown in Figure A.2. The maximum waste temperature is $202{ }^{\circ} \mathrm{F}$ at 4.4 feet from the waste bottom. The pool temperature is $119^{\circ} \mathrm{F}$ and the bottom waste temperature is $105^{\circ} \mathrm{F}$. This is in excellent agreement with the GOTHIC model. The bottom waste temperature would be expected to be the same because both models use the same efficiency factor. However, the pool temperature is strongly related to the evaporation rate. The GOTH:IC and HUB models agree very will.

The Poisson's equation for one dimensional conduction through a two layer material can be solved in closed form. The temperature is parabolic in each region. At the interface between the regions the gradient of the temperature, which is porportional to the heat flux, is the same. Figure A. 3 shows the temperature distribution for a two layer regions with the same power and thermal conductivity used in the HUB and GOTHIC models. The boundary temperatures were set at $105^{\circ} \mathrm{F}$ and $120^{\circ} \mathrm{F}$. The maximum temperature is $204^{\circ} \mathrm{F}$ at 4.6 feet from the waste bottom. Given the discrete nodalization of the GOTHIC conductor, this is in excellent agreement. 


\section{HNF-SD-W320-ER-004 REV 0}

Figure A.1 Waste Temperature Distribution for GOTHIC Model.

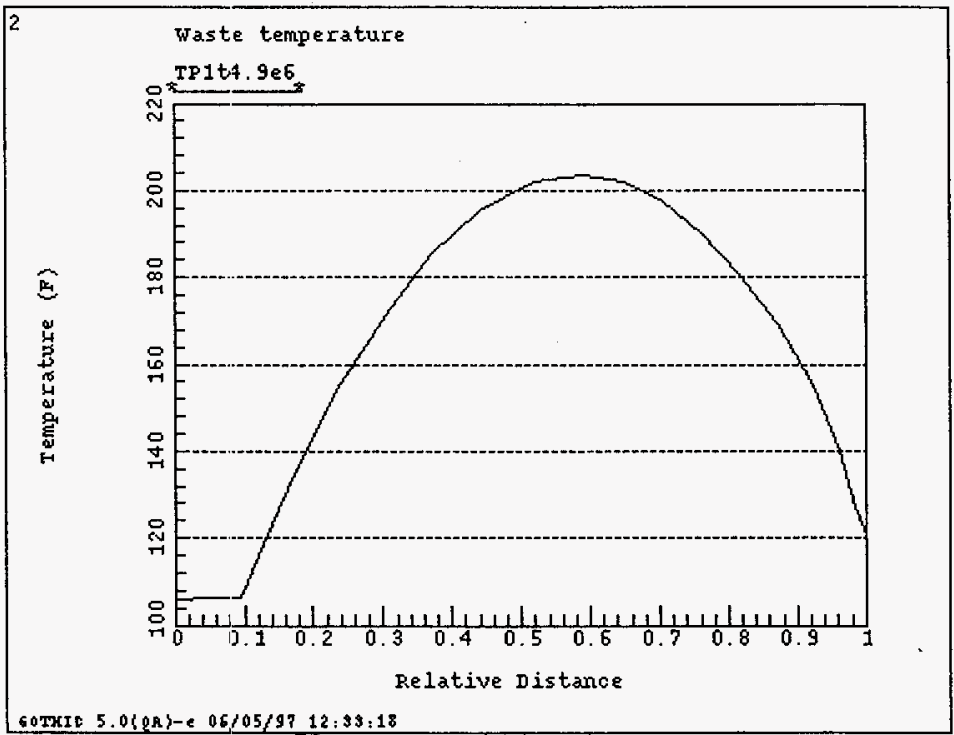

A-3 


\section{HNF-SD-W320-ER-004 REV 0}

Figure A.2 Waste Temperature Distibution for HUB Model.

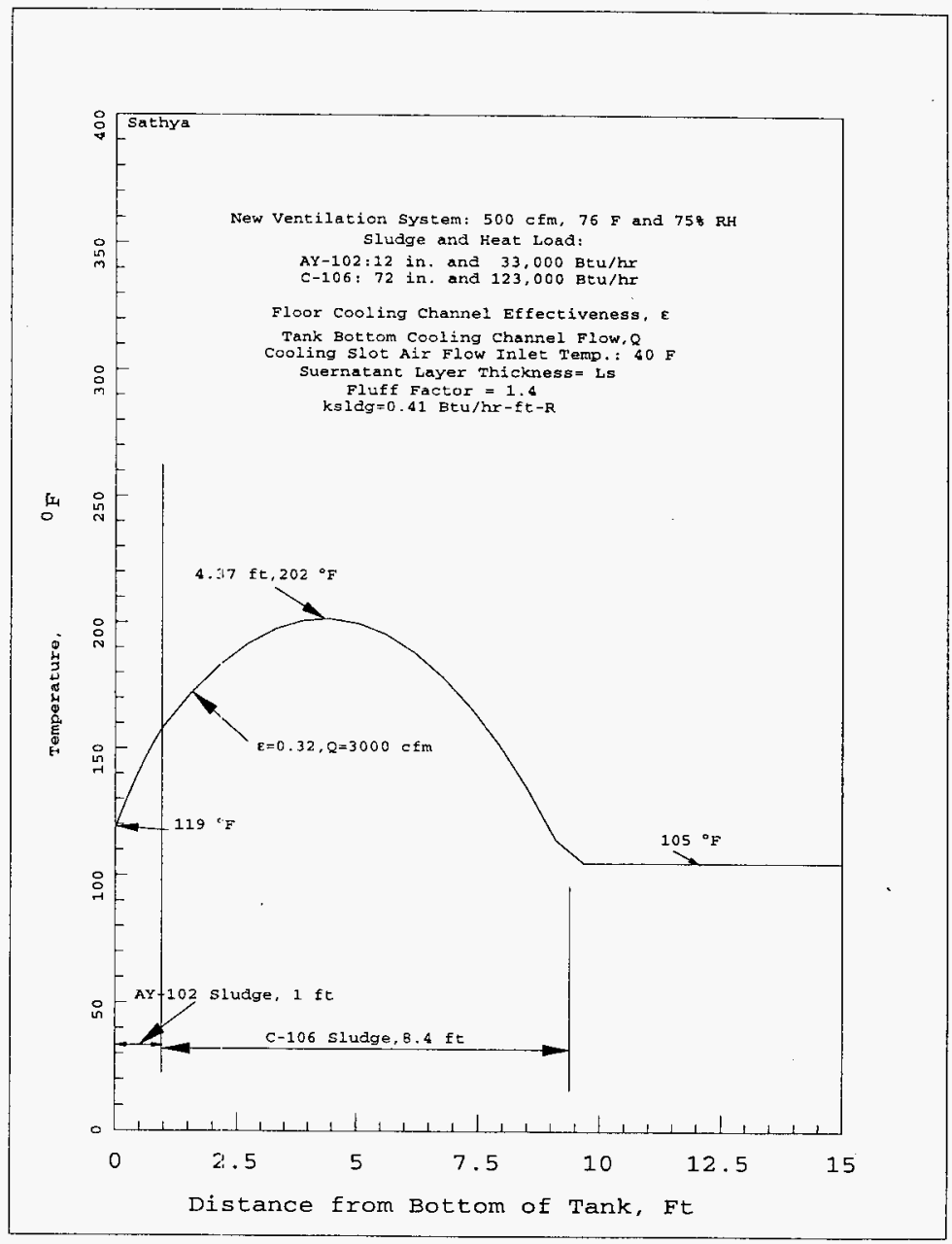


HNF-SD-W320-ER-004 REV 0

Figure A.3 Waste Temperature Distribution for Closed Form Solution.

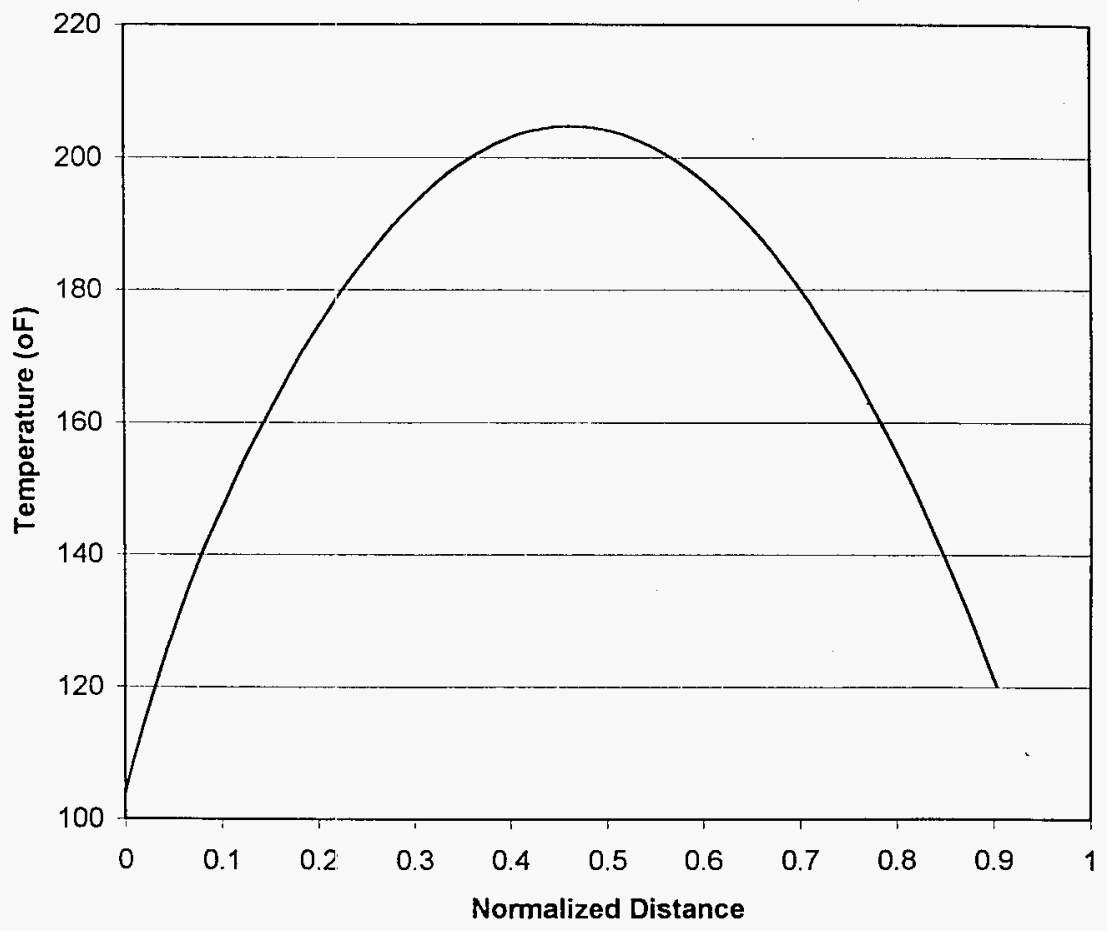

A-5 
THIS PAEF INTENTIONALLY LLFT BLANK 


\begin{tabular}{|c|c|c|c|c|c|c|}
\hline \multicolumn{7}{|c|}{ DISTRIBUTION SHEET } \\
\hline & \multirow{2}{*}{\multicolumn{3}{|c|}{$\begin{array}{l}\text { From } \\
\text { Process Analysis }\end{array}$}} & & \multicolumn{2}{|c|}{ Page 1 of 1} \\
\hline Distribution & & & & & \multicolumn{2}{|c|}{ Date $6 / 17 / 97$} \\
\hline \multirow{2}{*}{\multicolumn{5}{|c|}{$\begin{array}{l}\text { Project Title/Work Order } \\
\text { W-320/D2M78 }\end{array}$}} & \multirow{2}{*}{\multicolumn{2}{|c|}{$\begin{array}{ll}\text { EDT No. } & 607750 \\
\text { ECN No. } & N / A\end{array}$}} \\
\hline & & & & & & \\
\hline Name & & MSIN & $\begin{array}{l}\text { Text } \\
\text { With All } \\
\text { Attach. }\end{array}$ & Text Only & $\begin{array}{l}\text { Attach./ } \\
\text { Appendix } \\
\text { Only }\end{array}$ & $\begin{array}{l}\text { EDT/ECN } \\
\text { Only }\end{array}$ \\
\hline $\begin{array}{l}\text { DE\&S Hanford, InC. } \\
\text { C. E. Leach } \\
\text { R. J. Stickney }\end{array}$ & & $\begin{array}{l}R 1-49 \\
R 1-49\end{array}$ & $\begin{array}{l}x \\
x\end{array}$ & & & \\
\hline $\begin{array}{l}\text { Fluor Daniel Northwest, Inc. } \\
\text { J. C. Conner } \\
\text { D. L. Evans } \\
\text { S. K. Farnsworth }\end{array}$ & & $\begin{array}{l}\text { A2-25 } \\
\text { S2-47 } \\
\text { H } 5-57\end{array}$ & $\begin{array}{l}x \\
x \\
x\end{array}$ & & & \\
\hline $\begin{array}{l}\text { John Marvin Inc. } \\
\text { B. C. Fryer } \\
\text { M. J. Thurgood } \\
\text { D. M. Ogden (5) }\end{array}$ & & $\begin{array}{l}\mathrm{H} 0-34 \\
\mathrm{HO}-34 \\
\mathrm{HO}-34\end{array}$ & $\begin{array}{l}x \\
x \\
x\end{array}$ & & & \\
\hline $\begin{array}{l}\text { Lochheed Martin Hanford Corpo } \\
\text { B. A. Crea } \\
\text { R. V. Gutierrez } \\
\text { N. W. Kirch } \\
\text { K. W. Leliefeld } \\
\text { J. W. Lentsch } \\
\text { L. B. McDaniel } \\
\text { W. P. Nelson } \\
\text { W. J. Powell } \\
\text { S. H. Rifaey }\end{array}$ & & $\begin{array}{l}\text { S2-24 } \\
\text { S5-04 } \\
\text { R2- } 11 \\
\text { S2-48 } \\
\text { S2-48 } \\
\text { H6- } 12 \\
\text { S5-12 } \\
\text { S2-48 } \\
\text { R } 1-56\end{array}$ & $\begin{array}{l}x \\
x \\
x \\
x \\
x \\
x \\
x \\
x \\
x\end{array}$ & & & \\
\hline $\begin{array}{l}\text { Numatec Hanford Corporation } \\
\text { Jean-Noel Alibert } \\
\text { J. W. Bailey } \\
\text { A. F. Choho } \\
\text { T. A. Flament } \\
\text { W. C. Miller } \\
\text { K. Sathyanarayana (5) } \\
\text { J. P. Sloughter } \\
\text { Central Files (Original }+2 \text { ) }\end{array}$ & & $\begin{array}{l}\text { S2-48 } \\
\text { S2-48 } \\
H 6-35 \\
\mathrm{~K} 9-46 \\
\mathrm{H} 5-25 \\
\mathrm{H} 0-34 \\
\mathrm{H} 5-49 \\
\mathrm{~A} 3-88\end{array}$ & $\begin{array}{l}x \\
x \\
x \\
x \\
x \\
x \\
x \\
x\end{array}$ & & & \\
\hline$\frac{\text { Pacific Northwest National La }}{\text { C. W. Stewart }}$ & tory & $K 7-15$ & $x$ & & & \\
\hline$\frac{\text { SGN Eurisys Services Corpora }}{\text { J. R. Bellomy }}$ & & $S 2-48$ & $x$ & & & \\
\hline
\end{tabular}


THIS PAGF INTENTIONALLY LLFT BLANK 